\author{
Universidade de São Paulo \\ Instituto de Física
}

\title{
Competição entre dinâmica individual e coletiva em modelos de agentes econômicos
}

\author{
Diego Ferreira de Almeida
}

Orientador: Prof. Dr. André de Pinho Vieira

Dissertação de mestrado apresentada ao Instituto de Física para a obtenção do título de Mestre em Ciências

Banca Examinadora:

Prof. Dr. André de Pinho Vieira (IF-USP)

Prof $^{\mathrm{a}}$. Dr ${ }^{\mathrm{a}}$. Carmen Pimentel Cintra do Prado (IF-USP)

Prof. Dr. José Raimundo Novaes Chiappin (FEA-USP)

São Paulo

2015 
FICHA CATALOGRÁFICA

Preparada pelo Serviço de Biblioteca e Informação do Instituto de Física da Universidade de São Paulo

Almeida, Diego Ferreira de

Competição entre dinâmica individual e coletiva em modelos de agentes econômicos. São Paulo, 2015.

Dissertação (Mestrado) - Universidade de São Paulo. Instituto de Física. Depto. de Física Geral.

Orientador: Prof. Dr. André de Pinho Vieira

Área de Concentração: Física Estatística.

Unitermos: 1. Física; 2. Mecânica estatística; 3. Segregação urbana. 


\section{Agradecimentos}

Acima de tudo agradeço à minha mãe, Maria Arlete, meu maior porto seguro, que mesmo em momentos difíceis sempre esteve ao meu lado me incentivando e não deixando que eu desistisse sem seu apoio nada em minha vida teria sido possível.

Agradeço aos meus filhos, Victor, Eduarda e Leonardo, que são a minha razão de existir.

Agradeço a Heloisa, uma amiga e companheira em especial, que me ergueu durante todos os meus momentos de crise.

E por fim, agradeço ao Professor André Vieira por toda paciência e por todo apoio que meu ao longo do desenvolvimento deste trabalho. 


\section{Resumo}

Usando a generalização de Grauwin et al. [Ref. 3] do modelo de segregação de Schelling foi possível estudar, em um modelo simplificado, as consequências da "guerra fiscal" travada entre os estados de uma federação e os resultados da chamada "guerra da taxa" que os bancos adotaram depois de implantada a portabilidade de crédito bancário. No modelo de Grauwin a cidade é dividida em $Q$ quarteirões e todos os quarteirões possuem a mesma função utilidade dependente da densidade $u(m, \rho)$, que mede a satisfação dos agentes que ali residem. Inserimos um parâmetro de desordem $m_{b}$ em um dos blocos para torná-lo mais atrativo que os demais. Ter um dos blocos diferente é a essência do modelo de guerra entre os quarteirões.

Foi analisada uma aplicação deste modelo fazendo um paralelo com o cenário de uma guerra fiscal entre os estados de uma nação. Para tal, interpretamos os agentes econômicos como sendo as de indústrias (ou pessoas) que tomam decisões em busca de aumentar sua própria satisfação e os quarteirões como os estados de uma federação. A guerra fiscal é um instrumento usado por alguns estados brasileiros que reduzem impostos, cedem terrenos, fornecem infra-estrutura, etc para atrair investimentos na sua região. Esta guerra no primeiro momento pode ser benéfica para a sociedade, pois contribui para a descentralização da economia e reduz as diferenças de PIB e social entre os estados. Porém, em âmbito nacional, o embate econômico entre os estados geralmente resulta em perda de arrecadação para a nação. Um Estado totalmente desocupado, caso queira "roubar" empresas de Estados já consolidados, precisa dar muito mais incentivos para atrair investimento por conta da sua baixa população e consequentemente baixa utilidade. Neste trabalho tentamos quantificar os gastos que os Estados têm com este tipo de ação.

Outra releitura dos resultados pode ser aplicada ao modelo de portabilidade de crédito, onde interpretamos os agentes econômicos de Grauwin como tomadores de empréstimo e os quarteirões como bancos de crédito ao varejo. A taxa de juros cobrada de cada banco dependerá do tamanho da carteira que este possui. Ter um banco com uma taxa de juros diferenciada o torna mais atrativo que os demais e este começa a "roubar" clientes dos outros bancos, contudo, o mercado reage e também reduz suas taxas, criando uma "guerra da taxa" no mercado financeiro. Estudando o cenário egoísta (onde o governo não desestimule a troca entre bancos) e supondo que a quantidade de tomadores no mercado seja suficientemente pequena, a dinâmica conduzirá a uma situação onde teremos apenas alguns bancos coexistindo e outros falindo. No limite egoísta o banco que se dispôs a dar incentivo terá a carteira maior que os demais bancos com taxas menores e isto vai ser invertendo à medida que o governo impõe comportamento mais altruísta da sociedade.

Estudamos analiticamente os efeitos das variações da densidade e dos parâmetros $(m)$ e altruísmo $(\alpha)$ no cenário global bem como os resultados esperados com a inserção de uma desordem $\left(m_{b}\right)$ em um dos blocos. E por fim foram feitas simulações em computador para verificar se comportamento das dinâmicas em todos os cenários eram compatíveis com as soluções obtidas. 


\section{Abstract}

Using Grauwin's generalization [Ref. 3] of Schelling's segregation model we study, in a simplified model, some consequences of the "fiscal war" waged between the states of a federation, and of the "rate tax" generated by the recent Brazilian Central Bank regulation of bank credit portability. In Grauwin's model the city is divided into blocks and all blocks have the same utility function, which measures the satisfaction of agents living there and depends on the density of agents. We introduced a disorder parameter in one of the blocks to make it more attractive than the others, in order to mimick the essential igredient of competition between states or banks.

We first analyze an application of this model in the scenario of a fiscal war between the states of a nation. We interpret blocks as the states of a federation and economic agents as the industries (or people) who make decisions seeking to increase their own satisfaction. The fiscal war is an instrument used by some Brazilian states consisting in reducing taxes, subsidize land, provide infrastructure, etc in order to attract investment. This war at first can be beneficial for society as it contributes to the decentralization of the economy and reduces the differences of GDP and social discrepancies between states. Nationwide, however, the economic struggle between states usually results in loss of revenue at the global level. A vacated state, in order to attract agents already established elsewhere, need to give more incentives to attract investment because of its low population and consequently low utility. In this work we try to quantify the costs that states have with this kind of action.

Another analysis of the results can be applied to a bank credit portability model, where we interpret economic agents as customers and blocks as retail credit banks. The interest rate levied on each bank will depend on the size of the portfolio of that bank. Having a bank with a differentiated interest rate makes it more attractive than others, and it begins to "steal" customers from other banks.However, those react and also reduce their rates, creating a "war tax" in the financial market. Studying the selfish scenario (where the government doesn't discourage a client from taking his/her debt to another bank), and assuming that the number of customers in the market is sufficiently small, the dynamics leads to a situation where we have just a few coexisting banks, the others having gone bankrupt. In the selfish limit the bank that was willing to give encouragement will have the largest portfolio while offering lower interest rates than the others, but this will be reversed as the government imposes a more altruistic behavior to the clients.

We study analytically the effects, at the global level, of variations in the density, in the altruism parameter and in the parameter determining the utility function at saturation, as well as the effects of introducing disorder in one or more blocks. Finally, computer simulations were performed to check that the dynamic behavior in all scenarios was consistent with those obtained solutions.

Keywords: Schelling' segregation model segregation, competition between individual and collective dynamics,

fiscal war.

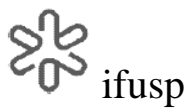




\section{Lista de figuras}

Figura 1: Ref [3] - Função potencial - Separação de fase .................................................. 18

Figura 2: Ref [3] - Função utilidade escolhida pelos autores ......................................... 19

Figura 3: Resultados das simulações para o modelo de Grauwin ....................................23

Figura 4: Distribuição das indústrias no Brasil em 2009 ................................................ 33

Figura 5: Distribuiç̧ão inicial das indústrias nos estados durante as simulações. ................ 35

Figura 6: Gráficos com os resultados das simulações do modelo homogêneo ................... 42

Figura 7: Situação em equilíbrio das indústrias para o caso homogêneo ...........................43

Figura 8: Gráficos com os resultados do caso homogêneo quando mais de um Estado adere

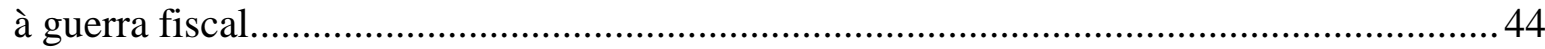

Figura 9: Resultados para as simulações 1, 15, 35 e 59 das tabelas 4A e 4B...................46

Figura 10: Gráficos com os resultados das simulações do modelo segregado....................49

Figura 11: Gráficos com os resultados do caso segregado quando mais de um Estado adere

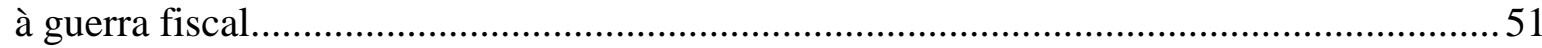

Figura 12: Resultado da simulação considerando que cada Estado possui um benefício

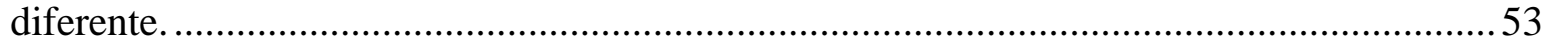

Figura 13: Gráficos com os resultados das simulações do modelo segregado quando um Estado vazio fornece incentivos para baixas densidades. ............................................62

Figura 14: Resultado das simulações do modelo uniforme de portabilidade bancária ........68

Figura 15: Gráficos com os resultados das simulações do modelo homogêneo para a

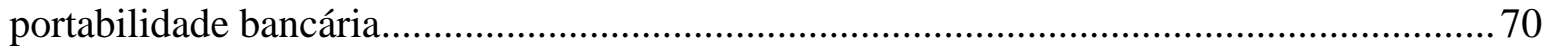

Figura 16: Gráficos com os resultados das simulações do modelo segregado para a portabilidade bancária......................................................................................... 73

Figura 17: Ref [12] - Algumas funções utilidade conhecidas na literatura ........................ 76

Figura 18: Gráfico com os resultados das simulações para outras funções utilidade...........77

Figura 19: Simulações para diferentes tipos de funções utilidade.................................... 78 


\section{Sumário}

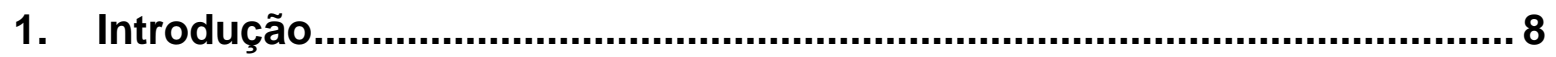

2. Modelo de Grauwin e Colaboradores ...................................................... 11

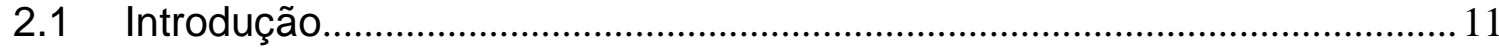

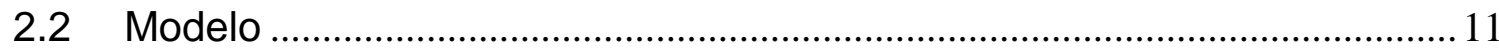

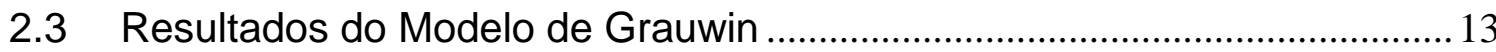

3. Versão desordenada do modelo de Grauwin ............................................ 24

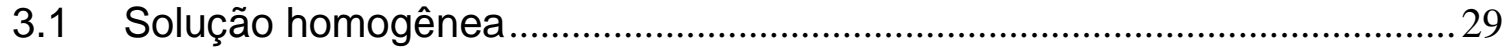

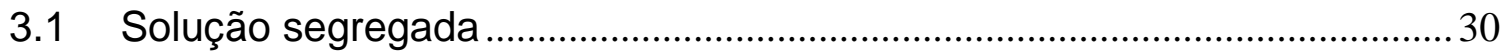

4. Guerra fiscal entre as unidades de uma federação.....................................33

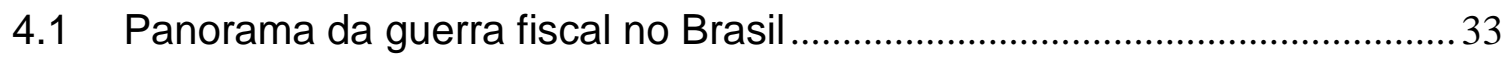

4.2 Aplicação do modelo desordenado de Grauwin ..............................................34

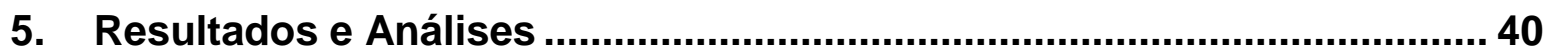

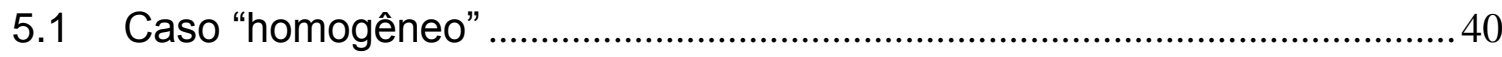

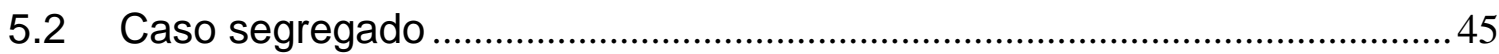

6. Reinterpretação dos resultados aplicados ao sistema de portabilidade de

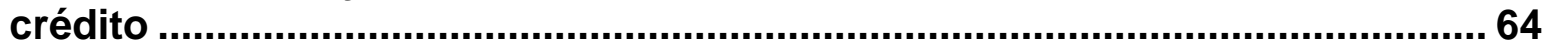

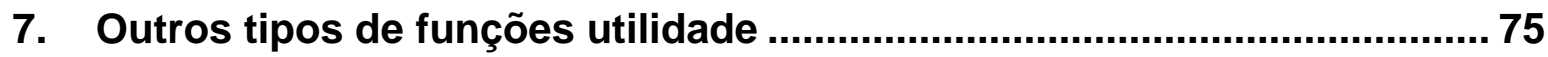

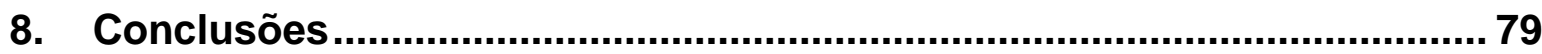

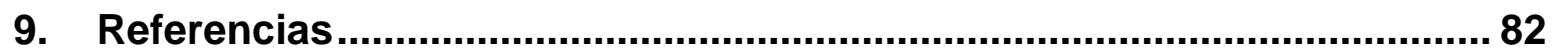




\section{Introdução}

Em 1971, o economista Schelling propôs um modelo de interações sociais [1] para estudar a segregação em cidades norte-americanas. Mais precisamente, Schelling se interessou por estudar dois tipos de segregação, por renda e a segregação racial, que no estado de Nova lorque, por exemplo, era bem notória. Qual seria a motivação desta segregação? Apenas o racismo das pessoas que preferem viver ao redor de outras pessoas com as mesmas características que ela? Schelling explorou este comportamento a partir das decisões de cada individuo e o que acontece com cenário global baseando-se nestas decisões unilaterais. A essência do modelo é saber que pessoas podem decidir onde querem morar e a quantidade de pessoas semelhantes influenciará na decisão desta determinada pessoa. Como exemplo; vamos supor que em uma vizinhança existam 10 casas e que em 5 destas casas residam pessoas ricas, então a densidade de famílias ricas nesta região é 0,50. Agora, 0,50 é bom ou ruim? Isso é o que Schelling chama de threshold rule, ou regra do limite da tolerância. Cada individuo possui seu próprio threshold rule e baseado nisso o indivíduo decide se deve mudar ou se deve permanecer na vizinhança. Se 0,50 é uma quantidade razoável segundo seu limite de tolerância então ele fica, agora, se um de seus vizinhos ricos por uma decisão unilateral aleatória decide se mudar, a primeira família também se mudará, pois a densidade de ricos na região caiu para 0,40 , abaixo de seu limite de tolerância. Então, o que acontece com o cenário global? Haverá uma migração de todas as demais famílias, gerando uma macrosegregação. Porém se o limite de tolerância da população for muito alto ( 1) não existirá nenhuma vizinhança que satisfaça as vontades dos indivíduos, tornando a quantidade de movimentos da dinâmica infinitos.

A essência do modelo de Schelling é mostrar que a configuração global de uma região é definida por decisões individuais, porém se o numero de agentes intolerantes for suficientemente grande, os comportamentos micro e macro podem não estar mais interligados. Cada mudança de um agente em busca de sua satisfação alterará o cenário em outra vizinhança, o que influenciará as decisões dos agentes que lá vivem, e assim sucessivamente, levando a uma configuração macro que será independente das decisões (ou desejos) individuais.

Os resultados do modelo de Schelling têm atraído a atenção de muitos cientistas sociais, matemáticos e também físicos estatísticos. L. Dall'Asta e colaboradores [2], por exemplo, apresentam uma variante do modelo a partir do modelo de misturas binárias. Representando os agentes por spins, eles estudaram as semelhanças da dinâmica do 
modelo de Schelling com o processo de separação de fase e buscaram responder se havia uma segregação total dos agentes e quais as propriedades do estado estacionário. Dall' Asta propôs dois modelos:

i-) O modelo restrito (como em sólidos), onde apenas os indivíduos insatisfeitos podem se mover, o que só ocorre caso haja algum espaço vago e contanto que o movimento produza satisfação.

ii-) O modelo sem restrições (como em líquidos), onde todos os agentes podem transitar livremente desde que o movimento aumente sua satisfação. Este modelo líquido é próximo da dinâmica que usamos nesta dissertação, diferindo apenas pelo fato de, em nosso caso, não necessariamente a satisfação dos agentes aumentar a cada movimento.

Dall' Asta criou uma função de densidade local de agentes insatisfeitos $u(t)$ e analisou, para ambos os modelos, como essa grandeza evolui. Nos dois modelos Dall' Asta estudou quais são as propriedades estáticas do regime estacionário. No modelo líquido, o sistema atingirá o equilíbrio num determinado limite estacionário onde a densidade $u(t)$ permanecerá constante.

Embora seja tentador fazer um paralelo deste modelo com sistemas de matéria condensada, isto não é totalmente correto, já que os indivíduos aqui, ao contrário dos átomos e moléculas, movem-se unicamente para maximizar sua própria satisfação, sem levar em conta o bem estar dos vizinhos, ou seja, mesmo que o movimento aumente sua satisfação isto poderá tornar seus vizinhos descontentes e aumentará a densidade de agentes insatisfeitos, em contraposição aos sistemas de física da matéria condensada, que são submetidos a uma dinâmica que tende a maximizar uma função coletiva, representada em geral por uma energia livre. Esse tipo de dinâmica pode ser aplicado em diversas outras áreas do conhecimento, como por exemplo, em teoria econômica, para modelar os "agentes racionais", que se movem exclusivamente para maximizar seus ganhos.

Uma generalização recente do modelo de Schelling, proposta por Grauwin e colaboradores [3], consiste em introduzir um parâmetro de "imposto", que força cada agente a levar em conta os efeitos de suas decisões sobre a função utilidade média de todos os agentes. Esse parâmetro permite introduzir uma dinâmica que varia de puramente egoísta (como no modelo de Schelling) a puramente altruísta. Nesse último limite, a dinâmica é ditada pela extremização de uma função potencial que corresponde à energia livre de um sistema de física da matéria condensada. 
Mais especificamente, os agentes habitariam uma cidade composta de quarteirões distintos, cada um dos quais contém um número fixo de células (residências) que podem ser ocupadas. Os agentes movem-se de um quarteirão a outro buscando maximizar a função utilidade, que depende das respectivas densidades de ocupação. Ocorre que, sob condições bastante gerais, quaisquer desvios do comportamento puramente altruísta levam a um estado de equilíbrio caracterizado por algum grau de segregação, impedindo a maximização da função utilidade média [3].

Há muitas interpretações possíveis para o modelo de Grauwin. Uma delas é supor que os quarteirões representam estados de uma federação, enquanto os agentes representam empresas ou profissionais que se movem buscando aumentar seus ganhos. Variações na função utilidade e no parâmetro de imposto poderiam então ser introduzidas para modelar a "guerra fiscal" entre os estados, de que a federação brasileira é vítima recente. Estamos particularmente interessados em caracterizar os efeitos da competição entre estados sobre a função utilidade média, vista como uma medida da otimização da economia federativa, e em estudar os processos que se seguem à modificação súbita de algum parâmetro. Essa modificação poderia ocorrer, por exemplo, na taxa de imposto cobrada em algum estado da federação esvaziado, em resposta à fuga de agentes para outros estados.

Outra aplicação que pode ser feita é sobre a "guerra da taxa" do sistema financeiro. Neste caso interpretamos os quarteirões como bancos, os agentes econômicos representam os clientes tomadores de crédito, a função utilidade está relacionada com a taxa de juros dos empréstimos cobrados pelas entidades bancárias, que varia com a quantidade de tomadores de crédito que o banco possui em sua carteira, e o parâmetro de altruísmo, controlado pelo governo, pode ser entendido como um imposto idealizado (que chamamos de taxa de portabilidade) que inibe os clientes a portarem suas dívidas para outros bancos. O imposto que mais se assemelha a esse é o imposto sobre operações financeiras (IOF), porém, na prática, a determinação do Banco Central é que se não houver troco em um processo de portabilidade não pode ser cobrado o imposto novamente. Por conta da ausência deste imposto o cenário que mais se aproxima da situação real da portabilidade é a situação egoísta $(\alpha=0)$. Nesta linha é possível modelar de forma simplificada a recente dinâmica de portabilidade de crédito no sistema bancário. 


\section{Modelo de Grauwin e Colaboradores}

\subsection{Introdução}

Grauwin e colaboradores ilustraram em seu artigo a diferença entre a dinâmica coletiva e individual sobre um modelo que pode ser resolvido exatamente, similar ao modelo de Schelling.

O modelo considera agentes que preferem viver em um ambiente com metade da capacidade ocupada $(\rho=1 / 2)$, com uma dinâmica que os conduzem para padrões segregados ou padrões homogêneos em um nível global, dependendo da densidade de agentes. O parâmetro "imposto" monitora continuamente o grau de altruísmo dos agentes, ou seja, é este parâmetro que irá controlar o nível de satisfação da sociedade. Para valores altos de altruísmo, o sistema estará numa fase homogênea de utilidade máxima. À medida que o parâmetro de altruísmo decresce, ocorre a transição de fase para um estado segregado. Nesta fase, a utilidade dos agentes permanecerá baixa apesar de seus contínuos esforços para maximizar suas satisfações.

No artigo, Grauwin e colaborares introduziram uma rigorosa generalização da energialivre dos modelos físicos, que inclui a dinâmica individual dos agentes. Introduzindo uma função "link" que é maximizada nos estados estacionários, eles construíram um tratamento analítico para uma larga classe de sistemas onde a dinâmica é governada por estratégias individuais. Aplicado sobre o modelo de segregração de Schelling, a aproximação de Grauwin oferece uma solução quantitativa para muitas funções utilidade gerais.

\subsection{Modelo}

O modelo apresentado por Grauwin é descrito como a dinâmica dos movimentos residenciais em uma cidade. Para facilitar, a apresentação é feita para um único tipo de agente, porém, os resultados podem ser generalizados para dois tipos de agentes, assim como o modelo original de Schelling.

A cidade é dividida em $Q$ blocos, com $Q \gg 1$, cada um dos quais contém um numero $H$ de células. Estas células podem ser entendidas como residências, e cada célula pode conter apenas um agente, de modo que o número de agentes $n_{q}$ sobre 0 dado bloco $q(q=1,2 \ldots, Q)$ satisfaça $n_{q} \leq H$. Definimos a densidade de agentes no bloco $q$ como

$\rho_{q}=\frac{n_{q}}{H}$. Cada agente, nesse bloco, tem a mesma função utilidade $u\left(\rho_{q}\right)$ que descreve 
seu grau de satisfação acerca da sua localização. A forma específica da função utilidade é uma escolha de entrada do modelo, que pode ser postulada sobre uma base fenomenológica ou pode depender de uma teoria das interações entre os agentes.

A utilidade coletiva é definida como a utilidade total de todos os agentes do sistema, e é dada por

$$
U(x)=H \sum_{q} \rho_{q} u\left(\rho_{q}\right)
$$

Equação 1

onde $x \equiv\left[\rho_{q}\right]$ corresponde à configuração de grão grosso da cidade, ou seja, o conhecimento da densidade de cada bloco. Para um dado $x$, existe um grande número de maneiras $N(x)$ para arranjar os agentes nas diferentes células, e a entropia é definida $\operatorname{como} S(x)=\ln [N(x)]$.

A regra dinâmica que permite aos agentes se moverem de um bloco para qualquer outro é dada por

$$
P_{x y}=\frac{1}{1+e^{-\frac{G}{T}}},
$$

Equação 2

onde $x$ e $y$ são respectivamente a configuração antes e depois do agente se mover, $G$ é o ganho que se obtém em um dado movimento proposto, e $T$ é um parâmetro positivo que pode ser entendido no modelo como temperatura, introduzindo ruídos sobre o processo de decisão, dando conta de efeitos que não são explicitamente incluídos na função utilidade, mas que afetam o processo de decisão do movimento. Para o sistema atingir o estado estacionário devemos iniciar com a perturbação de $T>0$ e decair lentamente para $T=0$ durante o processo.

O ganho $G$ é dado por

$$
G=\Delta u+\alpha(\Delta U-\Delta u)
$$

Equação 3

onde $\Delta u$ é a variação da utilidade própria do agente e $\Delta U$ é a variação da utilidade total de todos os agentes. O parâmetro $\alpha(0 \leq \alpha \leq 1)$ calibra a contribuição da utilidade global sobre o ganho $G$ e pode ser interpretado como o grau de altruísmo dos agentes.

Para $\alpha=0$ a probabilidade de se mover só depende do interesse egoísta de um determinado agente $(G=\Delta u$ ), a exemplo de vários modelos econômicos semelhantes ao 
modelo de Schelling. Para $\alpha=1$, a decisão de se mover só depende da mudança da utilidade coletiva $(G=\Delta U)$, como nos modelos físicos. Variando $\alpha$ em um caminho contínuo pode-se interpolar os dois comportamentos, o individual e o coletivo.

Podemos reescrever a regra da dinâmica e temos a probabilidade de um agente se mover para uma célula vazia como

$$
P_{x y}=\frac{1}{1+e^{-((1-\alpha) \Delta u+\alpha \Delta U) / T}}
$$

Equação 4

\subsection{Resultados do Modelo de Grauwin}

Chamaremos de $\Pi(x)$ a distribuição de probabilidade estacionária de uma configuração microscópica $x$. Se o ganho $G$ pode ser escrito como

$$
G=\Delta V=V(y)-V(x),
$$

Equação 5

onde $V(x)$ é uma função da configuração $x$, a dinâmica satisfaz o balanceamento detalhado e a distribuição estacionária pode ser escrita como

$$
\Pi(x)=\frac{1}{Z} e^{F(x) / T},
$$

Equação 6

onde $Z$ é a constante de normalização e

$$
F(x)=V(x)+T S(x)
$$

Equação 7

A entropia é dada pela expressão

$$
\begin{gathered}
S(x)=\ln \left(\prod_{q} \frac{H !}{n_{q} !\left(H-n_{q}\right) !}\right)=\sum_{q} \ln \left(\frac{H !}{n_{q} !\left(H-n_{q}\right) !}\right) \\
=\sum_{q}\left\{\ln (H !)-\ln \left(n_{q} !\left(H-n_{q}\right) !\right)\right\}=\sum_{q}\left\{\ln (H !)-\left[\ln \left(n_{q} !\right)+\ln \left(H-n_{q}\right) !\right]\right\} .
\end{gathered}
$$

Para $H \gg 1$, usando a aproximação de Stirling, $\ln (n !)=n \cdot \ln (n)-n+O(\ln (n))$, a entropia pode ser escrita como 


$$
\begin{aligned}
& S(x)=\sum_{q}\left\{H \cdot \ln (H)-H+O(\ln (H))-\left\{n_{q} \cdot \ln \left(n_{q}\right)-n_{q}+O\left(\ln \left(n_{q}\right)\right)\right.\right. \\
& \left.+\left(H-n_{q}\right) \ln \left(\left(H-n_{q}\right)\right)-\left(H-n_{q}\right)+O\left(\ln \left(H-n_{q}\right)\right)\right\},
\end{aligned}
$$

e desprezando os termos $O(\ln (n))$ obtemos

$$
\begin{gathered}
S(x)=\sum_{q}\left\{H \cdot \ln (H)-H-\left\{n_{q} \cdot \ln \left(n_{q}\right)-n_{q}+\left(H-n_{q}\right) \cdot \ln \left(\left(H-n_{q}\right)\right)-\left(H-n_{q}\right)\right\}\right\} \\
=\sum_{q}\left\{H \cdot \ln (H)-n_{q} \cdot \ln \left(n_{q}\right)-\left(H-n_{q}\right) \cdot \ln \left(\left(H-n_{q}\right)\right)\right\} \\
=\sum_{q}\left\{-n_{q} \cdot \ln \left(\frac{n_{q}}{H}\right)-\left(H-n_{q}\right) \ln \left(\left(1-\frac{n_{q}}{H}\right)\right)\right\} \\
=H \cdot \sum_{q}\left\{-\rho_{q} \cdot \ln \left(\rho_{q}\right)-\left(1-\rho_{q}\right) \ln \left(\left(1-\rho_{q}\right)\right)\right\},
\end{gathered}
$$

ou seja,

$$
S(x)=H \sum_{q} s\left(\rho_{q}\right),
$$

Equação 8

com

$$
s(\rho)=-\rho \ln \rho-(1-\rho) \ln (1-\rho) .
$$

Equação 9

Para encontrar $V(x)$, é preciso tentar escrever $G(x)$ como função de $V(x)$ e definir uma função "link" $L(x)$, que conecta os níveis individual e coletivo, de modo que $\Delta u=\Delta L$. Deve-se então supor que é possível escrever

$$
V(x)=(1-\alpha) L(x)+\alpha U(x) .
$$

Equação 10

Por analogia ao que foi feito na Equação 8, espera-se que $L(x)$ possa ser escrito como uma soma sobre todos os blocos,

$$
L(x)=H \sum_{q} l\left(\rho_{q}\right) .
$$

Equação 11 
Considerando que o movimento ocorre de um bloco de densidade $\rho_{1}$ para um bloco com densidade $\rho_{2}$, então teremos

$$
\begin{gathered}
\Delta L_{x \rightarrow y}=\left[H l_{2}\left(\rho_{2}+\frac{1}{H}\right)-H l_{2}\left(\rho_{2}\right)\right]+\left[H l_{1}\left(\rho_{1}-\frac{1}{H}\right)-H l_{1}\left(\rho_{1}\right)\right] \\
\Delta L_{x \rightarrow y}=\frac{l_{2}\left(\rho_{2}+\frac{1}{H}\right)-l_{2}\left(\rho_{2}\right)}{1 / H}+\frac{l_{1}\left(\rho_{1}-\frac{1}{H}\right)-l_{1}\left(\rho_{1}\right)}{1 / H},
\end{gathered}
$$

e, no limite de $H \gg 1, \Delta L$ se reduz a $l^{\prime}\left(\rho_{2}\right)-l^{\prime}\left(\rho_{1}\right)$, onde $l^{\prime}(\rho)$ é a derivada de $l(\rho)$. A condição $\Delta u=\Delta L$ leva à identificação $l^{\prime}(\rho)=u(\rho)$, de forma que a expressão para $l(\rho)$ será dada por

$$
l(\rho)=\int_{0}^{\rho_{q}} u\left(\rho^{\prime}\right) d \rho^{\prime} .
$$

Equação 12

Portanto podemos escrever

$$
L(x)=H \sum_{q} \int_{0}^{\rho_{q}} u\left(\rho^{\prime}\right) d \rho^{\prime},
$$

Equação 13

e com isso $V(x)$ será

$$
V(x)=(1-\alpha) H \sum_{q} \int_{0}^{\rho_{q}} u\left(\rho^{\prime}\right) d \rho^{\prime},+\alpha H \sum_{q} \rho_{q} u\left(\rho_{q}\right),
$$

Equação 14

o que leva ao resultado para a função $F(x)$, no limite de $H$ grande,

$$
\begin{gathered}
F(x)=V(x)+T S(X)=(1-\alpha) L(x)+\alpha U(X)+T S(X) \\
F(x)=(1-\alpha) H \cdot \sum_{q} l\left(\rho_{q}\right)+\alpha H \cdot \sum_{q} \rho_{q} \cdot u\left(\rho_{q}\right)+T H \sum_{q} s\left(\rho_{q}\right) \\
F(x)=H \cdot \sum_{q}\left\{(1-\alpha) l\left(\rho_{q}\right)+\alpha \rho_{q} \cdot u\left(\rho_{q}\right)+T \cdot(-\rho \ln \rho-(1-\rho) \ln (1-\rho))\right\} .
\end{gathered}
$$

Portanto, 


$$
F(x)=H \sum_{q} f\left(\rho_{q}\right)
$$

Equação 15

com o potencial $f(\rho)$ dado por

$$
f(\rho)=-T \rho \ln \rho-T(1-\rho) \ln (1-\rho)+\alpha \rho u(\rho)+(1-\alpha) \int_{0}^{\rho_{q}} u\left(\rho^{\prime}\right) d \rho^{\prime} .
$$

Equação 16

As configurações (ou estados) $x=\left\{\rho_{q}\right\}$ de equilíbrio são aquelas que maximizam $\Pi(x)$ (Equação 6) para um certo valor de $\rho_{0}$ da densidade global. Portanto os estados maximizam a soma $F(x)=\sum_{q} f\left(\rho_{q}\right)$ com o vínculo de $\sum_{q=1}^{Q} n_{q}=N \rightarrow \frac{1}{Q} \sum_{q=1}^{Q} \rho_{q}=\rho_{0}$.

O potencial aparece como a generalização da noção de energia livre introduzido em um sistema físico. Podemos definir a utilidade global $U$ como sendo o oposto da energia de um sistema físico comum, porém com a consideração que para o limite de $\alpha=1$ o máximo da função $U+T S$ do modelo de Grauwin equivale ao mínimo da energia livre $E-T S$. Desta forma escrevemos o potencial como

$$
F=(1-\alpha) L+\alpha U+T S .
$$

\section{Equação 17}

Para a situação $\alpha<1$ o potencial $F$ leva em conta os movimentos individuais através da função link $L$.

Se o potencial $f(\rho)$ tiver mais de um máximo, a solução homogênea com densidade $\rho_{0}$ é instável, e o sistema separa-se em duas fases de densidades $\rho_{1}$ e $\rho_{2}$.

Para resolver este problema de maximização com vínculo fazemos uso do método dos multiplicadores de Lagrange, segundo o qual o problema pode ser substituído pela maximização sem vínculo da combinação

$$
\Phi(x, \xi)=F(x)+\xi\left(\frac{1}{Q} \sum_{q=1}^{Q} \rho_{q}-\rho_{0}\right)
$$

Equação 18 
com $\rho_{0}$ fixo. Isto nos leva ao sistema de equações

$$
\begin{aligned}
& \Phi\left(\rho_{q}, \xi\right)=H \sum_{q=1}^{Q} f_{q}\left(\rho_{q}\right)+\xi\left(\frac{1}{Q} \sum_{q=1}^{Q} \rho_{q}-\rho_{0}\right), \\
& \frac{\partial \Phi\left(\rho_{q}, \xi\right)}{\partial \rho_{i}}=0 \rightarrow \frac{\partial F}{\partial \rho_{i}}+\frac{\xi}{Q}=0, i \in\{1,2, \ldots Q\},
\end{aligned}
$$

ou seja,

$$
H f^{\prime}{ }_{q}\left(\rho_{i}\right)+\frac{\xi}{Q}=0, \forall i, j
$$

Portanto,

$$
f^{\prime}\left(\rho_{i}\right)=f^{\prime}\left(\rho_{j}\right), \forall i, j
$$

Equação 19

Essa condição é trivialmente satisfeita pela solução homogênea $\rho_{q}=\rho_{0}, \forall q$. Entretanto, para o caso em que a função $f(\rho)$ é não-concava em $\rho=\rho_{0}$ ocorrerá separação de fase, com o sistema convergindo para duas densidades $\rho_{1}$ e $\rho_{2}$, com $\rho_{1}<\rho_{0}<\rho_{2}$ tais que

$$
\gamma f\left(\rho_{1}\right)+(1-\gamma) f\left(\rho_{2}\right)>f\left(\rho_{0}\right)
$$

Equação 20

de modo que $F(x)$ será maximizado pela combinação $F(x)=\gamma H f\left(\rho_{1}\right)+(1-\gamma) H f\left(\rho_{2}\right)$. Esta condição significa que o valor da soma $\sum_{q} f\left(\rho_{q}\right)$ é maior para o estado difásico do que para o estado homogêneo, portanto o estado difásico terá maior probabilidade de ocorrer.

As densidades $\rho_{1}$ e $\rho_{2}$ são obtidas pela Equação 20 e devem satisfazer

$$
f^{\prime}\left(\rho_{1}\right)=f^{\prime}\left(\rho_{2}\right) \text {. }
$$

Equação 21

O parâmetro $\gamma(0<\gamma<1)$ corresponde à fração dos blocos que ficam com densidade $\rho_{1}$ no estado difásico, e é determinado pela conservação de massa,

$$
\gamma \rho_{1}+(1-\gamma) \rho_{2}=\rho_{0} \text {. }
$$

Equação 22 
As equações 19 e 20 oferecem duas condições sobre as três incógnitas $\rho_{1}, \rho_{2}$ e $\gamma$. A terceira equação necessária para determinar univocamente a solução é obtida a partir da imposição da continuidade das derivadas de $F(x)$, o que obriga que

$$
f^{\prime}\left(\rho_{1}\right)=f^{\prime}\left(\rho_{2}\right)=\frac{f\left(\rho_{2}\right)-f\left(\rho_{1}\right)}{\rho_{2}-\rho_{1}} .
$$

\section{Equação 23}

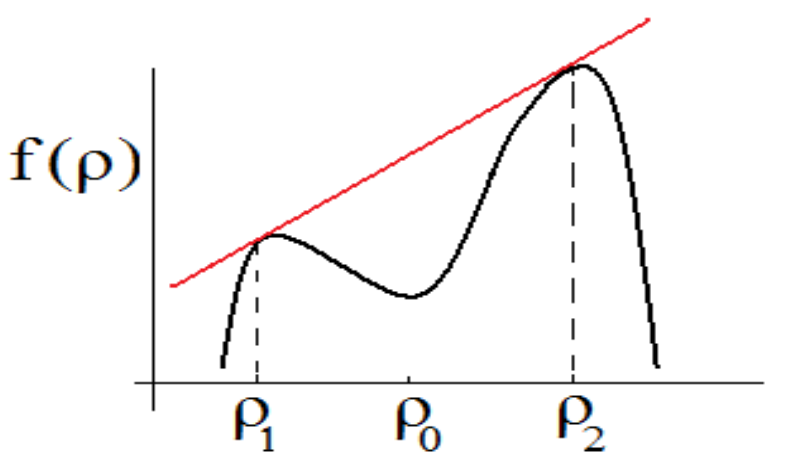

Figura 1: Ref [3] - Função potencial - Separação de fase

$\mathrm{Na}$ separação de fase o sistema se divide em duas fases de densidade $\boldsymbol{\rho}_{\mathbf{1}}$ e $\boldsymbol{\rho}_{\mathbf{2}}$. A construção da dupla tangente determina a densidade destas duas fases no equilíbrio.

A utilidade coletiva normalizada é definida como

$$
U^{*}(x)=U(x) / \sum_{q} n_{q} .
$$

Equação 24

No ponto $f\left(\rho_{0}\right)$ o estado da cidade é homogêneo e todos os blocos terão a mesma densidade $\rho_{0}$ e a utilidade de cada agente será igual à utilidade coletiva normalizada, ou seja,

$$
U^{*}(x)=u\left(\rho_{0}\right)
$$

Equação 25

Caso ocorra separação de fase, alguns blocos terão densidade $\rho_{1}<\rho_{0}$ e outros blocos terão a densidade $\rho_{2}>\rho_{0}$ e então a utilidade coletiva normalizada será dada por

$$
U^{*}(x)=\gamma \frac{\rho_{1}}{\rho_{0}} u\left(\rho_{1}\right)+(1-\gamma) \frac{\rho_{2}}{\rho_{0}} u\left(\rho_{2}\right) \text {. }
$$

Equação 26

A conservação do número de agentes leva à relação $\gamma=\left(\rho_{2}-\rho_{0}\right) /\left(\rho_{2}-\rho_{1}\right)$.

O potencial $F$ pode ser calculado para uma função utilidade arbitrária, que permite analisar o comportamento do estado global de uma cidade. Para ilustrar a influência do 
parâmetro $\alpha$, os autores escolheram uma função que indica que os agentes preferem viver em blocos com densidade $\rho=1 / 2$, definida como

$$
u(\rho)= \begin{cases}2 \rho & \text { para } \rho \leq \frac{1}{2} \\ m+2(1-m)(1-\rho) & \text { para } \rho>\frac{1}{2}\end{cases}
$$

Equação 27

onde $m$ é um parâmetro real.

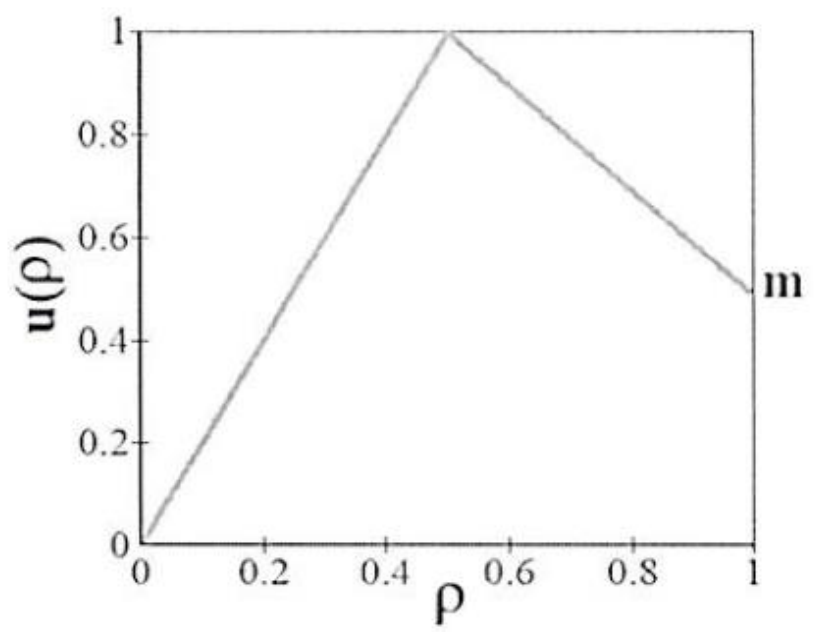

Figura 2: Ref [3] - Função utilidade escolhida pelos autores Esta função foi escolhida pelos autores para medir a utilidade individual dos agentes. Os agentes tendem a preferir a situação $\rho=1 / 2$ com o máximo de utilidade.

A função $f(\rho)$ para $\rho \leq \frac{1}{2}$ escrita explicitamente é dada por

$$
\begin{gathered}
f(\rho)=-T \rho \ln \rho-T(1-\rho) \ln (1-\rho)+\alpha \rho u(\rho)+(1-\alpha) \int_{0}^{\rho} u\left(\rho^{\prime}\right) d \rho^{\prime} \\
f(\rho)=-T \rho \ln \rho-T(1-\rho) \ln (1-\rho)+\alpha \rho \cdot 2 \rho+(1-\alpha) \int_{0}^{\rho} 2 \rho^{\prime} d \rho^{\prime} \\
f(\rho)=-T \rho \ln \rho-T(1-\rho) \ln (1-\rho)+2 \alpha \rho^{2}+\left.(1-\alpha) \rho^{2}\right|_{0} ^{\rho} \\
f(\rho)=-T[\rho \ln \rho+(1-\rho) \ln (1-\rho)]+(1+\alpha) \rho^{2},
\end{gathered}
$$

Equação 28

e para $\rho>\frac{1}{2}$ teremos

$$
\begin{gathered}
f(\rho)=-T \rho \ln \rho-T(1-\rho) \ln (1-\rho)+\alpha \rho u(\rho)+(1-\alpha) \int_{0}^{\rho} u\left(\rho^{\prime}\right) d \rho^{\prime} \\
f(\rho)=-T \rho \ln \rho-T(1-\rho) \ln (1-\rho)+\alpha \rho[m+2(1-m)(1-\rho)]+
\end{gathered}
$$




$$
(1-\alpha)\left[\int_{0}^{\frac{1}{2}} 2 \rho^{\prime} d \rho^{\prime}+\int_{\frac{1}{2}}^{\rho}\left[m+2(1-m)\left(1-\rho^{\prime}\right)\right] d \rho^{\prime}\right] .
$$

Resolvendo a integral $I=\int_{0}^{1 / 2} 2 \rho^{\prime} d \rho^{\prime}+\int_{1 / 2}^{\rho}\left[m+2(1-m)\left(1-\rho^{\prime}\right)\right] d \rho^{\prime}$, temos

$$
\begin{gathered}
I=\int_{0}^{1 / 2} 2 \rho^{\prime} d \rho^{\prime}+\int_{1 / 2}^{\rho}\left[m+2(1-m)\left(1-\rho^{\prime}\right)\right] d \rho^{\prime} \\
I=\left.\rho^{2}\right|_{0} ^{1 / 2}+\int_{1 / 2}^{\rho}\left[-m+2-2 \rho^{\prime}+2 m \rho^{\prime}\right] d \rho^{\prime} \\
I=\left.\rho^{2}\right|_{0} ^{1 / 2}+\left[\rho(2-m)+\rho^{2}(m-1)\right]_{1 / 2}^{\rho} \\
I=\frac{1}{4}+\left[\rho(2-m)+\rho^{2}(m-1)\right]-\left[\frac{1}{2}(2-m)+\frac{1}{4}(m-1)\right] \\
I=\frac{1}{2}\left(\frac{m}{2}-1\right)+\left[\rho(2-m)+\rho^{2}(m-1)\right] .
\end{gathered}
$$

Voltando a $f(\rho)$, obtemos, para $\rho>\frac{1}{2}$,

$$
\begin{gathered}
f(\rho)=-T \rho \ln \rho-T(1-\rho) \ln (1-\rho)+\alpha \rho[-(m+2)+2 \rho(m-1)]+ \\
(1-\alpha) \cdot\left[\frac{1}{2}\left(\frac{m}{2}-1\right)+\rho(2-m)+\rho^{2}(m-1)\right],
\end{gathered}
$$

ou seja,

$$
f(\rho)=-T(\rho \ln \rho+(1-\rho) \ln (1-\rho))-(1+\alpha)(1-m) \rho^{2}+(2-m) \rho-(1-\alpha)(2-m) / 4
$$

Equação 29

No caso coletivo $\alpha=1$ o estado ótimo corresponde àquela configuração que maximiza a utilidade global, (figura 3B), ou seja, todos os $q$ quarteirões terão densidade $\rho_{q}=1 / 2$, para a configuração $\rho_{0}=1 / 2$.

Nestas condições a utilidade coletiva dada pela Equação 25 será $U^{*}=\frac{U}{\rho_{0} H Q}=$ $u\left(\rho_{0}=\frac{1}{2}\right)=1$ e a função link normalizada será $L^{*}=\frac{L}{\rho_{0} H Q}=l\left(\rho_{0}\right) / \rho_{0}=1 / 2$, onde $l\left(\rho_{0}\right)$ é dada pela Equação 12.

No limite egoísta $\alpha=0$ (figura 3A), o equilíbrio coletivo $\rho_{\mathrm{q}}=1 / 2$ é um equilíbrio instável de Nash para uma dada temperatura $\mathrm{T}>0$. Esta instabilidade é notada sabendo que para todo o $\mathrm{T}>0$ existe uma probabilidade de um agente aceitar uma leve diminuição em sua própria utilidade e deixar um bloco com de utilidade $\rho_{q}=1 / 2$. A maximização do potencial $F(x)$ mostrará que a cidade se concentrará somente em alguns 
blocos com densidade $\rho_{q}>1 / 2$ e haverá outra fração de blocos que serão esvaziados. Os agentes que permanecem no bloco ocupam agora uma região com utilidade mais baixa, e por isso passam a estar dispostos a deixarem seus blocos para outro com utilidade $\rho_{q}=1 / 2$. Este movimento cria uma avalanche que esvazia cada vez mais 0 bloco, a cada movimento diminuindo a utilidade dos agentes que ali ficaram. Esta sequencia de movimentos só para quando se atinge o equilíbrio estável de Nash, determinado pelo máximo do potencial $F(x)$. A configuração final corresponde à divisão segregada dos agentes na cidade. O equilíbrio de Nash é a situação na qual, dadas as decisões tomadas pelos demais indivíduos, nenhum agente poderá melhorar sua utilidade mudando sua própria decisão unilateralmente. Em outras palavras, não há incentivos um agente mudar de bloco.

Para evitar os efeitos da entropia vamos tratar o limite $T \rightarrow 0$ nas equações 23 e 24. Neste limite a função $f(\rho)$ é convexa para $0<\rho<1 / 2$ e côncava para $1 / 2<\rho<1$, com $m<1$. Para $\rho<1 / 2$ a solução homogênea é instável, e ocorrerá a separação de fase entre os blocos com densidade $\rho_{2}$. O esquema da página 20 permite calcular $\rho_{2}$ para $T=0$. No entanto, devido à convexidade de $f$ em $[0,1 / 2]$, resulta que $\rho_{1}=0$.

Para calcular $\rho_{2}$, assume-se que $1 / 2<\rho_{2}<1$, e sabendo que $\rho_{1}=0$ então, pela Equação 23, a tangente de $f$ para $\rho_{2}$ será expressa por $f^{\prime}\left(\rho_{2}\right)=\frac{1}{\rho_{2}}\left(f\left(\rho_{2}\right)-f(0)\right)$.

Resolvendo explicitamente para $f^{\prime}(\rho)$ temos

$$
\begin{gathered}
f(\rho)=-T[\rho+\ln \rho(1-\rho) \ln (1-\rho)]+\alpha \rho u(\rho)+(1-\alpha) \int_{0}^{\rho} u\left(\rho^{\prime}\right) d \rho^{\prime} \\
f^{\prime}(\rho)=-T\left\{1 \cdot \ln \rho+\rho \cdot \frac{1}{\rho}-1 \cdot \ln (1-\rho)-\frac{(1-\rho)}{(1-\rho)}\right\}+\alpha \cdot u(\rho)+\alpha \rho \cdot u^{\prime}(\rho)+(1-\alpha) \cdot u(\rho) \\
f^{\prime}(\rho)=-T\{\ln \rho-\ln (1-\rho)\}+\alpha \cdot u(\rho)+\alpha \rho \cdot u^{\prime}(\rho)+(1-\alpha) \cdot u(\rho) \\
f^{\prime}(\rho)=-T\left(\ln \frac{\rho}{(1-\rho)}\right)+u(\rho)+\alpha \rho \cdot u^{\prime}(\rho) .
\end{gathered}
$$

Equação 30

Considerando $u(\rho)$ dado pela Equação 27 então

$$
u^{\prime}(\rho)=\left\{\begin{array}{r}
2, \rho \leq 1 / 2 \\
-2(1-m), \rho>1 / 2
\end{array}\right.
$$




\section{Equação 31}

Usando os resultados das equações 23 e 30 e restringindo ao limite de $T=0$, podemos calcular $\rho_{2}$

$$
\begin{gathered}
f^{\prime}\left(\rho_{2}\right)=\frac{1}{\rho_{2}} f\left(\rho_{2}\right) \Rightarrow u\left(\rho_{2}\right)+\alpha \rho \cdot u^{\prime}\left(\rho_{2}\right)=f\left(\rho_{2}\right) \cdot \rho_{2}^{-1} \\
\Rightarrow\left[m+2(1-m)\left(1-\rho_{2}\right)\right]-\alpha \rho_{2} \cdot 2(1-m) \\
=\left[-(1+\alpha)(1-m) \rho_{2}^{2}+(2-m) \rho_{2}-(1-\alpha)(2-m) / 4\right] \cdot \rho_{2}^{-1} \\
\Rightarrow \rho_{2}[2 m(1+\alpha)-2(1+\alpha)]+2-m \\
=\left[-(1+\alpha)(1-m) \rho_{2}^{2}+(2-m) \rho_{2}-(1-\alpha)(2-m) / 4\right] \cdot \rho_{2}^{-1} \\
\Rightarrow \rho_{2}^{2}[2 m(1+\alpha)-2(1+\alpha)-m(1+\alpha)+(1+\alpha)]+\rho_{2}(2-m-2+m) \\
=-\frac{1}{4}[(1-\alpha)(2-m)] \\
\Rightarrow \rho_{2}^{2}[m(1+\alpha)-(1+\alpha)]=-\frac{1}{4}[(1-\alpha)(2-m)]
\end{gathered}
$$

assim

$$
\rho_{2}=\frac{1}{2} \sqrt{\frac{1-\alpha}{1+\alpha} \frac{2-m}{1-m}}
$$

Equação 32

Em uma fase segregada, espera-se que $1>\rho_{2}>\frac{1}{2}$, ou seja, $1>\frac{1}{2} \sqrt{\frac{1-\alpha}{1+\alpha} \frac{2-m}{1-m}}>\frac{1}{2}$, portando a condição a seguir deverá ser satisfeita;

$$
\begin{gathered}
\rho_{2}=\frac{1}{2} \sqrt{\frac{1-\alpha}{1+\alpha} \frac{2-m}{1-m}}>\frac{1}{2} \Rightarrow\left(\frac{1-\alpha}{1+\alpha}\right)\left(\frac{2-m}{1-m}\right)>1 \\
\Rightarrow \frac{1-\alpha}{1+\alpha}>\frac{1-m}{2-m} \Rightarrow \alpha_{c}<\frac{1}{3-2 m}
\end{gathered}
$$

e também

$$
\begin{gathered}
\rho_{2}=\frac{1}{2} \sqrt{\frac{1-\alpha}{1+\alpha} \frac{2-m}{1-m}}<1 \Rightarrow\left(\frac{1-\alpha}{1+\alpha}\right)\left(\frac{2-m}{1-m}\right)<4 \\
\Rightarrow \frac{1-\alpha}{1+\alpha}<4 \frac{1-m}{2-m} \Rightarrow \alpha_{t}>\frac{3 m-2}{6-5 m}
\end{gathered}
$$


Para $\alpha>\alpha_{c}, \rho_{2}$ converge para $\rho_{2}=1 / 2$ e no outro limite, $\alpha<\alpha_{t}, \rho_{2}$ converge para $\rho_{2}=1$. Esta transição é diferente das transações de equilíbrio de fase padrões conhecido em física, onde a competição é feita entre a entropia e a energia, enquanto aqui a competição é entre o comportamento individual e coletivo dos agentes.

Se $\alpha_{t}(m)<\alpha<\alpha_{c}$ e $\rho_{0}<\rho_{2}$ os dois tipos de blocos surgirão e a utilidade global será dada por

$$
U^{*}=u\left(\rho_{2}\right)=\left\{\begin{aligned}
m, & \text { se } \alpha \leq \alpha_{t} \\
2-m-\sqrt{\frac{1-\alpha}{1+\alpha}(2-m)(1-m),} & \text { se } \alpha_{t} \leq \alpha \leq \alpha_{c} \\
1, & \text { se } \alpha \geq \alpha_{c}
\end{aligned}\right.
$$

Equação 33

No caso oposto onde $\rho_{0} \geq \frac{1}{2}$ e $\alpha>\alpha_{c}$ a utilidade será

$$
U^{*}=u\left(\rho_{0}\right)=2-m-2(1-m) \rho_{0}
$$

Equação 34

A

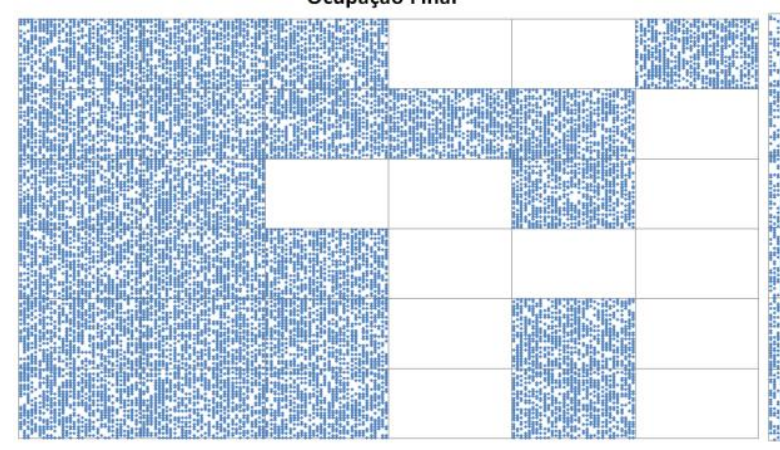

B

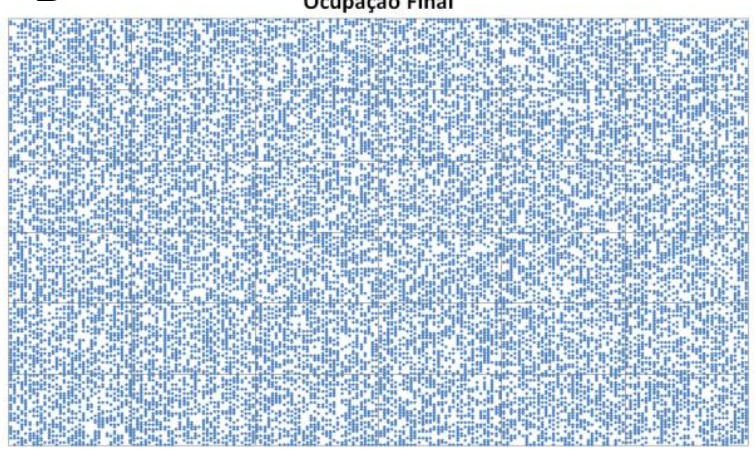

Figura 3: Resultados das simulações para o modelo de Grauwin

3A: Resultado da simulação feita em computador do modelo de Grauwin para o caso onde há segregação. $\boldsymbol{Q}=\mathbf{3 6}, \boldsymbol{H}=\mathbf{1 0 2 4}, \boldsymbol{\rho}_{\mathbf{0}}=\mathbf{0 . 4}, \boldsymbol{m}=\mathbf{0 . 5} \boldsymbol{e} \boldsymbol{\alpha}=\mathbf{0 . 3}$. Nesta configuração obtiveram-se 13 blocos completamente vazios e 23 blocos ocupados com densidade $\boldsymbol{\rho}_{2}=\mathbf{0 , 6 4 0}(\mathbf{0 . 0 1 6})$. O valor analítico de $\boldsymbol{\rho}_{2}$, conforme Equação 32, é $\boldsymbol{\rho}_{\mathbf{2}}=\mathbf{0}, \mathbf{6 3 5}$

3B: Resultado da simulação feita em computador do modelo de Grauwin para o caso homogêneo. $\mathbf{Q}=$ $36, \mathrm{H}=1024, \rho_{0}=0.5, \mathrm{~m}=0.5$ e $\alpha=0.6$.

Calculando diferentes valores de $\mathrm{m}$ para 0 caso $\alpha=0$ pode-se entender a transição entre configuração homogênea e segregada. Quanto maior $0 \mathrm{~m}$, maior será $\mathrm{o}$ valor do parâmetro "imposto" necessário para alcançar a configuração homogênea. 
A partir do modelo de Grauwin surge um número de questões interessantes sobre o ponto de vista individual e coletivo. No caso puramente altruísta $(\alpha=1)$, o estado estacionário corresponde à maximização da utilidade média, em analogia à minimização da energia dos sistemas físicos. No caso oposto $(\alpha=0)$, o estado estacionário será conveniente para um indivíduo e se distanciará do estado ótimo do sistema coletivo.

A estratégia de otimização baseia-se nas limitações da dinâmica individual apresentado por Schelling, criando um link entre a micro-motivação e o macrocomportamento. O estado coletivo pode ser obtido pela maximização da função "link" $(l(p))$ que conecta a dinâmica individual com a coletiva. No estado estacionário, o valor máximo para o potencial $L$ é alcançado e nenhum agente poderá aumentar sua utilidade movendo-se arbitrariamente (por conta de $\Delta u=\Delta L$ ), consistente com a definição dos economistas para o equilíbrio de Nash.

A mecânica estatística desenvolveu ferramentas poderosas para juntar os níveis microscópicos com macroscópicos. Estas ferramentas estão limitadas a sistemas físicos, onde as dinâmicas são governadas por uma quantidade global tal como a energia total. Com a função "link" introduzida por Grauwin, um análogo para funções de estado em termodinâmica ou funções potenciais em teoria dos jogos, foi possível estender a abordagem da mecânica estatística para um modelo semelhante ao de Scheling. Esta aproximação criou os caminhos para o tratamento analítico de uma classe ampla de sistemas, cuja dinâmica é governada por estratégias individuais.

Vamos a seguir generalizar o tratamento proposto por Grauwin para o caso desordenado, com o objetivo de analisar os efeitos produzidos quando um ou mais quarteirões passam a se caracterizar por um parâmetro $m$ distinto dos demais.

\section{Versão desordenada do modelo de Grauwin}

Vamos considerar uma generalização do modelo de Grauwin em que há apenas um único tipo de agente, porém existem dois tipos de quarteirões, com parâmetros de utilidade de máxima ocupação $m$ diferentes. Denotaremos por $m_{b} \circ$ parâmetro do quarteirão que teve seu parâmetro de utilidade de saturação alterado, e por $m_{a} 0$ parâmetro dos demais $Q-1$ quarteirões, com $Q>1$. A função utilidade dos agentes no $Q_{\text {-ésimo }}$ quarteirão é dada por 


$$
u_{q}(\rho)= \begin{cases}2 \rho & \text { para } \rho \leq \frac{1}{2} \\ m_{q}+2\left(1-m_{q}\right)(1-\rho) & \text { para } \rho>\frac{1}{2}\end{cases}
$$

Equação 35

com $q \in\{1,2, \ldots \ldots, Q\}$.

A utilidade global é então

$$
U(x)=H \sum_{q} \rho_{q} u_{q}\left(\rho_{q}\right),
$$

em que $x=\left\{\rho_{q}\right\}$ denota a configuração de grão-grosso dos quarteirões, $\rho_{q}=\frac{n_{q}}{H}$ é a densidade do $q_{\text {-ésimo }}, H$ é o número de vagas em cada quarteirão e $n_{q}$ é o número de agentes deste quarteirão.

A entropia total é dada por

$$
S(x)=\ln \left(\prod_{q} \frac{H !}{n_{q} !\left(H-n_{q}\right) !}\right)=\sum_{q} \ln \left(\frac{H !}{n_{q} !\left(H-n_{q}\right) !}\right),
$$

ou seja,

$$
S(x)=H \sum_{q} s\left(\rho_{q}\right)
$$

onde $s(\rho)=-\rho \ln \rho-(1-\rho) \ln (1-\rho)$ no limite de $H \gg 1$.

A probabilidade de que um agente realize um movimento que leva a configuração de grão-grosso de $x$ para $y$ é $P_{x \rightarrow y} \sim e^{G_{x \rightarrow y} / T}$, em que $T$ pode ser interpretado como a temperatura e $G_{x \rightarrow y}$ é o ganho definido como

$$
G_{x \rightarrow y}=(1-\alpha) \Delta u_{x \rightarrow y}+\alpha \Delta U_{x \rightarrow y}
$$

sendo $\alpha$ o parâmetro de altruísmo, $\Delta u_{x \rightarrow y}$ a variação na utilidade do agente que realizou o movimento e $\Delta U_{x \rightarrow y}$ a variação na utilidade global. Se pudermos escrever

$$
G_{x \rightarrow y}=\Delta V_{x \rightarrow y}=V(y)-V(x),
$$

a distribuição estacionária das configurações de grão-grosso é

$$
\Pi(x)=\frac{1}{Z} e^{F(x) / T}
$$

com

$$
F(x)=V(x)+T S(x),
$$

e $Z$ a constante de normalização. 
Temos que encontrar a função $V(x)$. Para tanto, precisamos construir uma função da configuração $x=\left\{\rho_{q}\right\}, L(x)$, cuja variação seja igual à variação da utilidade individual $\Delta u_{x \rightarrow y}:$

$$
\Delta \mathrm{u}_{\mathrm{x} \rightarrow \mathrm{y}}=\Delta \mathrm{L}_{\mathrm{x} \rightarrow \mathrm{y}}=L(y)-L(x) .
$$

Com a equação acima encontramos a combinação

$$
V(x)=(1-\alpha) L(x)+\alpha U(x),
$$

que fornece $V(x)$ com as propriedades que desejamos.

Vamos construir uma função $L(x)$ tal que

$$
L(x)=H \sum_{q} l_{q}\left(\rho_{q}\right)
$$

O movimento de um agente do quarteirão $j$, com densidade $\rho_{j}$, para um quarteirão $k$, com densidade $\rho_{k}$, provoca em $L$ a variação

$$
\begin{gathered}
\Delta \mathrm{L}_{\mathrm{x} \rightarrow \mathrm{y}}=\left[H l_{k}\left(\rho_{k}+\frac{1}{H}\right)-H l_{k}\left(\rho_{k}\right)\right]+\left[H l_{j}\left(\rho_{j}-\frac{1}{H}\right)-H l_{j}\left(\rho_{j}\right)\right] \\
=\frac{l_{k}\left(\rho_{k}+\frac{1}{H}\right)-l_{k}\left(\rho_{k}\right)+l_{j}\left(\rho_{j}-\frac{1}{H}\right)-l_{j}\left(\rho_{j}\right)}{\frac{1}{H}} \\
\Delta \mathrm{L}_{\mathrm{x} \rightarrow \mathrm{y}}=l_{k}^{\prime}\left(\rho_{k}\right)-l_{j}^{\prime}\left(\rho_{j}\right),
\end{gathered}
$$

e daí

$$
\Delta \mathrm{u}_{\mathrm{x} \rightarrow \mathrm{y}}=u_{k}\left(\rho_{k}+\frac{1}{H}\right)-u_{j}\left(\rho_{j}\right) \cong u_{k}\left(\rho_{k}\right)-u_{j}\left(\rho_{j}\right) \cong l_{k}^{\prime}\left(\rho_{k}\right)-l_{j}^{\prime}\left(\rho_{j}\right),
$$

com erros da ordem de $\frac{1}{H}$. Logo, no limite de $H \gg 1$, podemos tomar $u_{q}\left(\rho_{q}\right)=l_{q}^{\prime}\left(\rho_{q}\right)$, que nos leva a

$$
l_{q}\left(\rho_{q}\right)=\int_{0}^{\rho_{q}} u_{q}(\rho) d \rho \cong \frac{1}{H} \sum_{n=0}^{n_{q}} u_{q}\left(\frac{n}{H}\right),
$$

de modo que podemos associar $H l_{q}\left(\rho_{q}\right)$ à soma sobre as utilidades de todos os agentes que ocupam sucessivamente o quarteirão.

Portanto, podemos escrever

$$
V(x)=(1-\alpha) H \sum_{q} \int_{0}^{\rho} u_{q}\left(\rho^{\prime}\right) d \rho^{\prime},+\alpha H \sum_{q} \rho_{q} u_{q}\left(\rho_{q}\right),
$$

o que leva a 


$$
\begin{gathered}
F(x)=(1-\alpha) H \cdot \sum_{q} l_{q}\left(\rho_{q}\right)+\alpha H \cdot \sum_{q} \rho_{q} \cdot u_{q}\left(\rho_{q}\right)+T H \sum_{q} s\left(\rho_{q}\right) \\
F(x)=H \cdot \sum_{q}\left\{(1-\alpha) l_{q}\left(\rho_{q}\right)+\alpha \rho_{q} \cdot u_{q}\left(\rho_{q}\right)+T \cdot\left(-\rho_{q} \ln \rho_{q}-\left(1-\rho_{q}\right) \ln \left(1-\rho_{q}\right)\right)\right\},
\end{gathered}
$$

portanto;

$$
F(x)=H \sum_{q} f_{q}\left(\rho_{q}\right)
$$

com o potencial $f(\rho)$ dado por

$$
f_{q}(\rho)=-T \rho \ln \rho-T(1-\rho) \ln (1-\rho)+\alpha \rho u_{q}(\rho)+(1-\alpha) \int_{0}^{\rho} u_{q}\left(\rho^{\prime}\right) d \rho^{\prime}
$$

A configuração de equilíbrio, para certa escolha dos parâmetros $\left\{m_{q}\right\}$, com $m_{q} \in\left\{m_{a}, m_{b}\right\}$, corresponde àquela que maximiza a função $F(x)$.

Vamos considerar primeiro o caso em que $Q-1$ quarteirões têm parâmetro de assimetria $m_{a}$, e apenas 1 quarteirão tem parâmetro $m_{b}$, e por hipótese $m_{b}>m_{a}$. Assim, sem perda de generalidade, podemos assumir que o potencial $F(x)$ da Equação 15 toma a forma

$$
F(x)=H\left[\sum_{q=1}^{Q-1} f_{a}\left(\rho_{q}\right)+f_{b}\left(\rho_{Q}\right)\right]
$$

Equação 36

Temos agora que maximizar $F(x)$ sujeito ao vinculo de que $\sum_{q=1}^{Q} n_{q}=N \rightarrow$ $\frac{1}{Q} \sum_{q=1}^{Q} \rho_{q}=\rho_{0}$, sendo $N$ o número total de agentes. Maximizar $F(x)$ com o vínculo equivale a maximizar sem restrição a função

$$
\Phi(x, \xi)=F(x)+\xi\left(\frac{1}{Q} \sum_{q=1}^{Q} \rho_{q}-\rho_{0}\right)
$$

Equação 37

com $\rho_{0}$ fixo. Isto nos leva ao seguinte sistema de equações:

$$
\Phi\left(\rho_{q}, \rho_{Q}, \xi\right)=H\left[\sum_{q=1}^{Q-1} f_{a}\left(\rho_{q}\right)+f_{b}\left(\rho_{Q}\right)\right]+\xi\left(\frac{1}{Q} \sum_{q=1}^{Q} \rho_{q}-\rho_{0}\right)
$$




$$
\left\{\begin{array}{l}
\frac{\partial \Phi\left(\rho_{q}, \rho_{Q}, \xi\right)}{\partial \rho_{q}}=0 \Rightarrow H f_{a}^{\prime}\left(\rho_{q}\right)+\frac{\xi}{Q}=0 \\
\frac{\partial \Phi\left(\rho_{q}, \rho_{Q}, \xi\right)}{\partial \rho_{Q}}=0 \Rightarrow H f_{b}^{\prime}\left(\rho_{Q}\right)+\frac{\xi}{Q}=0
\end{array}\right.
$$

e resolvendo o sistema, temos

$$
f^{\prime}{ }_{a}\left(\rho_{q}\right)=f^{\prime}{ }_{b}\left(\rho_{Q}\right)
$$

\section{Equação 38}

com $q \neq Q$ e considerando que o multiplicador de Lagrange $\xi$ não depende de $q$.

Novamente considerando o limite de temperatura nula, o valor de $f_{q}^{\prime}(\rho)$ será dado por

$$
f_{q}^{\prime}(\rho)=u_{q}(\rho)+\alpha \rho \cdot u_{q}^{\prime}(\rho)
$$

$\operatorname{com} u_{q}^{\prime}(\rho)$

$$
u_{q}^{\prime}(\rho)=\left\{\begin{aligned}
2, & \rho \leq 1 / 2 \\
-2\left(1-m_{q}\right), & \rho>1 / 2^{\prime}
\end{aligned}\right.
$$

portanto

$$
f_{q}^{\prime}(\rho)=\left\{\begin{aligned}
2 \rho \cdot(1+\alpha), & \rho \leq 1 / 2 \\
-2 \rho\left[\left(1-m_{q}\right) \cdot(1+\alpha)\right]+2-m_{q}, & \rho>1 / 2^{\prime}
\end{aligned}\right.
$$

Equação 39

$\operatorname{com} m_{q} \in\left\{m_{a}, m_{b}\right\}$

Repare que $f_{q}^{\prime}(\rho)$ é uma função monótona crescente para $\rho<1 / 2$ e monótona decrescente para $\rho>1 / 2$.

Considerando os resultados obtidos no caso uniforme, esperamos dois tipos de soluções para o equilíbrio dos quarteirões:

i. Solução homogênea: $\rho_{1}^{*}=\rho_{q}, \forall q<Q$ e $\rho_{Q} \neq 0$ para $q=Q$.

ii. Solução segregada: $\rho_{1}=0$ e $\rho_{2} \neq \rho_{Q} \neq 0$, com o número de quarteirões vazios $Q_{v}<Q-1$ e $\rho_{Q}$ correspondendo ao quarteirão com parâmetro de assimetria $m_{b}$. 


\subsection{Solução homogênea}

As densidades de equilíbrio da solução homogênea do modelo desordenado de Grauwin devem então satisfazer as seguintes equações:

$$
\begin{gathered}
N_{0}=(Q-1) N_{1}^{*}+N_{Q} \\
\frac{N_{0}}{H Q}=\frac{(Q-1) N_{1}^{*}}{H Q}+\frac{N_{Q}}{H Q} \\
\left\{\begin{array}{c}
\rho_{0}=\frac{\rho_{Q}}{Q}+\left(1-\frac{1}{Q}\right) \rho_{1}^{*} ; \\
f_{a}^{\prime}\left(\rho_{1}^{*}\right)=f_{b}^{\prime}\left(\rho_{Q}\right)
\end{array}\right.
\end{gathered}
$$

Equação 40

onde $N_{0}$ é o número total de agentes, $N_{1}^{*}$ é o número de agentes do $Q-1$ quarteirões e $N_{Q}$ é a quantidade de agentes no quarteirão com o parâmetro de saturação alterado.

A penúltima equação pode ser reescrita como $\rho_{Q}=\rho_{1}^{*}(1-Q)+Q \rho_{0}$.

Como esperamos que esse caso ocorra somente para $\rho_{0}>1 / 2$ então podemos supor que $\rho_{1}^{*}>1 / 2$, para obter

$$
\begin{aligned}
& f_{a}^{\prime}\left(\rho_{1}^{*}\right)=-2 \rho_{1}^{*}\left[\left(1-m_{a}\right) \cdot(1+\alpha)\right]+2-m_{a} \\
& f_{b}^{\prime}\left(\rho_{Q}\right)=-2 \rho_{Q}\left[\left(1-m_{b}\right) \cdot(1+\alpha)\right]+2-m_{b}
\end{aligned}
$$

Da condição $f_{a}^{\prime}\left(\rho_{1}^{*}\right)$ e $f_{b}^{\prime}\left(\rho_{Q}\right)$ obtemos

$$
\begin{gathered}
f_{a}^{\prime}\left(\rho_{1}^{*}\right)=f_{b}^{\prime}\left(\rho_{Q}\right) \Rightarrow-2 \rho_{1}^{*}\left[\left(1-m_{a}\right) \cdot(1+\alpha)\right]+2-m_{a}=-2 \rho_{Q}\left[\left(1-m_{b}\right) \cdot(1+\alpha)\right]+2-m_{b} \\
\Rightarrow-2 \rho_{1}^{*}\left[\left(1-m_{a}\right) \cdot(1+\alpha)\right]+2-m_{a}=-2\left[\rho_{1}^{*}(1-Q)+Q \rho_{0}\right] \cdot\left[\left(1-m_{b}\right) \cdot(1+\alpha)\right]+2-m_{b} \\
\Rightarrow-2 \rho_{1}^{*}\left[\left(1-m_{a}\right) \cdot(1+\alpha)\right]-m_{a} \\
=2 \rho_{1}^{*}(Q-1)\left[\left(1-m_{b}\right) \cdot(1+\alpha)\right]-2 Q \rho_{0}\left[\left(1-m_{b}\right) \cdot(1+\alpha)\right]-m_{b} \\
\rho_{1}^{*}=\frac{m_{b}-m_{a}+2 Q \rho_{0}(1+\alpha)\left(1-m_{b}\right)}{2(1+\alpha)\left[m_{b}-m_{a}+\left(1-m_{b}\right) Q\right]}
\end{gathered}
$$

Para $\rho_{Q}$ teremos

$$
\rho_{Q}=\frac{(1-Q)\left(m_{b}-m_{a}\right)+2 Q \rho_{0}(1+\alpha)\left(1-m_{a}\right)}{2(1+\alpha)\left[m_{b}-m_{a}+\left(1-m_{b}\right) Q\right]} .
$$

Equação 41 
Note que para $m_{b}=m_{a}$ voltamos ao resultado original $\rho_{1}^{*}=\rho_{Q}=\rho_{0}$.

Para $m_{b}$ e $m_{a}$ quaisquer temos a relação

$$
\rho_{Q}-\rho_{1}^{*}=\frac{\left[2 Q \rho_{0}(1+\alpha)-Q\right]\left(m_{b}-m_{a}\right)}{2(1+\alpha)\left[m_{b}-m_{a}+\left(1-m_{b}\right) Q\right]^{\prime}}
$$

Equação 42

cujo resultado é positivo, já que, por hipótese, $m_{b}>m_{a}, \alpha>0$ e $\rho_{0}>1 / 2$.

\subsection{Solução segregada}

A solução segregada existirá porque a combinação $\gamma f_{a}\left(\rho_{1}\right)+(1-\gamma) f_{a}\left(\rho_{2}\right)$ pode ser maior que o potencial da solução homogênea $f_{a}\left(\rho_{1}^{*}\right)$. Isso sempre irá ocorrer se $\rho_{1}^{*}<1 / 2$, já que $f_{a}(\rho)$ é convexa no intervalo $0<\rho<1 / 2$, e portanto $f_{a}\left(\rho_{1}^{*}\right)$ é menor que $\gamma f_{a}\left(\rho_{1}\right)+(1-\gamma) f_{a}\left(\rho_{2}\right)$ desde que $\rho_{1}<\rho_{1}^{*}<\rho_{2}$. Além disto, novamente em razão da convexidade de $f_{a}(\rho)$ no intervalo $0<\rho<1 / 2$, devemos ter $\rho_{1}=0$ e $\rho_{2}>1 / 2$. As densidades de equilíbrio devem então satisfazer as equações

$$
\begin{gathered}
N_{0}=\left(Q-Q_{v}-1\right) N_{2}+N_{Q}, \\
\frac{N_{0}}{H Q}=\frac{\left(Q-Q_{v}-1\right) N_{2}}{H Q}+\frac{N_{Q}}{H Q^{\prime}} \\
\left\{\begin{array}{c}
\rho_{0}=\frac{\rho_{Q}}{Q}+\rho_{2}\left(1-\frac{\left(Q_{v}+1\right)}{Q}\right), \\
f_{a}^{\prime}\left(\rho_{2}\right)=\frac{f_{a}\left(\rho_{2}\right)}{\rho_{2}}, \\
f_{b}^{\prime}\left(\rho_{Q}\right)=f_{a}^{\prime}\left(\rho_{2}\right) .
\end{array}\right.
\end{gathered}
$$

Equação 43

a penúltima equação tem a mesma solução da Equação 32 do modelo ordenado de Grauwin, ou seja

$$
f_{a}^{\prime}\left(\rho_{2}\right)=\frac{f_{a}\left(\rho_{2}\right)}{\rho_{2}} \Rightarrow \rho_{2}=\frac{1}{2} \sqrt{\frac{1-\alpha}{1+\alpha} \frac{2-m_{a}}{1-m_{a}}},
$$

e novamente supondo que $\rho_{Q}$ e $\rho_{2} \geq 1 / 2$, teremos

$$
f_{b}^{\prime}\left(\rho_{Q}\right)=f_{a}^{\prime}\left(\rho_{2}\right) \Rightarrow-2 \rho_{q}\left[\left(1-m_{b}\right) \cdot(1+\alpha)\right]+2-m_{b}=-2 \rho_{2}\left[\left(1-m_{a}\right) \cdot(1+\alpha)\right]+2-m_{a}
$$




$$
\begin{gathered}
2 \rho_{q}\left[-(1+\alpha)+m_{b}(1+\alpha)\right]+2-m_{b}=2 \rho_{2}\left[-(1+\alpha)+m_{a}(1+\alpha)\right]+2-m_{a} \\
\rho_{q}\left[-(1+\alpha)+m_{b}(1+\alpha)\right]=\rho_{2}\left[-(1+\alpha)+m_{a}(1+\alpha)\right]+\frac{1}{2}\left(m_{b}-m_{a}\right) \\
\rho_{Q}=\frac{\rho_{2}\left\{(1+\alpha)\left(m_{a}-1\right)\right\}+\frac{1}{2}\left(m_{b}-m_{a}\right)}{(1+\alpha)\left(m_{b}-1\right)}
\end{gathered}
$$

e por último temos a relação do número de quarteirões vazios

$$
Q_{v}=\frac{1}{\rho_{2}}\left(\rho_{Q}-Q \rho_{0}\right)+Q-1,
$$

e para solução segregada o conjunto de soluções é dado por

$$
\left\{\begin{array}{c}
Q_{v}=\frac{1}{\rho_{2}}\left(\rho_{Q}-Q \rho_{0}\right)+Q-1 \\
\rho_{2}=\frac{1}{2} \sqrt{\frac{1-\alpha}{1+\alpha} \frac{2-m_{a}}{1-m_{a}}} ; \\
\rho_{Q}=\frac{\rho_{2}\left\{(1+\alpha)\left(m_{a}-1\right)\right\}+\frac{1}{2}\left(m_{b}-m_{a}\right)}{(1+\alpha)\left(m_{b}-1\right)} .
\end{array}\right.
$$

Equação 44

Claramente podemos observar que se $m_{b}=m_{a}$ teremos a solução segregada de Grauwin $\operatorname{com} \rho_{2}=\rho_{Q}$.

Novamente para $m_{b}$ e $m_{a}$ quaisquer temos a relação

$$
\begin{gathered}
\rho_{Q}-\rho_{2}=\frac{\rho_{2}\left\{(1+\alpha)\left(m_{a}-1\right)\right\}+\frac{1}{2}\left(m_{b}-m_{a}\right)}{(1+\alpha)\left(m_{b}-1\right)}-\rho_{2} \\
=\frac{\rho_{2}\left\{(1+\alpha)\left(m_{a}-1\right)\right\}+\frac{1}{2}\left(m_{b}-m_{a}\right)-\rho_{2} \cdot\left[(1+\alpha)\left(m_{b}-1\right)\right]}{(1+\alpha)\left(m_{b}-1\right)} \\
=\frac{\rho_{2}\left\{(1+\alpha)\left(m_{a}-m_{b}\right)\right\}-\frac{1}{2}\left(m_{a}-m_{b}\right)}{(1+\alpha)\left(m_{b}-1\right)} \\
\rho_{Q}-\rho_{2}=\frac{\left(m_{a}-m_{b}\right)\left\{\rho_{2}(1+\alpha)-\frac{1}{2}\right\}}{(1+\alpha)\left(m_{b}-1\right)}
\end{gathered}
$$

Equação 45 
cujo resultado é positivo já que por hipótese $1>m_{b}>m_{a}$ e $\rho_{2}>\frac{1}{2}$. Este é um resultado esperado, já que quanto maior for o parâmetro $m$ de um quarteirão mais atrativo ele será para os agentes.

Neste capítulo fizemos uma generalização no modelo de Grauwin incluindo dois tipos de quarteirões, com parâmetros de utilidade de máxima ocupação $m$ diferentes,

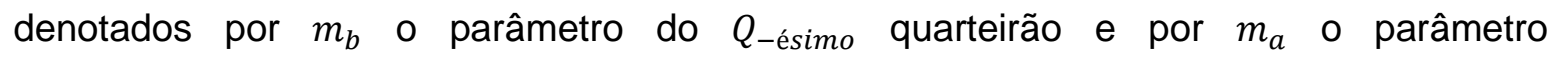
correspondente aos demais $Q-1$ quarteirões. Sem perda de generalidade, reescrevemos o potencial $F(x)$, e usando o método dos multiplicadores de Lagrange, encontramos quais seriam os estados estacionários, ou seja, aqueles que maximizam $F(x)$.

A partir destes resultados escrevemos a relação entre o potencial do $Q_{\text {-ésimo }}$ quarteirão e dos demais $Q-1$ quarteirões. Duas soluções possíveis foram obtidas: a solução homogênea e a solução segregada. Na primeira, o sistema se divide em duas

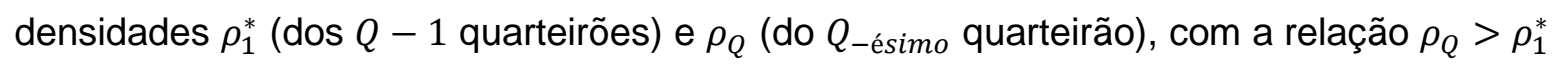
já que por hipótese supomos que $m_{b}>m_{a}$. Já na segunda, o sistema em equilíbrio se dividiu em três densidades, sendo elas $\rho_{1}=0$ (para os $Q_{v}$ blocos esvaziados), $\rho_{2}$ (para os $Q-Q_{v}-1$ blocos) e $\rho_{Q}$ (do $Q_{\text {-ésimo }}$ bloco), novamente com a relação $\rho_{Q}>\rho_{2}$. Verificouse que $\rho_{2}$ do modelo desordenado tem a mesma solução que o caso uniforme de Grauwin, e os valores de $Q_{v}, \rho_{1}^{*}$ e $\rho_{Q}$ foram todos obtidos analiticamente.

Há muitas aplicações possíveis do ponto de vista econômico para estes resultados, duas das quais abordaremos a seguir:

i. a guerra fiscal entre os estados de uma nação;

ii. a recente situação da portabilidade de crédito no sistema bancário. 


\section{Guerra fiscal entre as unidades de uma federação}

\subsection{Panorama da guerra fiscal no Brasil}

No Brasil, houve um processo paulatino de descentralização das indústrias, que outrora eram concentradas em São Paulo por conta do crescimento da indústria automobilística e toda sua cadeia produtiva de equipamentos neste Estado. Na década de 1970, a região metropolitana de São Paulo representava quase a metade $(45 \%)$ do valor da produção industrial no país. A concentração industrial no Sudeste aprofundava as desigualdades inter-regionais, motivando uma intensa dinâmica migratória. Isto causou o rápido e desordenado crescimento das cidades paulistas, gerando uma série de problemas sócio-econômicos. [6]

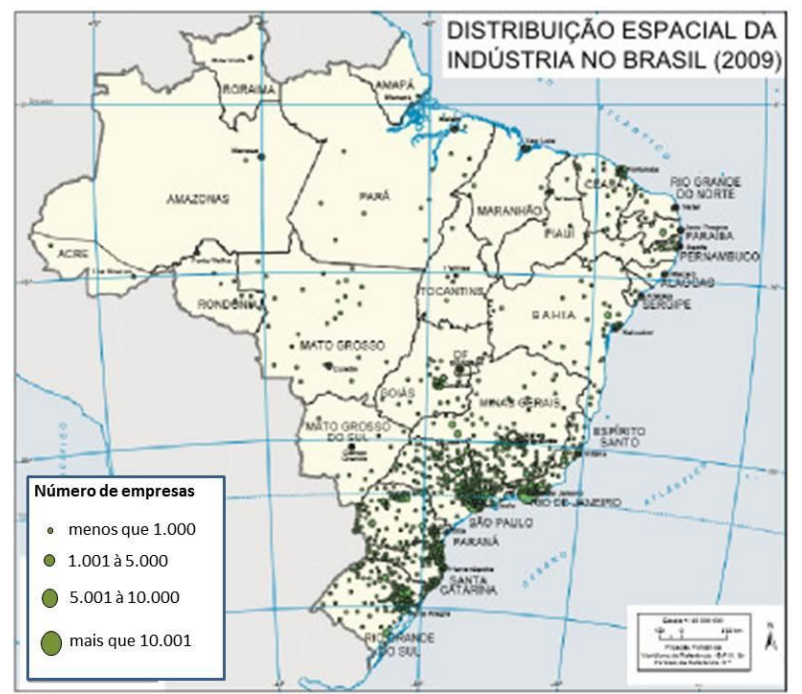

Figura 4: Distribuição das indústrias no Brasil em 2009

Após o início da descentralização da região Sudeste impulsionada guerra fiscal.
Devido a tais distorções regionais no território brasileiro e problemas sócioeconômicos gerados pelo modelo concentrador do processo industrial na região Sudeste, o governo federal desenvolveu, na década de 1970, uma série de incentivos fiscais para a desconcentração industrial. Mas de fato, foi na década de 1990 que a desconcentração no país veio a se intensificar, apoiada pela maior abertura econômica, pelo desenvolvimento técnicocientífico e principalmente pela concessão aos Estados de uma maior autonomia na definição dos impostos. As empresas começaram a mover suas bases para outras regiões do Brasil e este foi o inicio da guerra fiscal no país - termo pejorativo usado para definir competição tributária.

O embate entre os Estados brasileiros na chamada guerra fiscal e os seus impactos na logística são um assunto recorrente na macro-economia brasileira. $\mathrm{O}$ imposto sobre circulação de mercadorias e serviços (ICMS) é o principal agente da disputa. Os 
benefícios fiscais tornam mais vantajosa ou não a estadia de empresas em determinados Estados. A guerra fiscal no Brasil é um instrumento usado nos Estados mais pobres e distantes de grandes centros urbanos, para atrair investimentos e evitar que haja esvaziamento econômico. O Brasil tem trabalhado para reformar o ICMS, disciplinando a guerra entre os Estados. Em uma entrevista ao jornal Valor Econômico [5], o sócio da LCA Consultores e ex-secretário de Políticas Econômicas do Ministério da Fazenda, Bernard Appy, disse que "Os benefícios concedidos pelos estados para que empresas privadas se instalem em determinada região contrariam a lei e são altamente nocivos para o Brasil". Para ele, a guerra fiscal traz sérios riscos para as companhias, já que as vantagens tributárias podem ser convertidas em pesados custos, além de empobrecer o país. Appy destaca ainda o fato de que os Estados concedem benefícios fiscais sem a aprovação do Conselho Nacional de Política Fazendária (Confaz), desrespeitando a legislação. Em sua avaliação, houve uma tolerância com essa situação porque se entendia que tais benefícios ajudariam a contornar algumas questões fiscais do país e beneficiariam o desenvolvimento regional. "O problema é que isso se generalizou e a guerra fiscal também implicou o uso inadequado do sistema de logística do país, acarretando um custo social relevante para a economia”. Além destes fatos, o governo, não conhecendo totalmente as características de um determinado mercado, ao aumentar o incentivo fiscal pode alterar as vantagens competitivas de uma empresa em detrimento de outra, mudando a estrutura da concorrência e possivelmente abrindo portas para a formação de oligopólios.

Em uma entrevista à Exame em 2013 o então ministro da Fazenda, Guido Mantega, reafirma que as disputas estaduais em torno do "problemático" ICMS chegaram a um ponto de exacerbação e que é preciso aprimorar a lei. Segundo ele, hoje há mais perdas do que ganhos para os entes da Federação com a guerra fiscal.

A seguir vamos construir um paralelo da guerra fiscal com o modelo desordenado de Grauwin.

\subsection{Aplicação do modelo desordenado de Grauwin}

O objetivo deste trabalho é tentar construir um paralelo da guerra fiscal com a dinâmica de segregação proposta por Grauwin. Para tal, podemos imaginar que os blocos 
são como as unidades de uma federação e os agentes são as indústrias pertencentes a estes Estados.

Vamos supor que a nação seja dividida em $Q$ Estados e que cada Estado possa suportar o número máximo $H$ de indústrias, e que no país existam $N$ indústrias a serem distribuídas pelos seus Estados. Assim como ocorrera no Brasil, existem alguns Estados que se destacaram dos demais tendo inicialmente uma concentração maior de empresas. Os motivos por ser destacarem podem ser vários, como localização, condições geográficas, capacidade técnica, infra-estrutra, mão-de-obra qualificada, grande mercado de demanda, entre outros. Neste trabalho, colocamos como condição inicial do modelo alguns estados parcialmente ocupados e outros estados totalmente vazios.

A boa escolha da condição inicial do sistema será fundamental para que a dinâmica ocorra, pois se inicialmente a distribuição for homogênea, ou seja, a quantidade de indústria for igualmente distribuída entre os Estados, o sistema ira convergir para uma situação meta-estável que muito se assemelha a própria situação inicial. Se todos os Estados tiveram uma densidade $\rho_{0}$ antes das interações dificilmente os agentes sairão de um bloco para outro, e mesmo que isso ocorra, será apenas uma troca de lugar de tal sorte que após todas as interações não haverá diferença entre o estado inicial e o estado final.

Para evitar estes efeitos de meta-estabilidade nas simulações, as indústrias foram

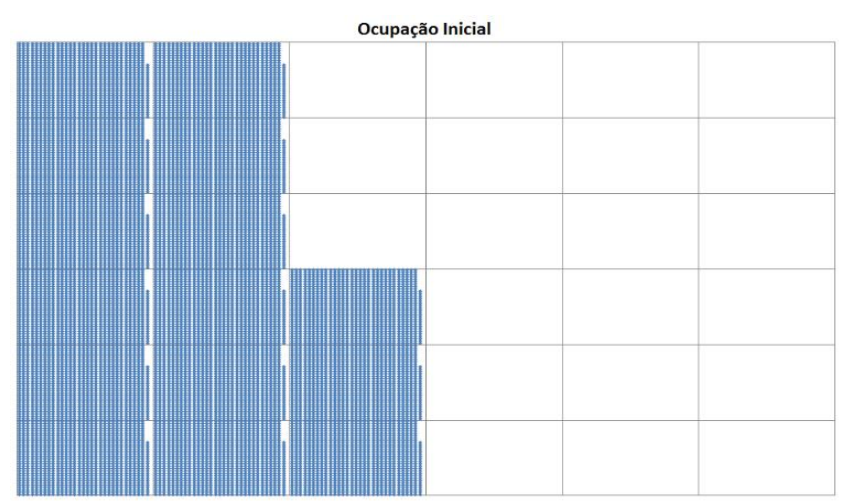
distribuídas de forma uniforme entre os primeiros, de tal sorte que cada primeiro estado possua a mesma quantidade de indústrias,

$$
\rho_{q i}=\frac{\rho_{0} \cdot Q}{\operatorname{Max} \operatorname{Int}\left(p_{0} Q\right)^{\prime}}
$$

onde $\operatorname{Má} x \operatorname{Int}\left(p_{0} Q\right)$ é o maior número inteiro menor que o produto $p_{0} Q$.

Figura 5: Distribuição inicial das indústrias nos estados durante as simulações.

Para evitar situações meta-estáveis o sistema é preparado de forma que os primeiros $\mathrm{n}$ estados ocupas tenha em média a mesma quantidade de agentes.

De volta ao modelo, a utilidade das empresas $u(\rho)$ mede os ganhos individuais de cada indústria e a utilidade global $U(x)$ é a soma dos ganhos de todas as indústrias sendo proporcional a arrecadação total de impostos da nação. A princípio 
quanto maior for a arrecadação global da nação maior será o nível de satisfação dos indivíduos que ali vivem.

O país tem o controle do parâmetro de imposto $\alpha$ e é este parâmetro que dita às regras da dinâmica. Não se deve esperar uma relação direta quantitativa entre o parâmetro $\alpha$ e um imposto específico, mas sim uma relação qualitativa entre os efeitos do $\alpha$ no modelo e os efeitos de impostos na dinâmica individual. Assim podemos dizer que quanto mais próximo de 10 valor de $\alpha$ estiver mais as indústrias estarão constrangidas a aumentar os ganhos do pais e, no caso contrário, as industrias estarão apenas interessadas em aumentar os seus próprios ganhos.

No Brasil o principal imposto controlado pelos Estados é o ICMS, mas a guerra fiscal também envolve a doação de terrenos e o custeio de obras de infraestrutura por parte dos governos estaduais. Sem pretensão de descrever quantitativamente a dinâmica da guerra fiscal, supomos que uma combinação de incentivos altera a função utilidade efetiva dos agentes de um certo Estado, alterando seu parâmetro $m$ com relação ao valor dos outros Estados e consequentemente aumentando o lucro dos agentes que ali se instalarem. A diferença com relação à função utilidade 'bruta' terá que sair dos cofres do Estado, e deve ser contabilizada de alguma forma.

Vimos no caso uniforme que todos os Estados possuem o mesmo valor do parâmetro $m$, então não há disputa fiscal entre eles, e a segregação dependerá apenas dos parâmetros de $\alpha$ e $\rho_{0}$ e no equilíbrio, com baixo ruído $(T=0)$, haverá dois tipos de Estados, com densidades $\rho_{1}=0$ e $\rho_{2}>\rho_{0}$.

Pode-se verificar a plausibilidade da forma da função utilidade escolhida nas interpretações que fizemos neste trabalho. Um Estado vazio tem utilidade nula porque carecem de fornecedores próximos, mão de obra qualificada, infraestrutura, etc. À medida que chegam indústrias, a utilidade aumenta, mas há um limite, quando a concorrência diminui os lucros. É nesse regime que altera o parâmetro $\mathrm{m}_{\mathrm{q}}$ produz efeito. Na versão desordenada, como a inclinação da função utilidade é dada por $2 m_{q}-2$ para $\rho_{q}>1 / 2$, quanto maior for o parâmetro $m_{q}$ de uma unidade, menos acentuada será a perda de utilidade com a chegada de novos indivíduos. Portanto, havendo diferentes valores de encargos em diferentes estados, a situação se assemelhará aos incentivos dados às empresas em uma disputa fiscal. 
A guerra fiscal visa atrair empreendimentos para as unidades federativas que as utilizam. São incentivos que resultam na redução ou devolução parcial do imposto. O governador de um Estado deverá estar empenhado em atender aos interesses maiores da nação, mas geralmente coloca os interesses de seu Estado acima dos demais. As justificativas para os estados darem tais incentivos, sob a ótica do administrador público, são: a geração de empregos, melhora na distribuição de renda, aumento do valor agregado ao longo das cadeias produtivas que as empresas geram, e ainda, o possível aumento da receita tributária com arrecadação de impostos da população.

Para medir este último, podemos supor que a lucro bruto total $A_{q}$ de um Estado seja proporcional ao produto do número de indústrias pela utilidade que estas possuem;

$$
A_{q}=H \cdot \rho_{q} \cdot u_{q}\left(\rho_{q}\right) \text {. }
$$

Por outro lado, tomamos a arrecadação total do Estado como

$$
R_{q}=\gamma \cdot H \cdot \rho_{q} \cdot u_{q}\left(\rho_{q}\right) \text {, }
$$

Equação 46

onde $\gamma$ é uma constante de proporcionalidade interpretada como a alíquota de imposto aplicado sobre o lucro bruto.

Devemos calcular o valor do incentivo dado pelo Estado $Q$ para atrair empresas para si. Faremos isso com a seguinte interpretação; a função utilidade de um agente, que mede sua satisfação, pode ser pensada como o lucro que o agente obtém a cada unidade de tempo. Por conta da técnica de reduzir a temperatura, necessária para evitar configurações metaestáveis, consideramos uma expressão aproximada para este incentivo individual. $O$ custo do incentivo individual é medido pela diferença do lucro (função utilidade) que o agente tem por estar no Estado com parâmetro $m_{b}$ em relação ao lucro que este agente teria se estivesse em um dos Estados com parâmetro $m_{a}$ com a mesma ocupação. Explicitamente

$$
i_{Q}=u_{Q}\left(\rho_{Q}\right)-u_{q}\left(\rho_{Q}\right),
$$

Equação 47

sendo $\rho_{Q}$ a densidade do $Q_{\text {-ésimo }}$ Estado após o movimento do agente. 
O custo total que o Estado $Q$ teve por conta da renuncia dos impostos é medido pelo benefício dado a todos os agentes que receberam incentivos, assim temos

$$
I_{Q}=H \rho_{Q} \cdot\left[u_{Q}\left(\rho_{Q}\right)-u_{q}\left(\rho_{Q}\right)\right] \text {. }
$$

Equação 48

Este custo pode estar relacionado com custos sociais (escolas, hospitais, segurança, etc), que crescem junto com o aumento da demanda.

Devemos subtrair da arrecadação bruta do $Q_{\text {-ésimo }}$ Estado este custo de incentivo, portanto a arrecadação líquida é dada por

$$
\begin{gathered}
R_{Q}^{L}=R_{Q}-I_{Q}, \\
R_{Q}^{L}=\gamma \cdot H \cdot \rho_{Q} \cdot u_{Q}\left(\rho_{Q}\right)-H \rho_{Q}\left[u_{Q}\left(\rho_{Q}\right)-u_{q}\left(\rho_{Q}\right)\right], \\
R_{Q}^{L}=H \cdot \rho_{Q}\left[(\gamma-1) \cdot u_{Q}\left(\rho_{Q}\right)+u_{q}\left(\rho_{Q}\right)\right] .
\end{gathered}
$$

Equação 49

A manobra de dar benefício fiscal para atrair empresas só será vantajosa para o Estado $Q$ se $\left[(\gamma-1) \cdot u_{Q}\left(\rho_{Q}\right)+u_{q}\left(\rho_{Q}\right)\right]>0$, portanto o valor mínimo da alíquota $\gamma_{Q}$ deve ser

$$
\begin{gathered}
\left(\gamma_{Q}-1\right) \cdot u_{Q}\left(\rho_{Q}\right)+u_{q}\left(\rho_{Q}\right)>0 \\
\gamma_{Q-\text { minimo }}>1-\frac{u_{q}\left(\rho_{Q}\right)}{u_{Q}\left(\rho_{Q}\right)}
\end{gathered}
$$

Equação 50

ou seja, quanto maior for a diferença entre os parâmetros $m_{b}$ e $m_{a}$, maior terá que ser a alíquota de imposto cobrada da sociedade pelo Estado $Q$ para que ele tenha vantagem por ter concedido benefícios. Podemos supor que o governo federal imponha que todos os Estados possuam a mesma alíquota de imposto sobre a arrecadação de forma que $\gamma_{q}=\gamma_{Q-\text { minimo }} \operatorname{com} q \in\{1,2 \ldots Q\}$.

Podemos medir também qual deveria ser o valor de $\gamma_{q}$ para que a arrecadação do Estado $Q$, mesmo com custo de incentivo, seja pelo igual ao lucro bruto dos Estados ocupados que não aderiram a guerra fiscal. Desta forma

$$
\begin{gathered}
R_{Q}^{L}=R_{q} \\
\gamma_{q} A_{Q}-I_{Q}=\gamma_{q} A_{q}
\end{gathered}
$$




$$
\begin{gathered}
H \cdot \rho_{Q}\left[\left(\gamma_{q}-1\right) \cdot u_{Q}\left(\rho_{Q}\right)+u_{q}\left(\rho_{Q}\right)\right]=\gamma_{q} \cdot H \cdot \rho_{q} \cdot u_{q}\left(\rho_{q}\right) \\
\gamma_{q}=\frac{\rho_{Q}\left[u_{Q}\left(\rho_{Q}\right)-u_{q}\left(\rho_{Q}\right)\right]}{\rho_{Q} \cdot u_{Q}\left(\rho_{Q}\right)-\rho_{q} \cdot u_{q}\left(\rho_{q}\right)}
\end{gathered}
$$

ou

$$
\gamma_{q}=\frac{I_{Q}}{A_{Q}-A_{q}}
$$

\section{Equação 51}

Esse é um resultado importante, já que informa que em alguns casos o Estado que oferece o incentivo tem que se conformar com uma receita líquida mais baixa que a dos demais Estados.

Apresentadas as semelhanças entre a versão desordenada do modelo de Grauwin e situação de uma disputa fiscal entre os estados, vamos a seguir analisar quais são os possíveis resultados e as consequências deste cenário em um país. 


\section{Resultados e Análises}

Para a simulação de uma guerra fiscal, vamos supor que o país tenha 36 estados $(Q=36)$ e que cada estado suporte 1024 indústrias $(H=1024)$. Por simplicidade, vamos nos concentrar inicialmente na situação onde 35 Estados tenham o parâmetro de utilidade máxima $m_{a}$ e apenas 1 Estado tenha parâmetro $m_{b}$ de forma que $m_{b}>m_{a}$, ou seja, supomos que apenas um Estado teria incentivo fiscal.

Como para temperatura nula o movimento ocorrerá somente caso haja aumento da utilidade, o sistema pode ficar preso em configurações metaestáveis. Para driblar este problema inserimos uma função $T$ na dinâmica, que dependerá da quantidade de passos de Monte Carlo que a dinâmica envolver, de forma que

$$
T(p)=\left\{\begin{array}{rl}
\frac{2 .\left(T_{f}-T_{i}\right)}{P M C} p+T_{i}, & \text { se } p<\frac{P M C}{2} \\
T_{f}, & \text { se } p \geq \frac{P M C}{2}
\end{array} ;\right.
$$

Equação 52

onde p é o contador de passos de Monte Carlo e PMC é o total de passos de Monte Carlo definido na dinâmica. Nas simulações inserimos a perturbação $T_{i}=0,1$, e a temperatura final é $\mathrm{T}_{\mathrm{f}}=0,001$.

Vamos dividir as análises em duas situações; a situação onde não há segregação, apenas uma concentração maior de indústrias no Estado que deu incentivo, e outra em que há esvaziamento total de alguns Estados, com a situação de equilíbrio com três densidades diferentes.

\subsection{Caso "homogêneo"}

Para o caso "homogêneo" $\left(\rho_{0}>\frac{1}{2}\right)$, as simulações mostram que houve uma concentração de indústrias maior no estado que deu incentivo do que nos demais estados, $\rho_{Q}>\rho_{1}^{*}$, corroborando o previsto na Equação 42. Foram feitas 50 simulações com 1.000 passos de Monte Carlo cada. Na tabela 1 constam os resultados médios destas simulações para diversos conjuntos de parâmetros. 


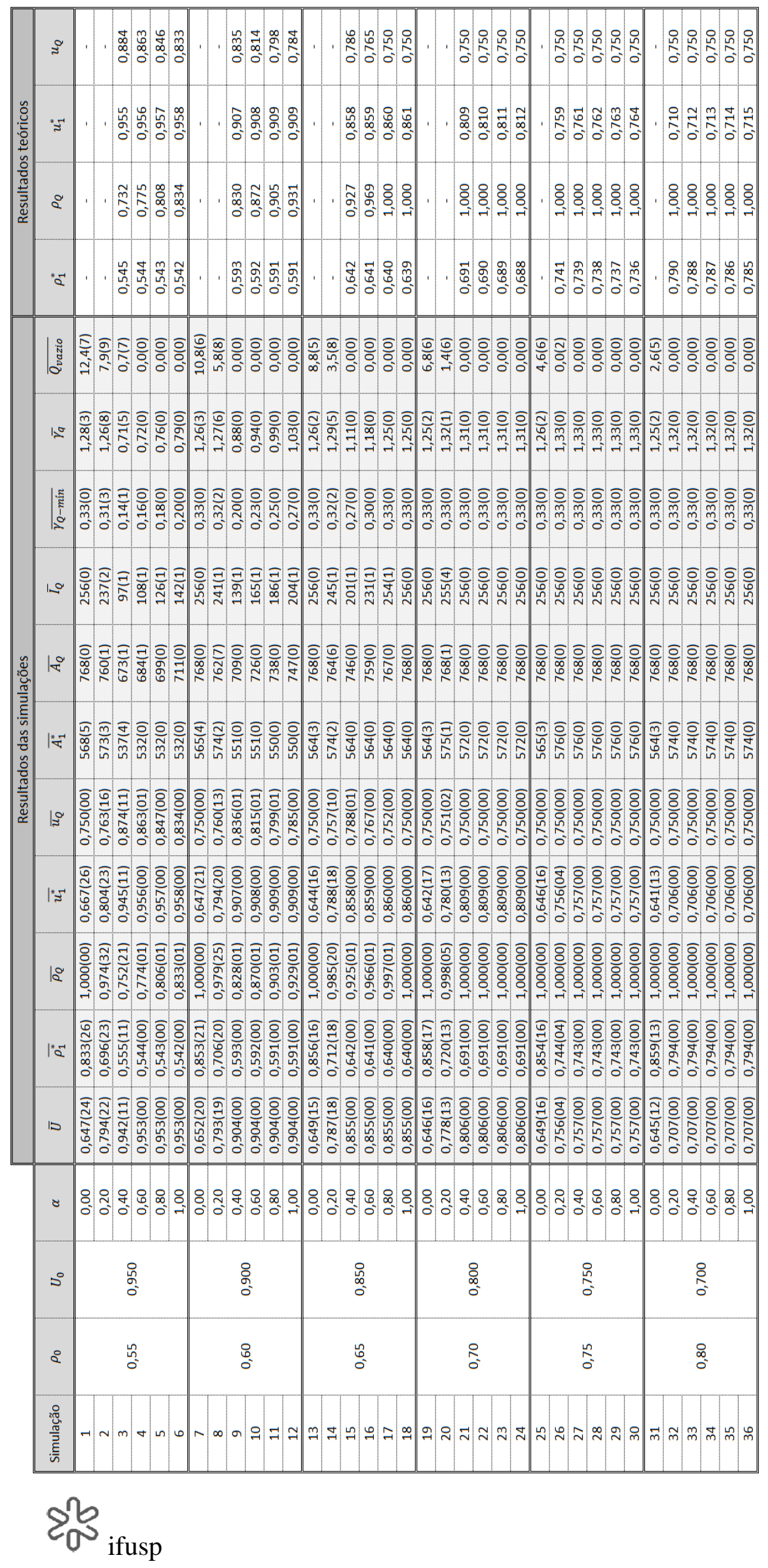

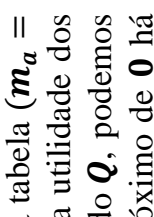

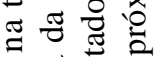

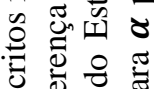

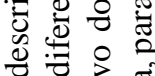

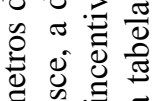

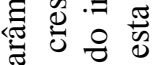

을

웅응

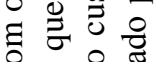

용요

急

를

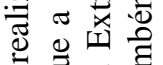

Fे

密

율 屯

월

웡

$\sum 0$ 잉

讨 过

论 总

口.

8 可

ㅇ. 영

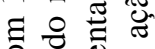

8 응 兰 웡

过 :

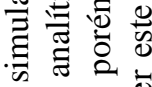

in 它言

野

量

记

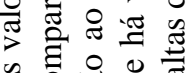

웡 웡 운

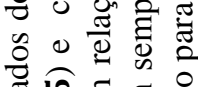

焉

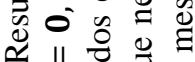

․ 11 है

$\ddot{1}$ हैष

要 010

*0 0 \% 

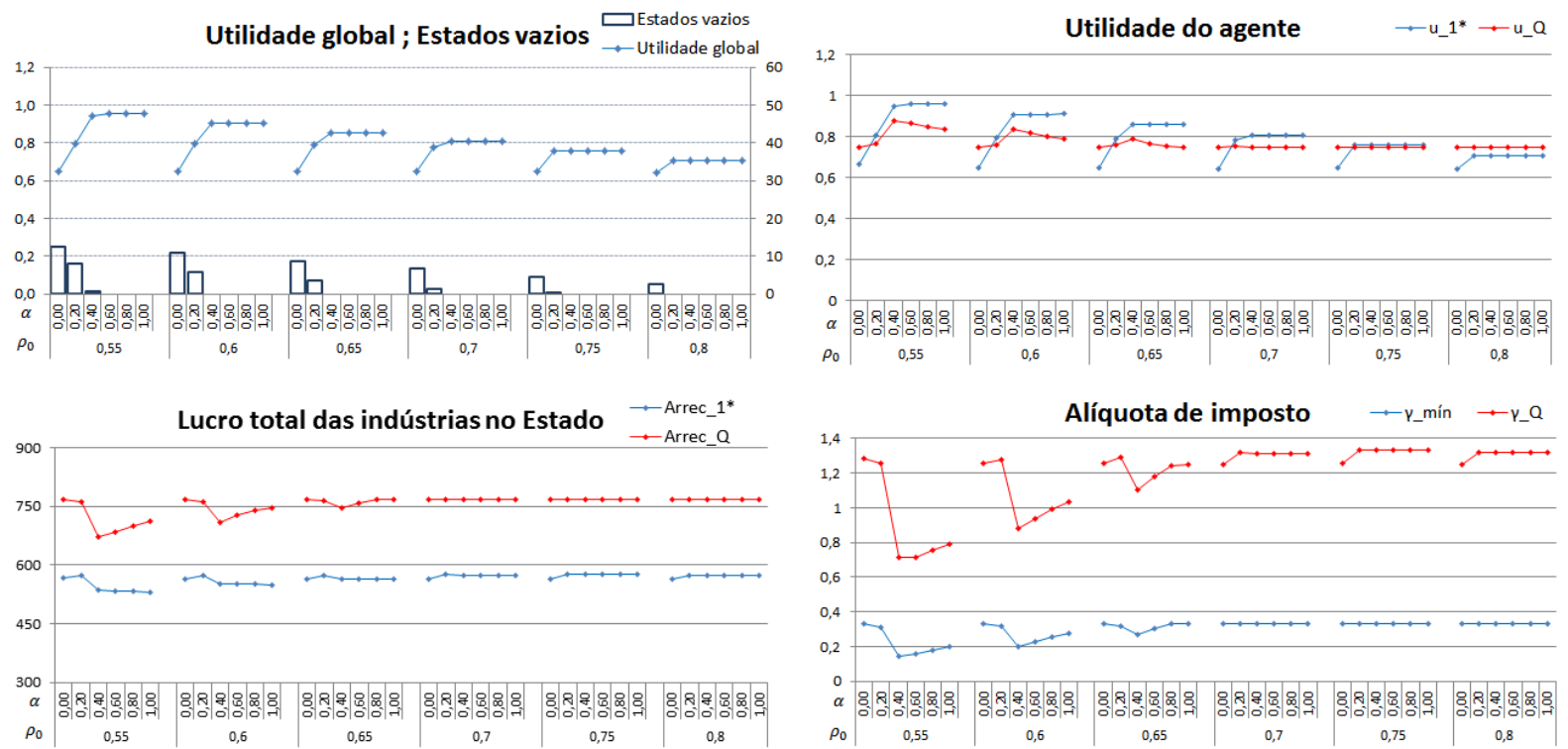

Figura 6: Gráficos com os resultados das simulações do modelo homogêneo

6A: A utilidade reduz a medida que a densidade inicial cresce por conta da superpopulação nos Estados.

6B: Os agentes que optaram por mudar para o Estado com incentivo acabam com uma utilidade menor do que os agentes que ficaram no Estado em que estava.

6C: O lucro total das industrias nos Estados com incentivo é que nos demais Estados por conta da alta densidade de agentes.

6D: A alíquota de imposto necessária para o Estado que deu incentivo ter alguma arrecadação é da ordem de $33 \%$ e para que este Estado arrecade igual aos demais é muitas vezes maior que $100 \%$.

A partir dos dados, vemos que os agentes começam a ocupar o Estado $Q$ para aumentar sua utilidade, mas por conta do acúmulo de outros agentes com este mesmo comportamento, a utilidade deste Estado acaba por ficar menor do que nos demais, o que indica que a satisfação dos indivíduos que optaram por mudar para o Estado Q é menor que a satisfação dos demais indivíduos (comparação entre as colunas $u_{Q}$ e $u_{1}^{*}$ ). Nota-se que a satisfação no Estado Q só é maior nos casos $\alpha=0$ ou $\rho_{0}=0,80$ (simulações 31 a 36). Por conta da sua alta densidade de indústrias o lucro total no Estado $Q$ é maior que nos demais Estados (coluna $A_{Q}^{*}$ ), mas deve-se levar em consideração o custo do incentivo (Equação 49) que este Estado tem para atrair indústrias para si (coluna $I_{Q}$ ). Por conta deste custo, a ação só não será negativa para o Estado se a alíquota de imposto cobrada sobre a arrecadação for muito grande, entre $14 \%$ e $33 \%$ (coluna $\left.\gamma_{Q-\min }\right)$.

Quando comparamos a utilidade global do modelo desordenado com a utilidade global do modelo uniforme vemos que há um ligeiro aumento quando o valor de $\alpha>0,4$ $\left(U_{0}^{*}=u\left(\rho_{0}\right)\right)$, que podemos interpretar da seguinte maneira; o governo possui o controle do imposto $\alpha$ e este imposto obriga os agentes a pensarem no cenário global na hora de 
tomar suas decisões. À medida que $\alpha$ aumenta mais os agentes ficarão inibidos em tomar decisões unilaterais, portanto os agentes só se mudarão para o Estado com incentivo fiscal se este movimento melhorar a situação do país. A única maneira de imaginar uma situação como esta seria se o governo federal bancasse os custos deste Estado durante um período, pois, por mais que o Estado $Q$ tenha uma arrecadação menor do que os demais Estados, a nação se beneficiará com estas ações (verificar os valores que devem ter a alíquota $\gamma_{q}$ para que todos os Estados ocupados tenham o mesmo rendimento).

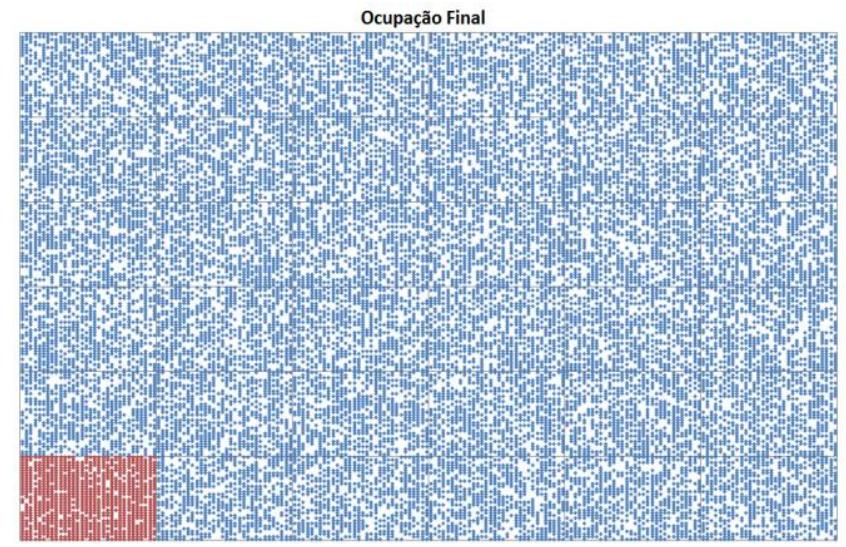

Figura 7: Situação em equilíbrio das indústrias para o caso homogêneo

Parâmetros $\boldsymbol{\rho}_{0}=0,60, \quad \boldsymbol{\alpha}=0,60, \quad \boldsymbol{m}_{\boldsymbol{a}}=$ $\mathbf{0 , 5} \boldsymbol{e} \boldsymbol{m}_{\boldsymbol{b}}=\mathbf{0 , 7 5}$. Nota-se maior densidade naquele Estado com o parâmetro $\boldsymbol{m}_{\boldsymbol{b}}$ (em vermelho).

Numa extrapolação do modelo, fizemos simulações para a situação onde mais de um Estado possui o incentivo fiscal, com foco no caso $\rho_{0}=0,60$. Simulamos situações de 1 a 12 Estados com parâmetro $m_{b}$ para analisar quais as variações nos resultados. A tabela 2 mostra uma relação entre a redução do valor da alíquota $\left(\gamma_{Q-\operatorname{mín}}\right)$ cobrada e o aumento da utilidade global $\left(U^{*}\right)$ com a quantidade de Estados adeptos da guerra. Isto ocorre porque os Estados dando incentivo atraem mais agentes para si, reduzindo o número de agentes nos Estados com parâmetro $m_{a}$ e por consequência aumentando sua utilidade. Esta situação não muda o fato dos Estados com incentivos terem um rendimento menor que os demais Estados ocupados. Pode-se perceber que o valor de $\gamma_{q}$ necessário para que estes Estados arrecadem o mesmo valor que os Estados sem incentivos é em média 4 vezes maior do que $\gamma_{Q-m i ́ n}$.

A simplicidade deste modelo nos leva a inferir que, caso o número de indústrias seja suficientemente grande, ter mais Estados concedendo incentivos fiscais não é prejudicial ao país, pelo contrário, aumentaria a satisfação de toda a nação. 


\begin{tabular}{|c|c|c|c|c|c|c|c|c|c|c|c|c|c|}
\hline \multirow[b]{2}{*}{ Simulação } & \multirow[b]{2}{*}{$\rho_{0}$} & \multirow[b]{2}{*}{$Q_{\text {difs }}$} & \multirow[b]{2}{*}{$U_{0}$} & \multicolumn{10}{|c|}{ Resultados das simulações } \\
\hline & & & & $\bar{U}$ & $\overline{\rho_{1}^{*}}$ & $\overline{\rho_{Q}}$ & $\overline{u_{1}^{*}}$ & $\overline{u_{Q}}$ & $\overline{A_{1}^{*}}$ & $\overline{A_{Q}}$ & $\overline{I_{Q}}$ & $\overline{\gamma_{Q-\min }}$ & $\overline{\gamma_{q}}$ \\
\hline 1 & \multirow{7}{*}{0,60} & 1 & \multirow{7}{*}{0,900} & $0,904(00)$ & $0,592(00)$ & $0,870(01)$ & $0,908(00)$ & $0,815(01)$ & $551(0)$ & $726(0)$ & $165(1)$ & $0,23(0)$ & $0,94(0)$ \\
\hline 2 & & 2 & & $0,908(00)$ & $0,585(00)$ & $0,856(01)$ & $0,915(00)$ & $0,822(00)$ & $548(0)$ & $720(0)$ & $156(0)$ & $0,22(0)$ & $0,90(0)$ \\
\hline 3 & & 3 & & $0,911(00)$ & $0,578(00)$ & $0,842(01)$ & $0,922(00)$ & $0,829(00)$ & $546(0)$ & $715(0)$ & $147(0)$ & $0,21(0)$ & $0,87(0)$ \\
\hline 4 & & 4 & & $0,914(00)$ & $0,571(00)$ & $0,829(01)$ & $0,929(00)$ & $0,836(00)$ & $543(0)$ & $709(0)$ & $139(0)$ & $0,20(0)$ & $0,84(0)$ \\
\hline 5 & & 5 & & $0,917(00)$ & $0,565(00)$ & $0,816(00)$ & $0,935(00)$ & $0,842(00)$ & $541(0)$ & $704(0)$ & $132(0)$ & $0,19(0)$ & $0,81(0)$ \\
\hline 6 & & 6 & & $0,920(00)$ & $0,559(00)$ & $0,804(00)$ & $0,941(00)$ & $0,848(00)$ & $539(0)$ & $698(0)$ & $125(0)$ & $0,18(0)$ & $0,79(0)$ \\
\hline 7 & & 12 & & $0,933(00)$ & $0,528(00)$ & $0,743(00)$ & $0,972(00)$ & $0,878(00)$ & $526(0)$ & $668(0)$ & $93(0)$ & $0,14(0)$ & $0,65(0)$ \\
\hline
\end{tabular}

Tabela 2: Valores médios de 50 simulações com 1.000 passos de Monte Carlo da cada da extrapolação do modelo para a situação de mais de um estado com incentivo fiscal - A carga da alíquota dos estados diferentes diminuem a medida que aumenta o numero de estados iguais a ele (maior partilha das indústrias) e consequentemente a arrecadação da nação aumenta com este movimento.
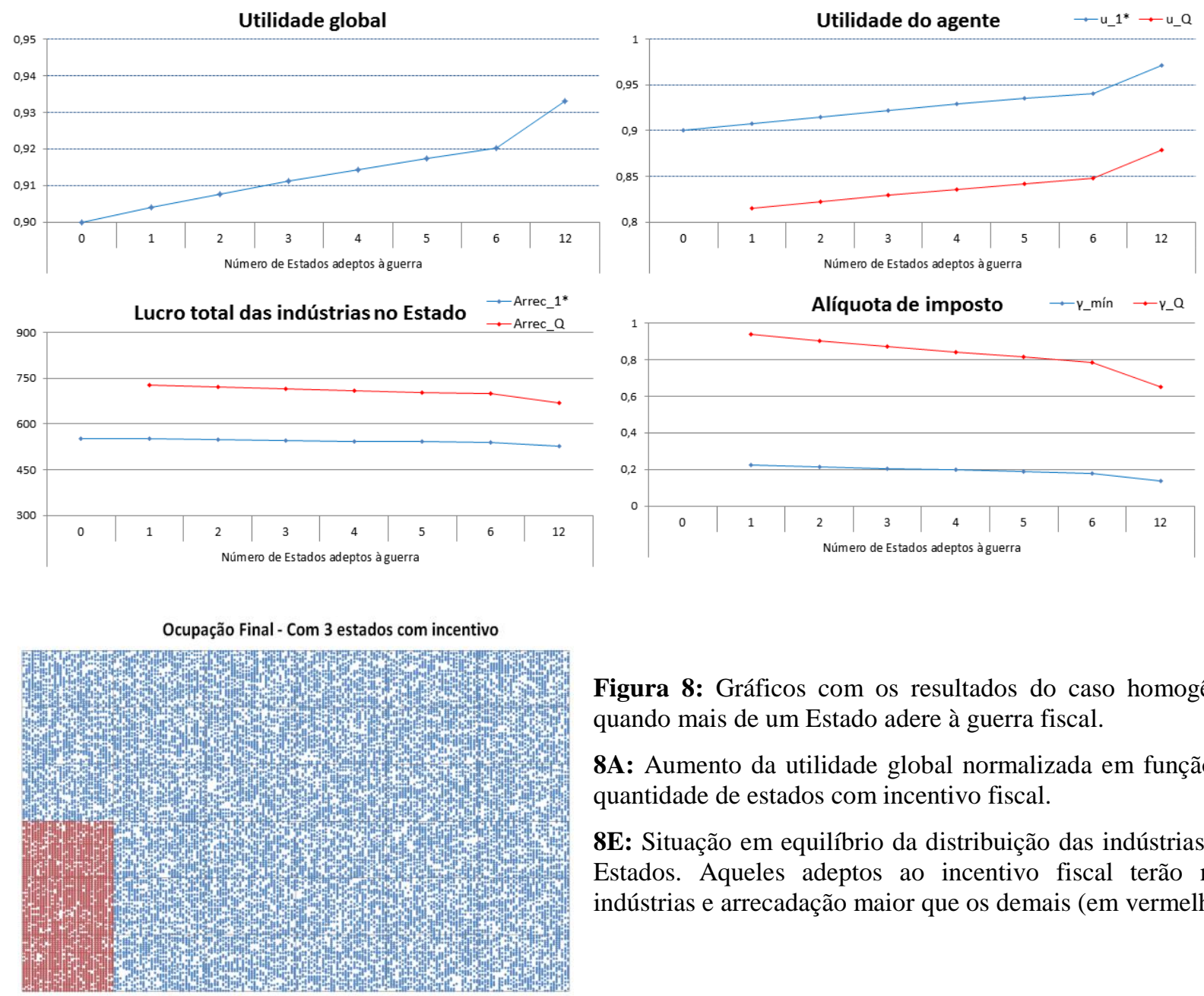

Figura 8: Gráficos com os resultados do caso homogêneo quando mais de um Estado adere à guerra fiscal.

8A: Aumento da utilidade global normalizada em função da quantidade de estados com incentivo fiscal.

8E: Situação em equilíbrio da distribuição das indústrias nos Estados. Aqueles adeptos ao incentivo fiscal terão mais indústrias e arrecadação maior que os demais (em vermelho).

Podemos imaginar agora como se comportariam as indústrias nos demais Estados, aqueles que não aderiram à guerra fiscal. 
Podemos fazer a hipótese de que a densidade inicial das indústrias agora nesses Estados não é mais $\rho_{0}$ e sim um $\rho_{0}^{\text {efetivo }}$ e que $\rho_{0}^{\text {efetivo }}=\rho_{1}^{*}$. As indústrias passam a ignorar a existência do Estado com parâmetro $m_{b}$, ou seja (novamente para apenas 1 estado diferente), a nação se comporta como se não houvesse mais 36 estados mas sim 35 .

Confirmando a expectativa, os resultados da tabela 3 mostram que as densidades são exatamente as mesmas obtidas no modelo uniforme de Grauwin, portanto podemos afirmar que isolar o estado com incentivo fiscal é o mesmo que de trabalhar em um sistema onde este Estado não exista e que possua uma densidade menor que $\rho_{0}$.

\begin{tabular}{|c|c|c|c|c|c|c|}
\hline \multirow[b]{2}{*}{ Simulação } & \multicolumn{3}{|c|}{ Resultados Teóricos } & \multicolumn{3}{|c|}{ Resultados Experimentais } \\
\hline & $\rho_{0}^{\text {efetivo }}$ & $U_{0}^{\text {efetivo }}$ & $R_{0}^{\text {efetivo }}$ & $\overline{\rho_{0}^{\text {efetivo }}}$ & $\overline{u_{0}}$ & $\overline{R_{0}}$ \\
\hline 1 & 0,544 & 0,956 & 0,520 & 0,544 & 0,956 & 0,520 \\
\hline 2 & 0,592 & 0,908 & 0,538 & 0,592 & 0,908 & 0,538 \\
\hline 3 & 0,641 & 0,859 & 0,551 & 0,641 & 0,859 & 0,551 \\
\hline 4 & 0,691 & 0,809 & 0,559 & 0,691 & 0,809 & 0,559 \\
\hline 5 & 0,743 & 0,757 & 0,562 & 0,743 & 0,757 & 0,562 \\
\hline 6 & 0,794 & 0,706 & 0,561 & 0,794 & 0,706 & 0,561 \\
\hline
\end{tabular}

Tabela 3: Resultados das simulações realizadas considerando um $\boldsymbol{\rho}_{\mathbf{0} \text {-efetivo }}$ para o modelo uniforme de Grauwin. $\mathrm{O}$ efeito de isolar um dos estados é exatamente o mesmo que simular uma situação onde não se permite troca de indústrias entre o estado com incentivo e os demais.

Com os resultados que obtivemos podemos afirmar que se houver um número de indústrias suficientes instaladas no país, mesmo com a prática de guerra fiscal entre as unidades da federação, a dinâmica não resultaria numa redução significativa da arrecadação de um país. E se cada vez mais Estados aderirem à disputa, a guerra fiscal vai perdendo sua a força e o cenário vai se aproximando da situação uniforme, como esperado.

\subsection{Caso segregado}

Numa situação mais realista, a quantidade de indústrias é pequena em relação à capacidade de um país $\left(\rho_{0}<\frac{1}{2}\right)$ e haverá risco de segregação. Este cenário é mais nocivo para a economia, principalmente para população dos Estados esvaziados. Se o número de Estados vazios for muito grande, além de uma segregação econômica, haverá uma queda brusca na arrecadação total da nação.

Para simular este cenário mantivemos constantes os parâmetros $m_{a}$ e $m_{b}$ de cada Estado, variamos $\rho_{0}$ de 0,2 até 0,5 (limite para o qual esse conjunto de parâmetros divide 
os estados homogêneos dos segregados) e procuramos os valores $\alpha$ (para $0<\alpha<\alpha_{c}$ para os quais os valores $Q_{v}$ (Equação 44 ) fossem números inteiros, de maneira a minimizar os efeitos de tamanho finito.

A

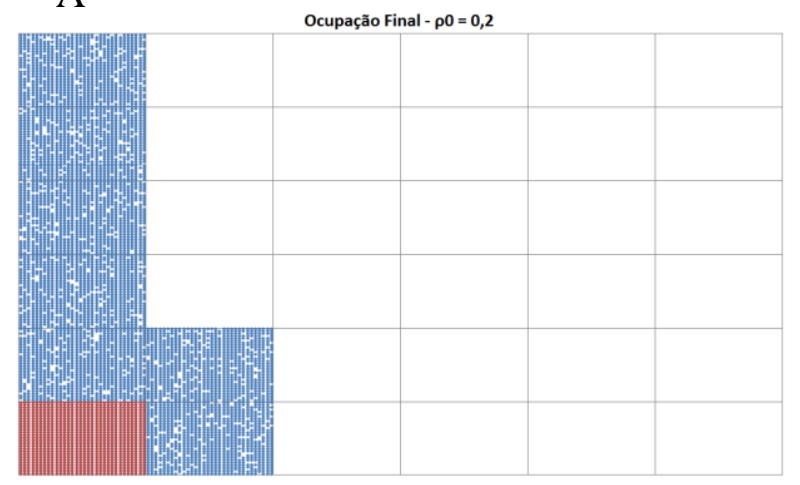

$\mathrm{C}$

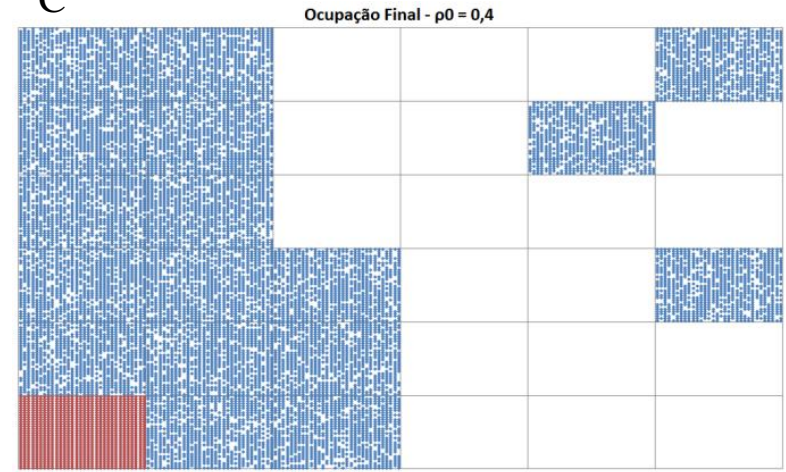

B

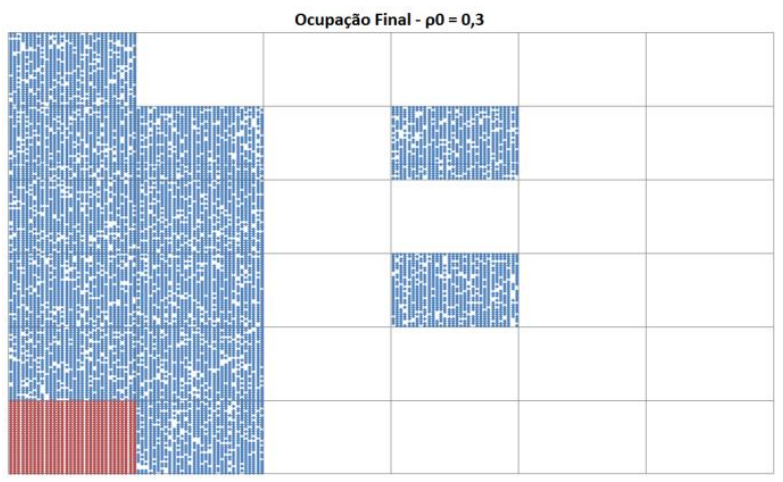

$\mathrm{D}$

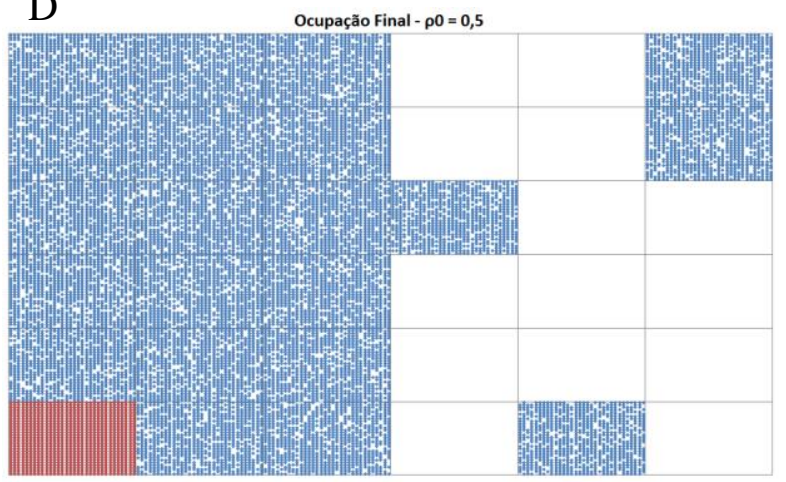

Figura 9: Resultados para as simulações 1, 15, 35 e 59 das tabelas 4A e 4B.

Para densidades baixas a segregação será maior - o Estado com incentivo fiscal (em vermelho) sempre terá ocupação máxima nos limites de $\boldsymbol{\alpha}$ testados. 


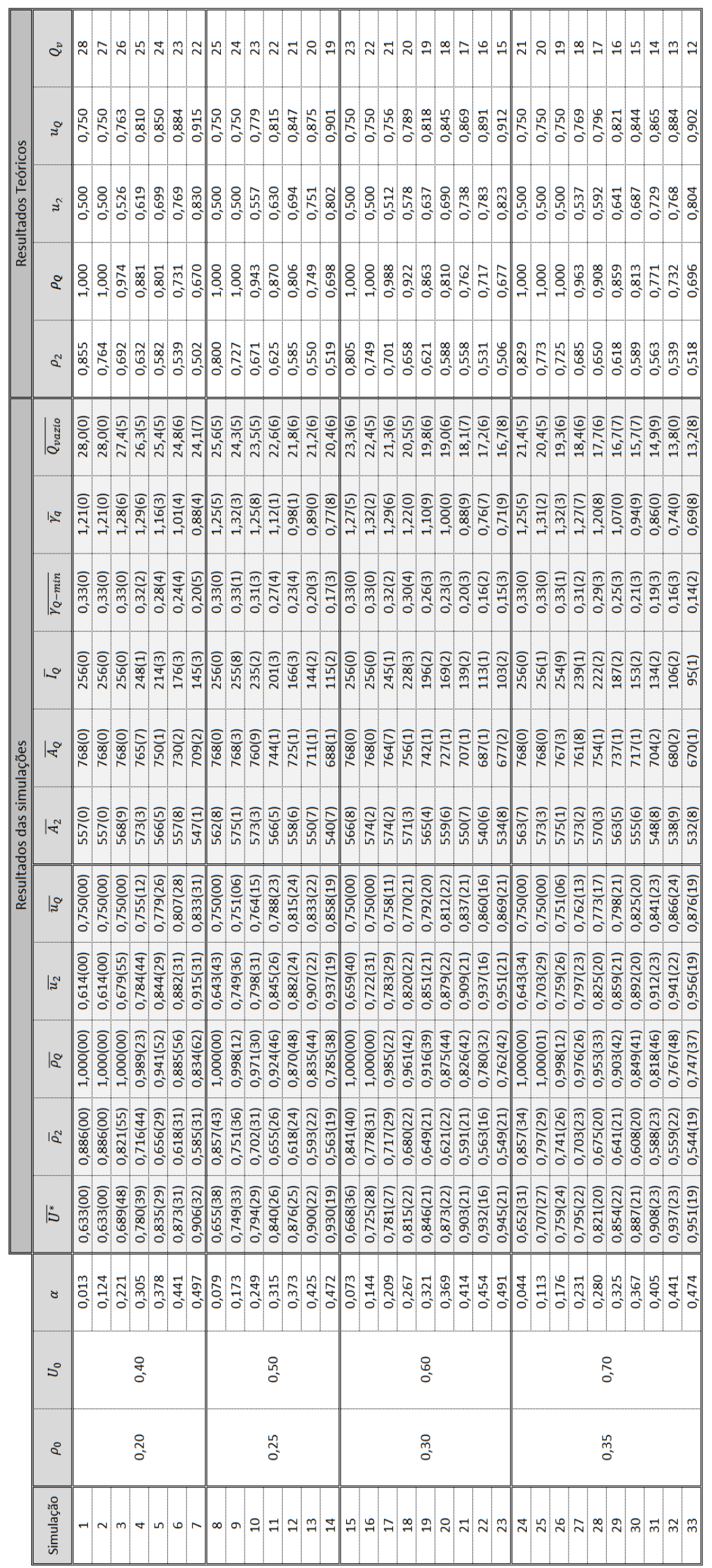

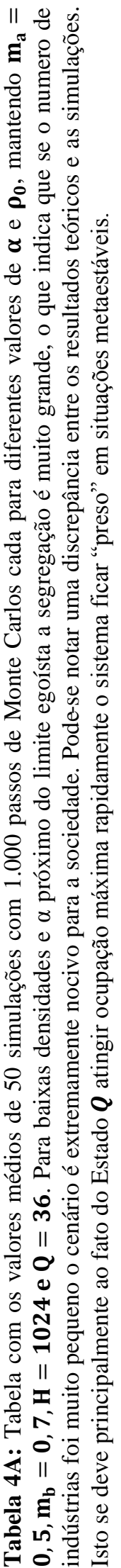
¿ి0 


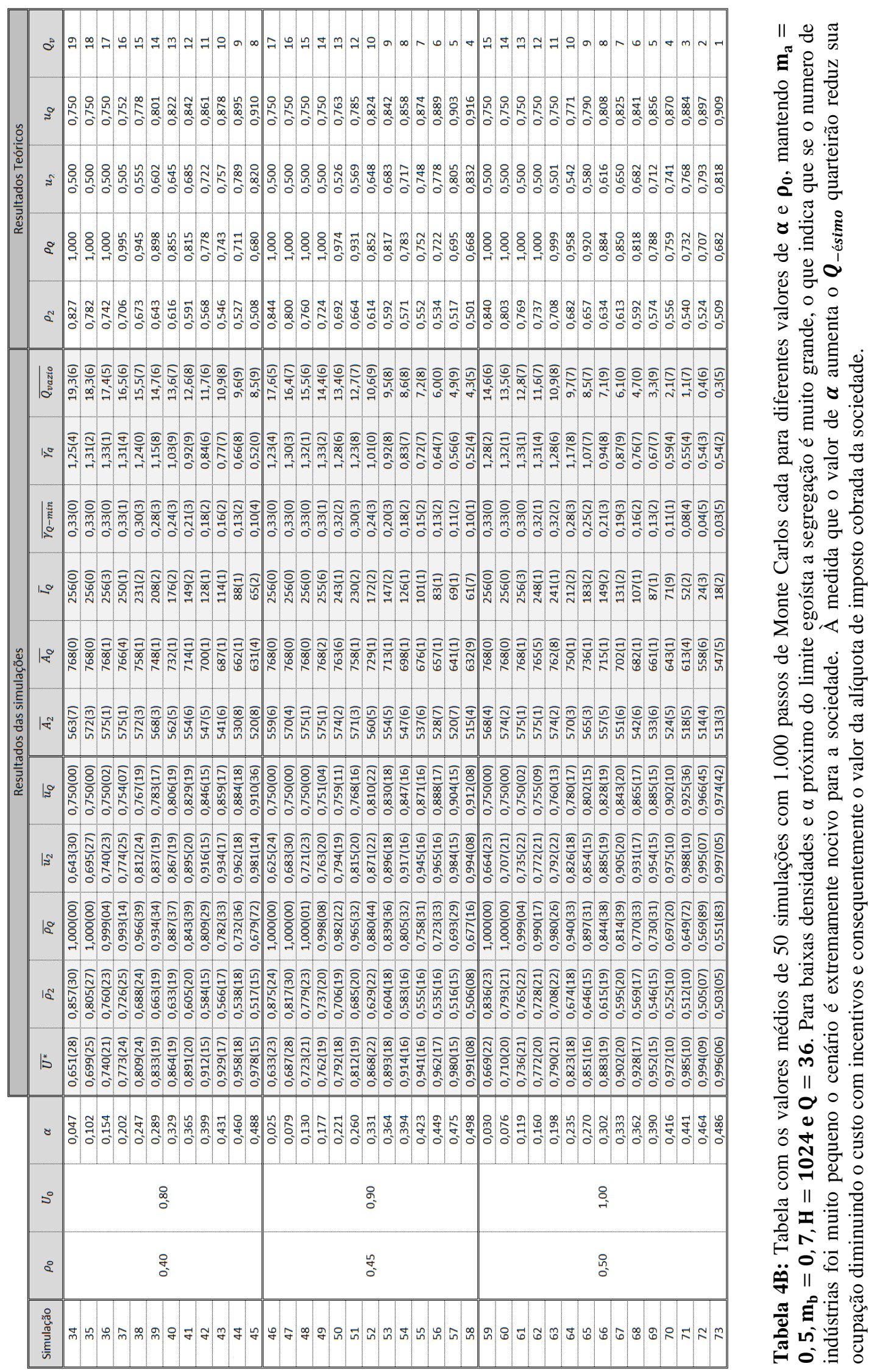

20 

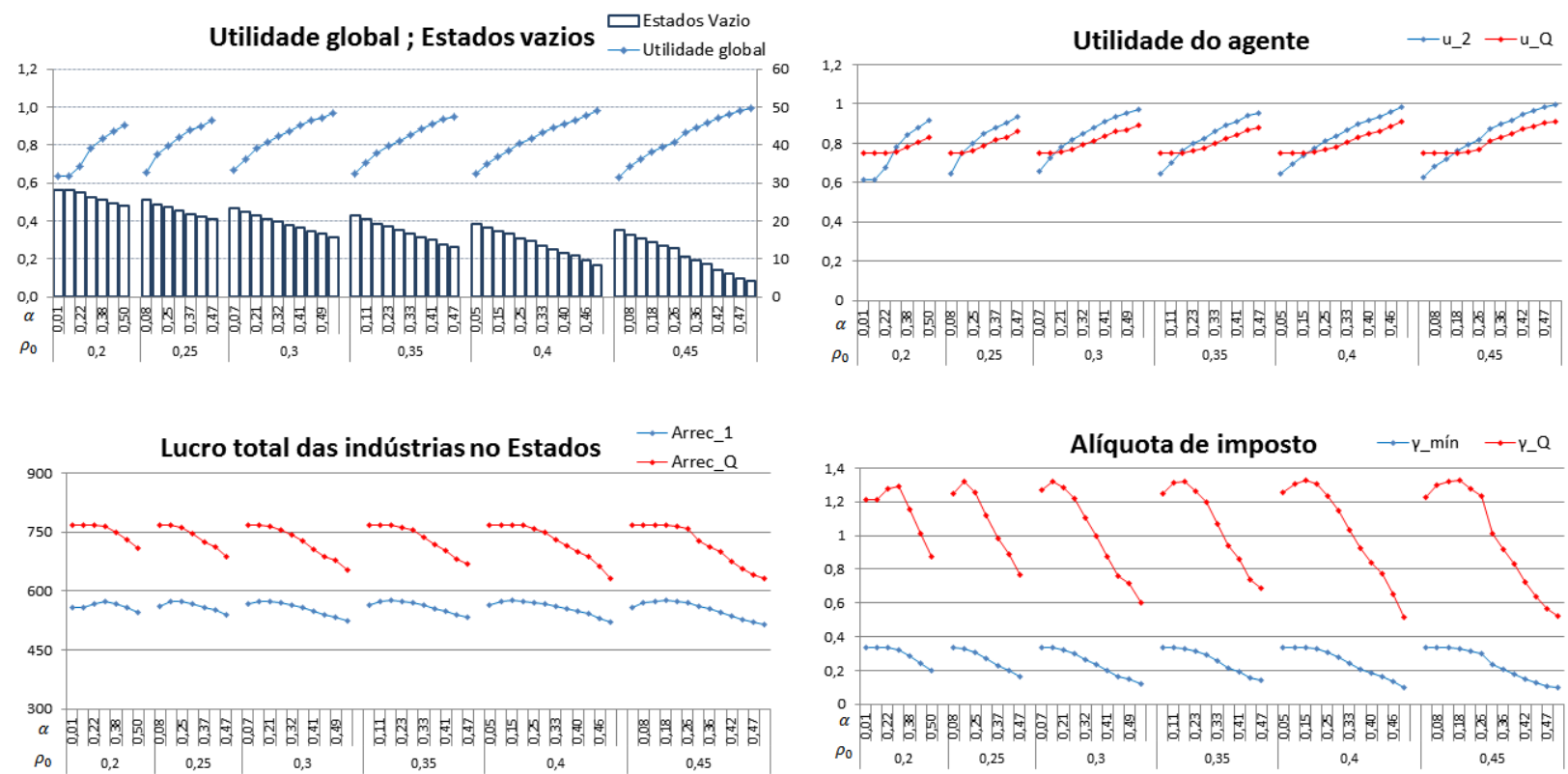

Figura 10: Gráficos com os resultados das simulações do modelo segregado

10A: A influencia do parâmetro $\alpha$ é mais notada no limite segregado, a quantidade de Estados vazios diminui (elevando a utilidade global) a medida que $\alpha$ cresce.

10B: Exceto para o limite egoísta os agentes que mudam para o Estado com incentivo em equilíbrio possui uma utilidade menor que os demais agentes.

10C: No caso segregado a diferença entre as arrecadações dos Estados diminui a medida que o governo obriga as indústrias a pensar mais no cenário coletivo.

10D: A alíquota de imposto para que o Estado com incentivo tenha alguma arrecadação é em geral da ordem de $20 \%$ e para densidades próximo de 0,5 este Estado precisaria de uma alíquota da ordem de $52 \%$ para arrecadar igual aos demais (mais razoável).

Com os resultados da tabela 4, verificamos como se comporta a segregação para diversos valores de $\rho_{0}$ e $\alpha$. Para baixas densidades $\left(\rho_{0}<0,3\right)$ a utilidade global inicial é tão pequena que a arrecadação sempre aumentará com a guerra fiscal (comparação entre as colunas $U_{0}$ e $U^{*}$ das simulações 1 até a 26). O que se pode perceber também é que o custo com incentivo dado pelo Estado $Q$ possui um padrão bem definido no limite segregado, sendo cada vez menor à medida que o parâmetro de altruísmo aumenta (coluna $I_{Q}$ ) e por consequência o Estado precisará cobrar uma alíquota de imposto menor da sociedade para não ter prejuízo com a renuncia de impostos (coluna $\gamma_{\min }$ ). Esse resultado pode ser interpretado da seguinte maneira: à medida que o governo incentive um comportamento mais altruísta das indústrias elas migrarão mais facilmente para os Estados com parâmetro $m_{b}$, pois percebem que com isto, além de obterem vantagens, a arrecadação da nação irá aumentar com a redução da segregação. 
Este cenário se assemelha à situação que o Brasil vivia na década de 1970 , quando o Sudeste sozinho respondia por $81 \%$ da produção, sendo que só o Estado de São Paulo detinha 58\%. Neste período da história fazia sentido os Estados aderirem a uma guerra fiscal para reduzir as diferenças entre os Estados e alterar a distribuição da produção. A utilidade global (arrecadação do país) é muito baixa para $\rho_{0}<0,4$ e por isso incentivar a guerra fiscal foi um recurso interessante para alavancar a arrecadação de Estados mais pobres. Para valores $\rho_{0}>0,4$ o país passa a arrecadar mais, dependendo do grau do parâmetro de imposto $(\alpha)$, sem que haja necessidade desta manobra. É importante notar que se houvesse indústrias suficientes para todos os estados $\left(\rho_{0} \geq 0,5\right)$ não haveria necessidade ter incentivo fiscal em momento algum da história. Em outras palavras, podemos dizer que a guerra fiscal trará benefícios em curto prazo até que a nação se industrialize o suficiente para que não mais seja necessário recorrer a este tipo de ação.

Mais uma vez fizemos uma extrapolação do modelo considerando, além da densidade baixa, mais de um Estado dando incentivo fiscal. A tabela 5 mostra os resultados médios de 50 simulações deste cenário com $\rho_{0}=0,4$ e diferentes valores de $\alpha$. 


\begin{tabular}{|c|c|c|c|c|c|c|c|c|c|c|c|c|c|}
\hline \multirow[b]{2}{*}{ Simulação } & \multirow[b]{2}{*}{$\alpha$} & \multirow[b]{2}{*}{ № Estados } & \multicolumn{11}{|c|}{ Resultados das simulações } \\
\hline & & & $\overline{U^{*}}$ & $\overline{\rho_{2}}$ & $\overline{\rho_{Q}}$ & $\overline{u_{2}}$ & $\overline{u_{Q}}$ & $\overline{A_{2}}$ & $\overline{A_{Q}}$ & $\overline{I_{Q}}$ & $\overline{\gamma_{Q-\min }}$ & $\overline{\gamma_{Q}}$ & $\overline{Q_{\text {vazio }}}$ \\
\hline 1 & \multirow{7}{*}{0,154} & 1 & $0,740(21)$ & $0,760(23)$ & $0,999(04)$ & $0,740(23)$ & $0,750(02)$ & $575(1)$ & $768(1)$ & 256(3) & $0,33(0)$ & $1,33(1)$ & $17,4(5)$ \\
\hline 2 & & 2 & $0,746(22)$ & $0,754(25)$ & $1,000(00)$ & $0,746(25)$ & $0,750(00)$ & $575(1)$ & $768(0)$ & $256(0)$ & $0,33(0)$ & $1,33(1)$ & $17,5(5)$ \\
\hline 3 & & 3 & $0,749(22)$ & $0,752(26)$ & $0,996(11)$ & $0,748(26)$ & $0,752(05)$ & $575(1)$ & $767(3)$ & $253(8)$ & $0,33(1)$ & $1,32(3)$ & $17,8(6)$ \\
\hline 4 & & 4 & $0,750(21)$ & $0,750(28)$ & $0,997(10)$ & $0,750(28)$ & $0,752(05)$ & $575(1)$ & $767(3)$ & $253(8)$ & $0,33(1)$ & $1,32(3)$ & $18,1(5)$ \\
\hline 5 & & 5 & $0,750(25)$ & $0,751(35)$ & $0,995(17)$ & $0,749(35)$ & $0,753(08)$ & $575(1)$ & $766(5)$ & $252(1)$ & $0,33(1)$ & $1,31(4)$ & $18,4(7)$ \\
\hline 6 & & 6 & $0,748(18)$ & $0,755(29)$ & $0,996(08)$ & $0,745(29)$ & $0,752(04)$ & $575(2)$ & $767(2)$ & $253(6)$ & $0,33(1)$ & $1,32(2)$ & $18,8(5)$ \\
\hline 7 & & 12 & $0,742(04)$ & $0,798(14)$ & $0,999(05)$ & $0,702(14)$ & $0,750(02)$ & 573(0) & $768(1)$ & $255(4)$ & $0,33(0)$ & $1,31(1)$ & $21,0(1)$ \\
\hline 8 & \multirow{7}{*}{0,202} & 1 & $0,773(24)$ & $0,726(25)$ & $0,993(14)$ & $0,774(25)$ & $0,754(07)$ & $575(1)$ & $766(4)$ & $250(1)$ & $0,33(1)$ & $1,31(4)$ & $16,5(6)$ \\
\hline 9 & & 2 & $0,778(20)$ & $0,718(22)$ & $0,987(20)$ & $0,782(22)$ & $0,756(10)$ & $574(2)$ & $764(6)$ & $246(1)$ & $0,32(2)$ & $1,30(5)$ & $16,7(6)$ \\
\hline 10 & & 3 & $0,779(23)$ & $0,715(26)$ & $0,987(24)$ & $0,785(26)$ & $0,756(12)$ & $574(2)$ & $764(7)$ & $246(1)$ & $0,32(2)$ & $1,29(6)$ & $17,0(7)$ \\
\hline 11 & & 4 & $0,779(22)$ & $0,714(26)$ & $0,980(24)$ & $0,786(26)$ & $0,760(12)$ & $574(2)$ & $763(7)$ & $241(1)$ & $0,32(2)$ & $1,28(6)$ & $17,3(7)$ \\
\hline 12 & & 5 & $0,777(18)$ & $0,713(22)$ & $0,984(22)$ & $0,787(22)$ & $0,758(11)$ & $574(2)$ & $763(6)$ & $244(1)$ & $0,32(2)$ & $1,29(6)$ & $17,7(6)$ \\
\hline 13 & & 6 & $0,779(19)$ & $0,708(25)$ & $0,980(23)$ & $0,792(25)$ & $0,760(12)$ & $574(2)$ & $762(7)$ & $241(1)$ & $0,32(2)$ & $1,27(6)$ & $17,9(6)$ \\
\hline 14 & & 12 & $0,760(16)$ & $0,739(53)$ & $0,982(16)$ & $0,761(53)$ & $0,759(08)$ & $573(0)$ & $763(4)$ & $242(1)$ & $0,32(1)$ & $1,27(4)$ & $20,4(5)$ \\
\hline 15 & \multirow{7}{*}{0,247} & 1 & $0,809(24)$ & $0,688(24)$ & $0,966(39)$ & $0,812(24)$ & $0,767(19)$ & $572(3)$ & $758(1)$ & $231(2)$ & $0,30(3)$ & $1,24(0)$ & $15,5(7)$ \\
\hline 16 & & 2 & $0,807(20)$ & $0,687(20)$ & $0,964(31)$ & $0,813(20)$ & $0,768(15)$ & $571(3)$ & $758(1)$ & $229(2)$ & $0,30(3)$ & $1,23(8)$ & $15,8(6)$ \\
\hline 17 & & 3 & $0,803(21)$ & $0,688(21)$ & $0,964(33)$ & $0,812(21)$ & $0,768(17)$ & $572(3)$ & $758(1)$ & $230(2)$ & $0,30(3)$ & $1,23(8)$ & $16,3(7)$ \\
\hline 18 & & 4 & $0,806(22)$ & $0,682(24)$ & $0,954(36)$ & $0,818(24)$ & $0,773(18)$ & $571(3)$ & $755(1)$ & $223(2)$ & $0,29(3)$ & $1,21(9)$ & $16,5(7)$ \\
\hline 19 & & 5 & $0,802(16)$ & $0,683(17)$ & $0,958(25)$ & $0,817(17)$ & $0,771(13)$ & $571(2)$ & $756(8)$ & $225(1)$ & $0,30(2)$ & $1,21(6)$ & $16,9(5)$ \\
\hline 20 & & 6 & $0,798(18)$ & $0,683(18)$ & $0,961(33)$ & $0,817(18)$ & $0,770(17)$ & $571(3)$ & $757(1)$ & $227(2)$ & $0,30(3)$ & $1,22(8)$ & $17,3(6)$ \\
\hline 21 & & 12 & $0,783(13)$ & $0,679(12)$ & $0,953(23)$ & $0,821(12)$ & $0,774(12)$ & $571(2)$ & $754(7)$ & $221(1)$ & $0,29(2)$ & $1,20(6)$ & $19,6(5)$ \\
\hline 22 & \multirow{7}{*}{0,289} & 1 & $0,833(19)$ & $0,663(19)$ & $0,934(34)$ & $0,837(19)$ & $0,783(17)$ & $568(3)$ & $748(1)$ & $208(2)$ & $0,28(3)$ & $1,15(8)$ & $14,7(6)$ \\
\hline 23 & & 2 & $0,828(21)$ & $0,665(21)$ & $0,940(40)$ & $0,835(21)$ & $0,780(20)$ & $568(4)$ & $750(1)$ & $212(2)$ & $0,28(3)$ & $1,16(0)$ & $15,2(7)$ \\
\hline 24 & & 3 & $0,833(19)$ & $0,663(19)$ & $0,934(34)$ & $0,837(19)$ & $0,783(17)$ & $568(3)$ & $748(1)$ & $208(2)$ & $0,28(3)$ & $1,15(8)$ & $14,7(6)$ \\
\hline 25 & & 4 & $0,830(16)$ & $0,656(16)$ & $0,922(31)$ & $0,844(16)$ & $0,789(15)$ & $567(3)$ & $744(1)$ & $200(2)$ & $0,27(2)$ & $1,12(7)$ & $15,7(6)$ \\
\hline 26 & & 5 & $0,827(19)$ & $0,656(19)$ & $0,921(36)$ & $0,844(19)$ & $0,790(18)$ & $567(4)$ & $744(1)$ & $199(2)$ & $0,27(3)$ & $1,12(9)$ & $16,0(7)$ \\
\hline 27 & & 6 & $0,819(17)$ & $0,660(17)$ & $0,928(32)$ & $0,840(17)$ & $0,786(16)$ & $567(3)$ & $747(1)$ & $204(2)$ & $0,27(3)$ & $1,14(8)$ & $16,6(6)$ \\
\hline 28 & & 12 & $0,795(14)$ & $0,663(13)$ & $0,934(26)$ & $0,837(13)$ & $0,783(13)$ & $568(2)$ & $749(8)$ & $208(1)$ & $0,28(2)$ & $1,15(6)$ & $19,2(6)$ \\
\hline 29 & \multirow{7}{*}{0,329} & 1 & $0,864(19)$ & $0,633(19)$ & $0,887(37)$ & $0,867(19)$ & $0,806(19)$ & $562(5)$ & $732(1)$ & $176(2)$ & $0,24(3)$ & $1,03(9)$ & $13,6(7)$ \\
\hline 30 & & 2 & $0,855(19)$ & $0,638(19)$ & $0,897(38)$ & $0,862(19)$ & $0,801(19)$ & $563(4)$ & $736(1)$ & $183(2)$ & $0,25(3)$ & $1,06(9)$ & $14,2(7)$ \\
\hline 31 & & 3 & $0,849(17)$ & $0,640(16)$ & $0,901(32)$ & $0,860(16)$ & $0,800(16)$ & $563(4)$ & $737(1)$ & $185(2)$ & $0,25(3)$ & $1,06(8)$ & $14,7(6)$ \\
\hline 32 & & 4 & $0,850(14)$ & $0,635(14)$ & $0,892(28)$ & $0,865(14)$ & $0,804(14)$ & $562(3)$ & $734(1)$ & $180(1)$ & $0,24(2)$ & $1,04(6)$ & $14,9(5)$ \\
\hline 33 & & 5 & $0,843(18)$ & $0,638(18)$ & $0,897(35)$ & $0,862(18)$ & $0,801(18)$ & $563(4)$ & $736(1)$ & $183(2)$ & $0,25(3)$ & $1,06(8)$ & $15,4(7)$ \\
\hline 34 & & 6 & $0,837(15)$ & $0,640(14)$ & $0,902(28)$ & $0,860(14)$ & $0,799(14)$ & $564(3)$ & $738(1)$ & $186(1)$ & $0,25(2)$ & $1,07(7)$ & $16,0(6)$ \\
\hline 35 & & 12 & $0,808(11)$ & $0,646(11)$ & $0,913(21)$ & $0,854(11)$ & $0,794(10)$ & $565(2)$ & $742(7)$ & 193(1) & $0,26(2)$ & $1,09(5)$ & $18,7(5)$ \\
\hline 36 & \multirow{7}{*}{0,365} & 1 & $0,891(20)$ & $0,605(20)$ & $0,843(39)$ & $0,895(20)$ & $0,829(19)$ & $554(6)$ & $714(1)$ & $149(2)$ & $0,21(3)$ & $0,92(9)$ & $12,6(8)$ \\
\hline 37 & & 2 & $0,882(18)$ & $0,610(18)$ & $0,853(36)$ & $0,890(18)$ & $0,824(18)$ & $556(5)$ & $719(1)$ & $155(2)$ & $0,21(3)$ & $0,95(8)$ & $13,2(7)$ \\
\hline 38 & & 3 & $0,877(17)$ & $0,611(17)$ & $0,854(33)$ & $0,889(17)$ & $0,823(17)$ & $556(5)$ & $719(1)$ & $155(2)$ & $0,22(2)$ & $0,95(8)$ & $13,6(7)$ \\
\hline 39 & & 4 & $0,869(16)$ & $0,616(16)$ & $0,863(32)$ & $0,884(16)$ & $0,818(16)$ & $557(4)$ & $723(1)$ & $161(2)$ & $0,22(2)$ & $0,97(7)$ & $14,2(7)$ \\
\hline 40 & & 5 & $0,843(18)$ & $0,638(18)$ & $0,897(35)$ & $0,862(18)$ & $0,801(18)$ & $563(4)$ & $736(1)$ & $183(2)$ & $0,25(3)$ & $1,06(8)$ & $15,4(7)$ \\
\hline 41 & & 6 & $0,854(15)$ & $0,622(14)$ & $0,876(28)$ & $0,878(14)$ & $0,812(14)$ & $559(4)$ & $728(1)$ & $169(1)$ & $0,23(2)$ & $1,00(6)$ & $15,3(6)$ \\
\hline 42 & & 12 & $0,823(14)$ & $0,628(13)$ & $0,888(26)$ & $0,872(13)$ & $0,806(13)$ & $561(3)$ & $732(1)$ & $177(1)$ & $0,24(2)$ & $1,02(6)$ & $18,0(6)$ \\
\hline
\end{tabular}

Tabela 5: Valores médios considerando mais de um Estado dando incentivo para atrair empresas. Para valores pequenos de $\boldsymbol{\alpha}$ o cenário global não se altera a medida que aumenta a quantidade de Estados adeptos a guerra fiscal. No entanto a medida que o governo impõe mais altruísmo dos agentes a utilidade global reduz com mais Estados.
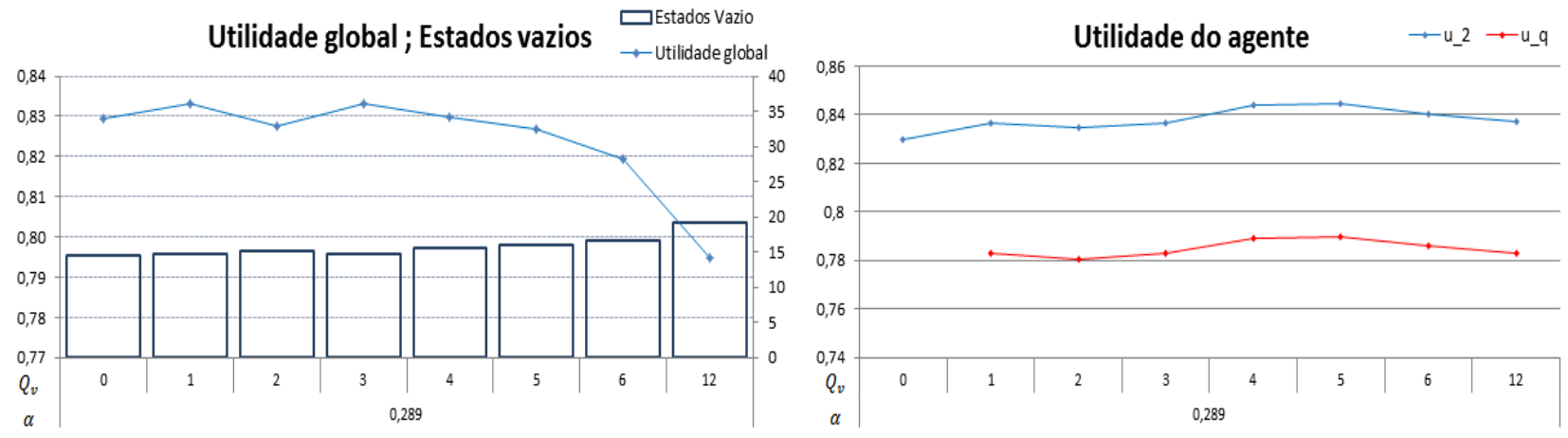

Figura 11: Gráficos com os resultados do caso segregado quando mais de um Estado adere à guerra fiscal.

11A: Ao contrário do modelo homogêneo, no limite segregado a medida de aumenta o número de Estados adeptos a guerra menor é a utilidade global. 
Vemos pelos resultados da tabela 5 que, para valores pequenos de $\alpha$ não faz diferença ter mais de um Estado dando incentivo fiscal, no entanto, à medida que o 0 valor de $\alpha$ aumenta, ao contrário do caso onde não há segregação, a utilidade global reduz quando se tem mais Estados adeptos da guerra fiscal, pois o número de Estados esvaziados aumenta, ou seja, haverá mais segregação.

Analisando os resultados de todas as simulações para o caso segregado, vemos que a arrecadação nacional é maior somente se não houver diferença de tributos entre os Estados, ou seja, no modelo uniforme. Se houver ao menos um Estado adepto da guerra fiscal, o resultado será nocivo para o país, e o prejuízo só cresce à medida que mais Estados que aderem à guerra. Este cenário só será positivo se o governo impuser um parâmetro de imposto $\alpha$ grande o suficiente para que decisões dos agentes levem em conta sempre o aumento da satisfação global (verifica os valores de $\alpha$ tais que $U^{*}>U_{0}$ simulações 1-33, 38-45, 54-58).

Aqui há contato com as afirmações de especialistas que afirmam que, do ponto de vista nacional, o país sempre perde com a guerra fiscal, pois a analisam a realidade brasileira onde a industrialização ainda é pequena [10].

De uma forma geral, se levado em consideração o custo de investimento que um Estado com incentivo tem para atrair indústrias, este terá que se conformar em ter uma arrecadação menor do que os demais Estados, pois o valor de $\gamma_{q}$ necessário para que sejam iguais na maioria do os casos é maior de 100\% (simulação 1-35). Isto quer dizer que toda a arrecadação do Estado tem que ser desviada para o governo.

Outra situação que pode ser explorada futuramente é considerando que cada Estado possua um parâmetro $m_{q}$ diferente, ou seja, os Estados terão (ou não) benefícios distintos. Na figura abaixo inserimos apenas um exemplo da situação em equilíbrio para o caso $\rho_{0}=0,4, \alpha=0,289$ e cada Estado com um parâmetro $m$. 

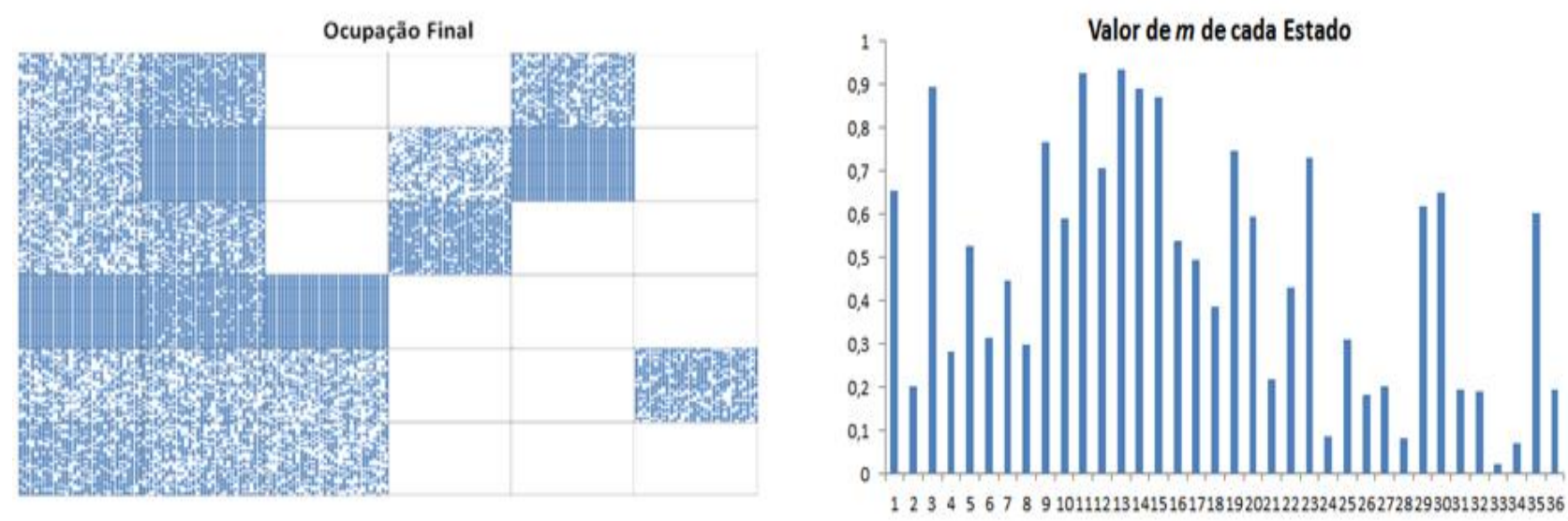

Figura 12: Resultado da simulação considerando que cada Estado possui um benefício diferente.

Os Estados serão ocupados conforme o valor que estarão dispostos a dar de incentivo. Os que optarem por não dar benefício algum fatalmente ficarão vazios. A utilidade global normalizada desta simulação é $\boldsymbol{U}^{*}=$ 0. 878, se comparada com os resultados 22 a 28 da tabela 4 (que possui o mesmo conjunto de parâmetros) pode-se concluir que a arrecadação da nação aumenta com esta "bagunça".

Como dissemos no capítulo anterior, a guerra fiscal é um instrumento utilizado por Estados mais pobres e distantes de grandes centros urbanos para atrair investimentos e nesta situação ela é importante para alavancar a economia deste lugar. Para Estados onde houve esvaziamento total, uma das opções para atrair investimento seria aumentar o incentivo fiscal mesmo para baixas densidades $\left(\rho_{0}<\frac{1}{2}\right)$, alterando a forma da função utilidade neste intervalo.

A forma da função utilidade para $j_{\text {-ésimo }}$ Estado seria

$$
u_{j}(\rho)=\left\{\begin{array}{c}
t_{j}+2 \rho\left(1-t_{j}\right) \quad \text { para } \rho \leq \frac{1}{2} \\
m_{q}+2\left(1-m_{q}\right)(1-\rho) \quad \text { para } \rho>\frac{1}{2}
\end{array},\right.
$$

Equação 53

onde $t_{j}$ é o valor do incentivo dado pelo $j_{\text {-ésimo }}$ estado para atrair as primeiras empresas. Como o sistema já se encontra em equilíbrio (em temperatura nula somente ganho da utilidade será levado em conta na hora de mover agentes), para que a mudança seja atrativa $t_{j}$ tem que ser da ordem de $u_{q}\left(\rho_{2}\right)$, a utilidade das empresas instaladas nos Estados ocupados. Vamos tomar então $t_{j}=u_{q}\left(\rho_{2}\right)$.

A princípio vamos supor que no novo equilíbrio haverá três tipos de quarteirões, com densidades $\rho_{2}^{\prime}, \rho_{2}^{*} e \rho_{Q}^{*}$, sendo $\rho_{2}^{\prime}$ a densidade dos Estados ocupados com parâmetro $m_{a}, \rho_{2}^{*}$ a densidade do Estado vazio que inseriu o parâmetro $t_{j}$ para atrair as primeiras 
empresas e $\rho_{Q}^{*}$ a nova densidade do Estado $Q$ (com parâmetro $m_{b}$ ). Sem perda de generalidade podemos dizer que as mesmas relações da Equação 37 e da Equação 38 são válidas, portanto

$$
\left\{\begin{array}{l}
f_{a}^{\prime}\left(\rho_{2}^{\prime}\right)=f_{a}^{\prime}\left(\rho_{2}^{*}\right) \\
f_{a}^{\prime}\left(\rho_{2}\right)=f_{b}^{\prime}\left(\rho_{Q}\right)
\end{array}\right.
$$

Equação 54

e por hipótese $\rho_{2}^{\prime}, \rho_{2}^{*}$ e $\rho_{Q}^{*}>\frac{1}{2}$. Neste intervalo as funções utilidade $u_{j}(\rho)$ e $u_{q}(\rho)$ são iguais, portanto da primeira relação temos $\rho_{2}^{\prime}=\rho_{2}^{*}$.

Nos resta agora escrever a relação entre $\rho_{2}^{*}$ e $\rho_{2}$ (densidade dos Estados ocupados antes da inclusão da perturbação). A partir da conservação do número de agentes podemos escrever a relação das densidades supondo que a quantidade de Estados vazios diminuirá em 1 unidade:

$$
\begin{gathered}
N_{0}=\left(Q-Q_{v}^{*}\right) N_{2}^{*}+N_{Q}^{*} \\
\frac{N_{0}}{H Q}=\left(Q-Q_{v}^{*}-1\right) \frac{N_{2}^{*}}{H Q}+\frac{N_{Q}^{*}}{H Q} \\
\rho_{0}=\left(1-\frac{Q_{v}^{*}-1}{Q}\right) \rho_{2}^{*}+\frac{\rho_{Q}^{*}}{Q},
\end{gathered}
$$

e portanto

$$
Q_{v}^{*}=\frac{1}{\rho_{2}^{*}}\left(\rho_{Q}^{*}-Q \rho_{0}\right)+Q-1 .
$$

Substituindo $Q_{v}$ pela primeira linha da Equação 44 temos $Q_{v}^{*}=Q_{v}-1$,

$$
\begin{gathered}
\frac{1}{\rho_{2}^{*}}\left(\rho_{Q}^{*}-Q \rho_{0}\right)+Q-1=\frac{1}{\rho_{2}}\left(\rho_{Q}-Q \rho_{0}\right)+Q-2 \\
\frac{1}{\rho_{2}^{*}}\left(\rho_{Q}^{*}-Q \rho_{0}\right)=\frac{1}{\rho_{2}}\left(\rho_{Q}-Q \rho_{0}\right)-1 \\
\frac{1}{\rho_{2}^{*}}=\frac{\left(\rho_{Q}-Q \rho_{0}-\rho_{2}\right)}{\left(\rho_{Q}^{*}-Q \rho_{0}\right)} \\
\rho_{2}^{*}=\frac{\rho_{2}\left(\rho_{Q}^{*}-Q \rho_{0}\right)}{\left(\rho_{Q}-Q \rho_{0}-\rho_{2}\right)} .
\end{gathered}
$$

Equação 55 
A linha 2 da Equação 54 tem mesma solução da Equação 44, porém agora relacionando $\rho_{Q}^{*}$ e $\rho_{2}^{*}$. Com isso podemos reescrever o sistema de equações para o caso desordenado,

$$
\left\{\begin{array}{c}
Q_{v}^{*}=\frac{1}{\rho_{2}^{*}}\left(\rho_{Q}^{*}-Q \rho_{0}\right)+Q-1 \\
\rho_{2}^{*}=\frac{\rho_{2}\left(\rho_{Q}^{*}-Q \rho_{0}\right)}{\left(\rho_{Q}-Q \rho_{0}-\rho_{2}\right)} \\
\rho_{Q}^{*}=\frac{\rho_{2}^{*}\left\{(1+\alpha)\left(m_{a}-1\right)\right\}+\frac{1}{2}\left(m_{b}-m_{a}\right)}{(1+\alpha)\left(m_{b}-1\right)}
\end{array}\right.
$$

Equação 56

Resolvendo o sistema temos

$$
\begin{gathered}
\rho_{2}^{*}=\frac{\rho_{2}\left(\rho_{Q}^{*}-Q \rho_{0}\right)}{\left(\rho_{Q}-Q \rho_{0}-\rho_{2}\right)} \Rightarrow \rho_{2}^{*}=A\left(\rho_{Q}^{*}-Q \rho_{0}\right) \\
\rho_{Q}^{*}=\frac{\rho_{2}^{*}\left\{(1+\alpha)\left(m_{a}-1\right)\right\}+\frac{1}{2}\left(m_{b}-m_{a}\right)}{(1+\alpha)\left(m_{b}-1\right)} \Rightarrow \rho_{Q}^{*}=\text { B. } \rho_{2}^{*},
\end{gathered}
$$

onde $A=\frac{\rho_{2}}{\left(\rho_{Q}-Q \rho_{0}-\rho_{2}\right)}$ e $B=\frac{(1+\alpha)\left(m_{a}-1\right)+\frac{1}{2}\left(m_{b}-m_{a}\right)}{(1+\alpha)\left(m_{b}-1\right)}$. Logo,

$$
\rho_{2}^{*}=A\left(B . \rho_{2}^{*}-Q \rho_{0}\right) \Rightarrow \rho_{2}^{*}(1-A B)=A Q \rho_{0} \Rightarrow \rho_{2}^{*}=\frac{A Q \rho_{0}}{(1-A B)^{\prime}}
$$

portanto

$$
\left\{\begin{array}{c}
\rho_{2}^{*}=\frac{\rho_{2} \cdot(1+\alpha)\left(m_{b}-1\right)}{\left(\rho_{Q}-Q \rho_{0}-\rho_{2}\right)-\rho_{2}\left\{(1+\alpha)\left(m_{a}-1\right)+\frac{1}{2}\left(m_{a}-m_{b}\right)\right\}} \\
\rho_{Q}^{*}=\frac{\rho_{2}^{*}\left\{(1+\alpha)\left(m_{a}-1\right)\right\}+\frac{1}{2}\left(m_{b}-m_{a}\right)}{(1+\alpha)\left(m_{b}-1\right)} .
\end{array}\right.
$$

Equação 57 
Estas são as novas densidades que devemos esperar com a inclusão do parâmetro $t$ em um Estado desocupado.

A partir da relação do lucro bruto (Equação 46) podemos calcular o lucro que todos os Estados teriam, sabendo que $u_{j}(\rho)=u_{q}(\rho)$ para $\forall \rho \geq \frac{1}{2}$, como

$$
\begin{gathered}
A_{i}=H \cdot\left\{\left(Q-Q_{v}-1\right) \rho_{2} \cdot u_{q}\left(\rho_{2}\right)+\rho_{Q} \cdot u_{Q}\left(\rho_{Q}\right)\right\} \\
A_{f}=H\left\{\left(Q-Q_{v}\right) \rho_{2}^{*} \cdot u_{q}\left(\rho_{2}^{*}\right)+\rho_{Q}^{*} \cdot u_{Q}\left(\rho_{Q}^{*}\right)\right\},
\end{gathered}
$$

sendo $A_{i}$ o lucro bruto de todos os Estados ocupados imediatamente após o sistema atingir o equilíbrio e $A_{f}$ é o lucro bruto de todos os Estados ocupados após o $j_{\text {-ésimo }}$ Estado ter dado incentivo para baixas densidades. E as arrecadações como

Fazendo

$$
\begin{gathered}
\Delta A=A_{f}-A_{i} \\
\Delta A=H\left\{\left(Q-Q_{v}\right)\left[\rho_{2}^{*} \cdot u_{q}\left(\rho_{2}^{*}\right)-\rho_{2} \cdot u_{q}\left(\rho_{2}\right)\right]+\rho_{2} \cdot u_{q}\left(\rho_{2}\right)+\left[\rho_{Q}^{*} \cdot u_{Q}\left(\rho_{Q}^{*}\right)-\rho_{Q} \cdot u_{Q}\left(\rho_{Q}\right)\right]\right\},
\end{gathered}
$$

Equação 58

$\operatorname{com} \rho_{2}^{*}=\rho_{2}+\Delta \rho_{2}$ e $\rho_{Q}^{*}=\rho_{Q}+\Delta \rho_{Q}$ obtemos

$$
\begin{gathered}
\Delta A_{2}=H\left(Q-Q_{v}\right)\left\{\left[\rho_{2}+\Delta \rho_{2}\right] \cdot u_{q}\left(\rho_{2}+\Delta \rho_{2}\right)-\rho_{2} \cdot u_{q}\left(\rho_{2}\right)\right\}+H \rho_{2} \cdot u_{q}\left(\rho_{2}\right), \\
\Delta A_{Q}=H\left[\rho_{Q}+\Delta \rho_{Q}\right] \cdot u_{Q}\left(\rho_{Q}+\Delta \rho_{Q}\right)-H \rho_{Q} \cdot u_{Q}\left(\rho_{Q}\right) .
\end{gathered}
$$

Como esperamos $\Delta \rho_{2} \ll \rho_{2}$, podemos fazer uma expansão de Taylor na função, então temos $u_{q}\left(\rho_{2}+\Delta \rho_{2}\right)=u_{q}\left(\rho_{2}\right)+u_{q}^{\prime}\left(\rho_{2}\right) \cdot \Delta \rho_{2}$.

$$
\begin{gathered}
\Delta A_{2}=H\left(Q-Q_{v}\right)\left\{\left[\rho_{2}+\Delta \rho_{2}\right] \cdot\left[u_{q}\left(\rho_{2}\right)+u_{q}^{\prime}\left(\rho_{2}\right) \cdot \Delta \rho_{2}\right]-\rho_{2} \cdot u_{q}\left(\rho_{2}\right)+\frac{\rho_{2} \cdot u_{q}\left(\rho_{2}\right)}{\left(Q-Q_{v}\right)}\right\} \\
\Delta A_{2}=H\left(Q-Q_{v}\right)\left\{\rho_{2}\left[u_{q}\left(\rho_{2}\right)+u_{q}^{\prime}\left(\rho_{2}\right) \cdot \Delta \rho_{2}\right]+\left[\Delta \rho_{2} \cdot u_{q}\left(\rho_{2}\right)+u_{q}^{\prime}\left(\rho_{2}\right) \cdot \Delta \rho_{2}{ }^{2}\right]-\rho_{2} \cdot u_{q}\left(\rho_{2}\right)\right. \\
\left.+\frac{\rho_{2} \cdot u_{q}\left(\rho_{2}\right)}{\left(Q-Q_{v}\right)}\right\}
\end{gathered}
$$

e desprezando os termos da ordem de $\Delta \rho^{2}$ chegamos

$$
\Delta A_{2}=H\left(Q-Q_{v}\right)\left[\Delta \rho_{2} \cdot\left[u_{q}\left(\rho_{2}\right)+\rho_{2} u_{q}^{\prime}\left(\rho_{2}\right)\right]+\frac{\rho_{2} \cdot u_{q}\left(\rho_{2}\right)}{\left(Q-Q_{v}\right)}\right] .
$$

E analogamente para $\Delta A_{Q}$ temos $\Delta A_{Q}=H \Delta \rho_{Q}\left[u_{Q}\left(\rho_{Q}\right)+\rho_{Q} u_{Q}^{\prime}\left(\rho_{Q}\right)\right]$. 
A relação entre $\Delta \rho_{Q}$ e $\Delta \rho_{2}$ vem da conservação do número de agentes

$$
\left\{\begin{array}{c}
N_{0}=\left(Q-Q_{v}-1\right) N_{2}+N_{Q} \\
N_{0}=\left(Q-Q_{v}\right) N_{2}^{*}+N_{Q}^{*}
\end{array}\right.
$$

portanto

$$
\begin{gathered}
\left(Q-Q_{v}\right)\left(N_{2}^{*}-N_{2}\right)+\left(N_{Q}^{*}-N_{Q}\right)+N_{2}=0 \\
\left(Q-Q_{v}\right) \Delta \rho_{2}+\Delta \rho_{Q}+\rho_{2}=0 \\
\Delta \rho_{2}=-\frac{\Delta \rho_{Q}+\rho_{2}}{\left(Q-Q_{v}\right)} .
\end{gathered}
$$

Substituindo em $\Delta A_{2}$, chegamos

$$
\begin{gathered}
\Delta A_{2}=H\left(Q-Q_{v}\right)\left[\frac{-\left(\Delta \rho_{Q}+\rho_{2}\right) \cdot\left[u_{q}\left(\rho_{2}\right)+\rho_{2} u_{q}^{\prime}\left(\rho_{2}\right)\right]+\rho_{2} \cdot u_{q}\left(\rho_{2}\right)}{\left(Q-Q_{v}\right)}\right] \\
\Delta A_{2}=H\left[-\left(\Delta \rho_{Q}+\rho_{2}\right) \cdot\left[u_{q}\left(\rho_{2}\right)+\rho_{2} u_{q}^{\prime}\left(\rho_{2}\right)\right]+\rho_{2} \cdot u_{q}\left(\rho_{2}\right)\right] \\
\Delta A_{2}=H\left\{-\Delta \rho_{Q} \cdot\left[u_{q}\left(\rho_{2}\right)+\rho_{2} u_{q}^{\prime}\left(\rho_{2}\right)\right]-\rho_{2}^{2} \cdot u_{q}\left(\rho_{2}\right)\right\} .
\end{gathered}
$$

Portanto a diferença é dada por

$$
\begin{gathered}
\Delta A=H\left\{-\Delta \rho_{Q} \cdot\left[u_{q}\left(\rho_{2}\right)+\rho_{2} u_{q}^{\prime}\left(\rho_{2}\right)\right]-\rho_{2}^{2} \cdot u_{q}\left(\rho_{2}\right)\right\}+\gamma H \Delta \rho_{Q}\left[u_{Q}\left(\rho_{Q}\right)+\rho_{Q} u_{Q}^{\prime}\left(\rho_{Q}\right)\right] \\
\Delta A=H\left\{\Delta \rho_{Q} \cdot\left[\left[u_{Q}\left(\rho_{Q}\right)+\rho_{Q} u_{Q}^{\prime}\left(\rho_{Q}\right)\right]-\left[u_{q}\left(\rho_{2}\right)+\rho_{2} u_{q}^{\prime}\left(\rho_{2}\right)\right]\right]-\rho_{2}^{2} \cdot u_{q}\left(\rho_{2}\right)\right\},
\end{gathered}
$$

$\operatorname{com} u_{q}^{\prime}\left(\rho_{2}\right)=2\left(m_{a}-1\right)$ e $u_{Q}^{\prime}\left(\rho_{Q}\right)=2\left(m_{b}-1\right)$ (Equação 31).

Para que o lucro bruto de todos os Estados aumente esta diferença tem que ser positiva. Como o termo $\left(-\rho_{2}^{2} \cdot u_{q}\left(\rho_{2}\right)\right)$ é positivo, então $\left[\left[u_{Q}\left(\rho_{Q}\right)+\rho_{Q} u_{Q}^{\prime}\left(\rho_{Q}\right)\right]-\right.$ $\left.\left[u_{q}\left(\rho_{2}\right)+\rho_{2} u_{q}^{\prime}\left(\rho_{2}\right)\right]\right]$ tem que ser negativo pelo fato de que $\Delta \rho_{Q}<0$, assim temos

$$
\begin{gathered}
{\left[\left[u_{Q}\left(\rho_{Q}\right)+\rho_{Q} u_{Q}^{\prime}\left(\rho_{Q}\right)\right]-\left[u_{q}\left(\rho_{2}\right)+\rho_{2} u_{q}^{\prime}\left(\rho_{2}\right)\right]\right]<0} \\
m_{b}+2\left(1-m_{b}\right)\left(1-\rho_{Q}\right)+2 \rho_{Q}\left(m_{b}-1\right)-\left[m_{a}+2\left(1-m_{a}\right)\left(1-\rho_{2}\right)+2 \rho_{2}\left(m_{a}-1\right)\right]<0 \\
2-m_{b}+4 \rho_{Q}\left(m_{b}-1\right)-\left[2-m_{a}+4 \rho_{2}\left(m_{a}-1\right)\right]<0 \\
\left(m_{a}-m_{b}\right)+4 \rho_{Q}\left(m_{b}-1\right)-4 \rho_{2}\left(m_{a}-1\right)<0 \\
\rho_{2-\text { mínimo }}>\frac{\rho_{Q}\left(1-m_{b}\right)+\frac{1}{4}\left(m_{b}-m_{a}\right)}{\left(1-m_{a}\right)}
\end{gathered}
$$

Equação 59 
ou seja, este é o valor mínimo que $\rho_{2}$ pode ter antes do investimento do Estado esvaziado para que todos os Estados ocupados se beneficiem deste artifício.

Para cada agente que decidiu mudar para um Estado $j$ vazio recebeu de incentivo um total da ordem de $t_{j}=u_{q}\left(\rho_{2}\right)$, portanto dizemos que os custos de investimento por agente é deste Estado é simplesmente

$$
i_{j}=u_{q}\left(\rho_{2}\right)
$$

Equação 60

sendo $\rho_{2}$ a densidade dos Estados ocupados antes da investida de um Estado vazio.

Novamente o incentivo total é dado por

$$
I_{j}=H \rho_{2}^{*} \cdot u_{q}\left(\rho_{2}\right)
$$

\section{Equação 61}

$\rho_{2}^{*}$ como a nova densidade dos Estados ocupados após a chegada das indústrias no Estado que estava vazio.

A nova arrecadação dos Estados com densidade $\rho_{2}^{*}$ é $R_{2}^{*}=\gamma \cdot H \rho_{2}^{*} \cdot u_{q}\left(\rho_{2}^{*}\right)$, portanto a arrecadação líquida do $j_{- \text {ésimo }}$ Estado será dada por

$$
\begin{gathered}
R_{j}^{L}=R_{2}^{*}-I_{j}, \\
R_{j}^{L}=\gamma \cdot H \rho_{2}^{*} \cdot u_{q}\left(\rho_{2}^{*}\right)-H \rho_{2}^{*} \cdot u_{q}\left(\rho_{2}\right), \\
R_{j}^{L}=H \cdot \rho_{2}^{*}\left[\gamma \cdot u_{q}\left(\rho_{2}^{*}\right)-u_{q}\left(\rho_{2}\right)\right] .
\end{gathered}
$$

O Estado $j$ só se beneficiará da renuncia de impostos se $\left[\gamma \cdot u_{q}\left(\rho_{2}^{*}\right)+u_{q}\left(\rho_{2}\right)\right]>0$, para tal o valor mínimo da alíquota de imposto $\gamma_{j}$ deve ser

$$
\gamma_{j-\text { mínimo }}>\frac{u_{q}\left(\rho_{2}\right)}{u_{q}\left(\rho_{2}^{*}\right)},
$$

que é $<1$ já que no intervalor $1>\rho>\frac{1}{2}$ temos $u_{q}\left(\rho_{2}^{*}\right)>u_{q}\left(\rho_{2}\right)$

E novamente vamos medir qual o valor de $\gamma_{q}$ para que a arrecadação do Estado $j$ com esse investimento, seja pelo menos igual ao lucro bruto dos outros Estados ocupados com densidade $\rho_{2}^{*}$. Com $R_{2}^{*}=H \gamma_{q} \rho_{2}^{*}$. $u_{q}\left(\rho_{2}^{*}\right)$ e $\gamma_{q}$ como a alíquota de imposto dos Estados ocupados determinado pela Equação 50; 


$$
\begin{gathered}
R_{j}^{L}=R_{2}^{*} \\
\gamma_{q} A_{2}^{*}-I_{j}=\gamma_{q} A_{2}^{*} \\
\gamma_{q}\left(A_{2}^{*}-A_{2}^{*}\right)=I_{j} \\
\gamma_{q}=\infty,
\end{gathered}
$$

\section{Equação 62}

em outras palavras, ao conceder o benefício para as primeiras empresas, não é possível ao Estado obter a mesma arrecadação dos demais.

Para medirmos o custo de investimento deste Estado para atrair as primeiras empresas, fizemos 50 simulações com 1.000 passos de Monte Carlo cada para este modelo considerando os mesmos conjuntos de parâmetros da tabela 6 . 


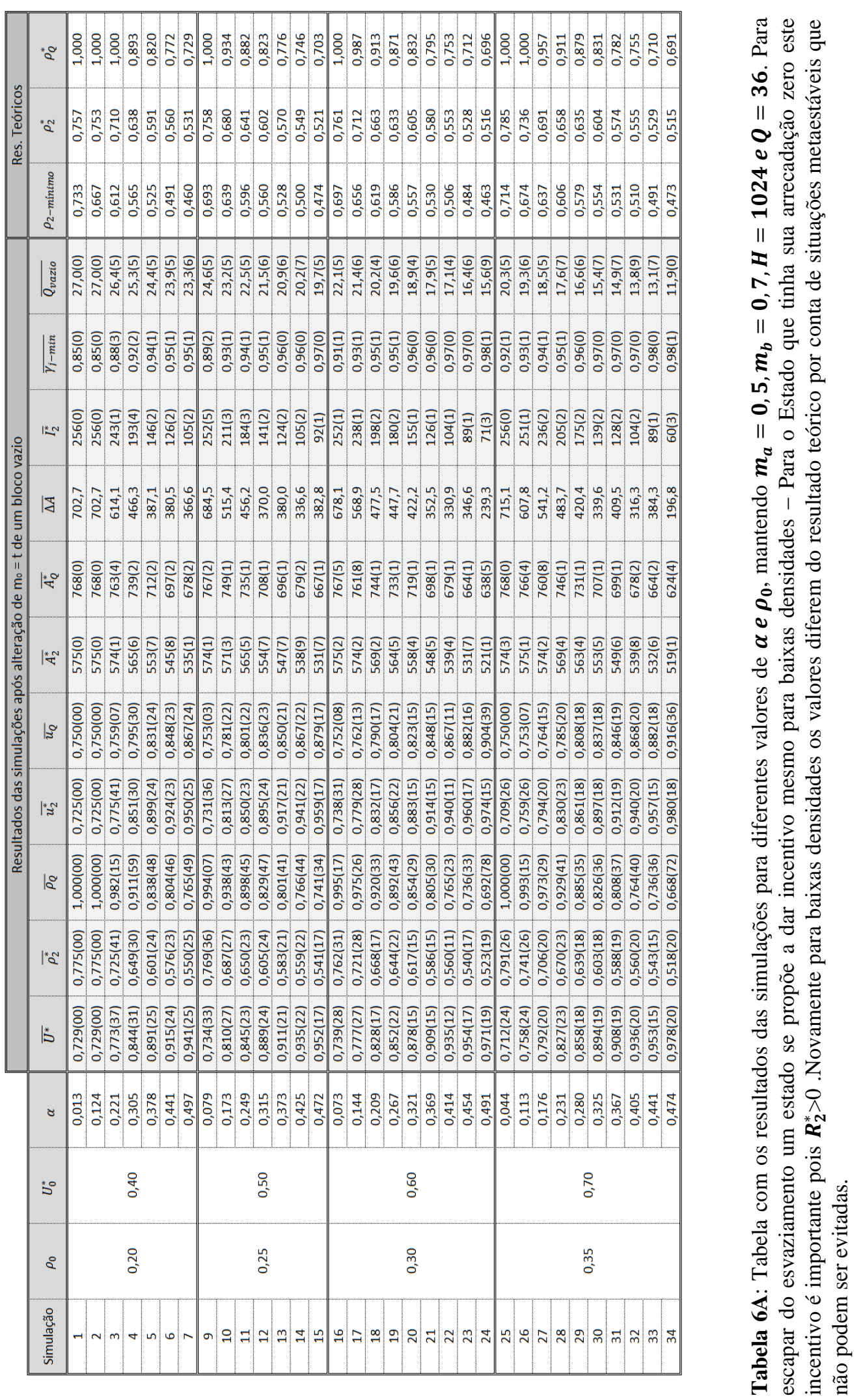

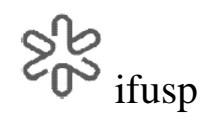




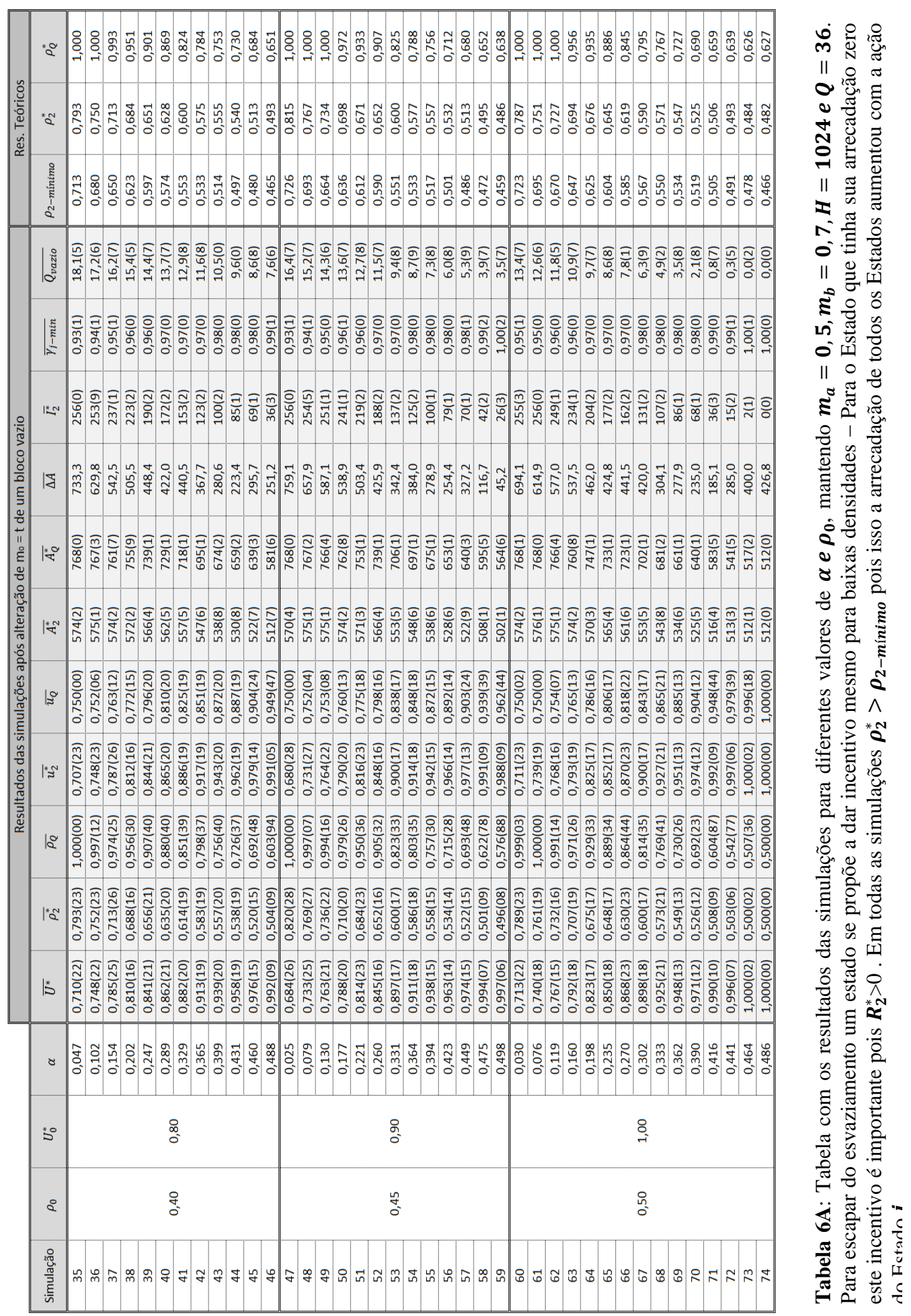



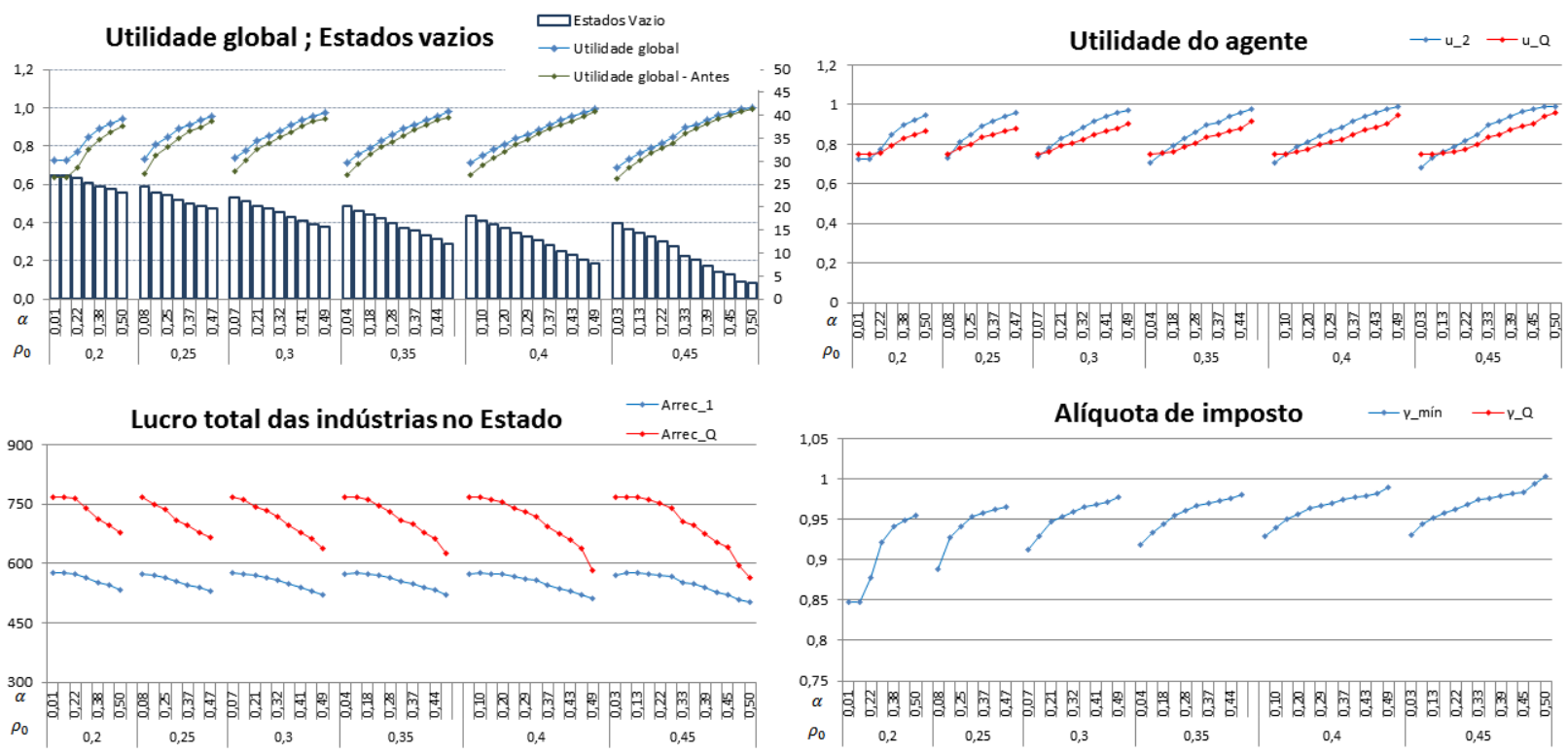

Figura 13: Gráficos com os resultados das simulações do modelo segregado quando um Estado vazio fornece incentivos para baixas densidades.

13A: A quantidade de Estados vazios diminui em 1 unidade quando comparado com o modelo segregado e com isso a utilidade global aumenta

13B: Como os Estados Q e os demais Estados ocupados cedem agentes para o Estado que estava vazio a utilidade de todos aumenta nesta situação.

13C: O total das industrias nos Estados reduz por conta da diminuição da densidade.

13D: Para o Estado que deu o incentivo para as baixas densidades a alíquota necessária para não ter alguma arrecadação é próxima de $100 \%$, ou seja, o Estado teria que absorver parte do custo deste investimento.

Os resultados da tabela 6 mostram que, para o Estado que fora esvaziado só é interessante abrir mão dos impostos para atrair as primeiras empresas porque isto tira sua arrecadação do zero (coluna $A_{2}^{*}$ ), porém seu custo de incentivo é extremamente alto, fazendo com que a carga de imposto sobre a sociedade que optou por viver ali seja muito alta, o valor de $\gamma_{j-\min }$ mostra o quão custosa esta ação é para sociedade, vejamos por exemplo os resultados das simulações 45, 58 e 73 onde a alíquota de imposto para que o Estado não tenha prejuízo chega a $100 \%$ da arrecadação. Contudo, podemos observar que investir desta forma aumenta a arrecadação de todos os Estados não vazios, essa arrecadação só não aumentaria se a densidade dos Estados ocupados antes do

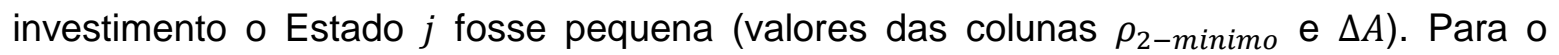
Estado que optou por abrir mão de seus encargos fazer isso é bom negócio, pois ele terá alguma arrecadação $A \neq 0$, devemos nos lembrar do resultado da Equação 62 que mostra que ao investir para atrair as primeiras empresas o Estado deve ter ciência de que nunca terá uma arrecadação igual aos Estados que não aderiram a guerra. 
Ainda assim o Estado fará esse investimento, pois não internaliza os danos que causarão do ponto de vista global e visa apenas os benefícios individuais, como aumento da industrialização, crescimento populacional e crescimento da infra-estrutura. Nota-se que custo com incentivo do Estado $j$ é maior do que os custos que o Estado $Q$ teve quando aderiu à guerra fiscal, indicando que há um esforço maior para um Estado esvaziado atrair as primeiras empresas do que para um Estado parcialmente ocupado "roubar" indústrias dos demais.

Contudo do ponto de visto da nação, esta manobra é interessante, pois reduz a quantidade de Estados vazios e aumenta sua arrecadação (coluna $U^{*}$ da tabela 6 comparado com a coluna $U^{*}$ da tabela 4)

No curto prazo, os Estados adeptos da guerra (e o país) se beneficiam dos incentivos (até um determinado limite de $\rho_{2}$ ). No longo prazo, a generalização do conflito faz com que os ganhos iniciais desapareçam, pois os incentivos fiscais perdem o seu poder de estímulo. Os estados que mais perderão serão os que mais concedem tais incentivos, já que paralelo ao desenvolvimento atraído para o seu território terão o crescimento das demandas por serviços públicos, tais como: educação, saúde, transporte, segurança, saneamento básico, entre outras despesas provenientes do crescimento populacional e da elevação da renda per capita [NASCIMENTO - 6]

\begin{tabular}{|c|c|c|c|c|c|c|c|c|}
\hline \multirow{2}{*}{ Grandes Regiōes } & \multicolumn{8}{|c|}{ Participação percentual no Produto Interno Bruto (\%) } \\
\hline & 2002 & 2003 & 2004 & 2005 & 2006 & 2007 & 2008 & 2009 \\
\hline Brasil & 100,0 & 100,0 & 100,0 & 100,0 & 100,0 & 100,0 & 100,0 & 100,0 \\
\hline Norte & 4,7 & 4,8 & 4,9 & 5,0 & 5,1 & 5,0 & 5,1 & 5,0 \\
\hline Nordeste & 13,0 & 12,8 & 12,7 & 13,1 & 13,1 & 13,1 & 13,1 & 13,5 \\
\hline Sudeste & 56,7 & 55,8 & 55,8 & 56,5 & 56,8 & 56,4 & 56,0 & 55,3 \\
\hline Sul & 16,9 & 17,7 & 17,4 & 16,6 & 16,3 & 16,6 & 16,6 & 16,5 \\
\hline Centro-Oeste & 8,8 & 9,0 & 9,1 & 8,9 & 8,7 & 8,9 & 9,2 & 9,6 \\
\hline
\end{tabular}

Fonte: IBGE, em parceria com os Órgãos Estaduais de Estatística, Secretarias Estaduais de Governo e Superintendência da Zona Franca de Manaus - Suframa.

Tabela 7: Evolução do PIB [8] nos últimos anos, mesmo com a continuidade da guerra fiscal não há significativas alterações na distribuição das indústrias entre as regiões - Mostra que o movimento perde o poder de estímulo.

Pela tabela 7 da referência 8, vemos que mesmo que guerra fiscal seja situação ainda atual no Brasil, já não há grandes movimentos migratórios para outras regiões, podendo afirmar que tal prática hoje em dia perdeu sua importância. 


\section{Reinterpretação dos resultados aplicados ao sistema de portabilidade de crédito}

No dia 05 de maio de 2014 entrou em vigor a resolução do Banco Central que permite que qualquer cliente tomador de crédito migre sua dívida para outro banco sem nenhum custo adicional [4]. O objetivo desta medida é incentivar a concorrência entre os bancos e possibilitar uma redução na taxa de juros cobrada nas operações. Esta medida tem um impacto positivo para o consumidor. Se os bancos adotarem a "guerra da taxa" esta resolução trará fragilidade ao sistema de crédito, pois a fidelidade de um cliente agora dependerá, além de vantagens de conveniência, de uma redução cada vez maior da taxa de juros de cada banco. Podemos fazer a seguinte releitura deste cenário a partir das resoluções dos capítulos anteriores.

A taxa de juros cobrada por um banco terá uma relação direta com a quantidade de clientes que este banco possui em sua carteira. Os bancos com carteiras maiores atraem mais depositantes e investidores (clientes superavitários) e com isso terão mais dinheiro em caixa para emprestar aos clientes deficitários. No entanto, se o número de clientes deficitários for muito maior do que de clientes superavitários a carga de risco do banco aumenta, ou seja, existe uma relação entre o tamanho da carteira de crédito e a carga de risco. O risco de crédito está relacionado à possibilidade do não recebimento do pagamento da contraparte na hora de pagar a dívida, seja por vontade ou por incapacidade de honrar suas dívidas. Os principais elementos do risco de crédito são: alteração do valor das dívidas e grande concentração em um único ou em poucos credores. Por conta disso o percentual de inadimplência aumenta com o tamanho da carteira, elevando a taxa de juros. Segundo o relatório do Banco Central de maio/2015 a taxa média de juros das operações de crédito do sistema financeiro alcançou 26,4\% a.a. em abril/2015, com elevações de 0,5 p.p. no mês e 2,5 p.p. em doze meses. Parte deste aumento deve-se à inadimplência no sistema financeiro, com atrasos superiores a noventa dias, que alcançou $3 \%$, e elevou-se em 0,2 p.p. no mês e 0,1 p.p. em doze meses. [9]

Definimos $\mathrm{H}$ como sendo a capacidade máxima de clientes tomadores de crédito que um banco suporta e $\mathrm{n}_{\mathrm{q}}$ o número de tomadores na carteira. $\mathrm{A}$ densidade do $q_{\text {-ésimo }}$

banco é definida como $\rho_{q}=\frac{n_{q}}{H}$, e assim como no modelo de segregação, a taxa de juros (utilidade) irá variar com a densidade de clientes tomadores de crédito na carteira. 
Podemos supor que a função utilidade, que mede a satisfação de um cliente, está relacionada com a taxa de juros $r(\rho)$ pela expressão

$$
r(\rho)=r_{0}+[1-u(\rho)]
$$

Equação 63

com $r_{0}$ sendo uma taxa básica constante para todos os bancos. Ou seja, a taxa de juros cobrada pelo $q_{\text {-ésimo }}$ banco diminui à medida que a utilidade dos agentes aumenta. $O$ rendimento total do sistema financeiro diminui conforme a utilidade global normalizada $U^{*}(\rho)$ aumenta. Da mesma forma que a utilidade global do modelo de Grauwin está relacionada com a utilidade por agente, o rendimento total dos bancos está relacionado com o rendimento por cliente tomador, e pode ser escrita como

$$
U_{B}^{*}=\left[1-U^{*}(\rho)\right] .
$$

\section{Equação 64}

O parâmetro m é relacionado à taxa de juros quando o banco tiver os tomadores possíveis da sua capacidade $(\rho=1)$. O parâmetro de altruísmo $\alpha$ é controlado pelo governo e pode ser um mecanismo idealizado (associado de alguma forma, por exemplo, a uma taxa de portabilidade) que inibe os tomadores a migrarem suas dívidas para outros bancos forçando-os a levar em conta o impacto desse movimento sobre a taxa média global de juros cobrada de todos os agentes. O mecanismo que guarda alguma semelhança com essa taxa é o IOF (imposto sobre movimentações financeiras), porém, no processo de portabilidade de crédito, se não houver tomada de mais dinheiro durante a portabilidade não se pode cobrar novamente o IOF. Por conta da falta desta taxa de portabilidade, o limite egoísta $(\alpha=0)$ é a situação que mais se aproxima do cenário real.

O lucro bruto de um banco ocupado é proporcional a $r(\rho)$, então

$$
A_{B}=H \rho \cdot r(\rho)
$$

e a arrecadação

$$
R_{B}=\beta . H \rho \cdot r(\rho)
$$

Equação 65

onde $\beta$ tem relação com o spread bancário - diferença entre a taxa de juros cobrada aos tomadores de crédito e a taxa de juros paga aos depositantes pelos bancos. Em outras palavras, é a diferença entre a remuneração que o banco paga ao aplicador para captar um recurso e o quanto esse banco cobra para emprestar o mesmo dinheiro. 
Dado esta considerações, conseguimos fazer uma correspondência entre as variáveis do modelo de segregação com a portabilidade de crédito que serão estudadas em duas situações, no caso uniforme e no caso desordenado. Um ingrediente que pode ser incorporado no futuro é a possibilidade do cliente poder refinanciar sua dívida no próprio banco com uma taxa menor. Isto é muito comum no mercado financeiro. Em geral, quando um cliente decide portar sua dívida, seu o banco atual inicia um trabalho de retenção deste tomador oferecendo uma redução na taxa de juros de um empréstimo ativo. No modelo apresentado neste trabalho não contemplamos este processo de retenção por parte dos bancos, ou seja, não há mudança de taxa quando um agente decide ficar no banco em que estava.

\section{i. Aplicação do caso uniforme ao modelo de portabilidade:}

O caso uniforme é a situação onde todos os bancos teriam a mesma taxa de juros de saturação $\left(m_{q}=m, \forall q \leq Q\right)$. Na situação inicial todos teriam a mesma quantidade de tomadores e por isso cobrariam a mesma taxa de juros de seus clientes. Como vimos no capitulo 2, se a quantidade de tomadores no mercado for suficientemente pequeno, esta situação corresponde a um equilíbrio instável de Nash. Se ao acaso ou por conveniência um desses clientes resolver migrar sua dívida para outro banco haverá uma movimentação em massa de muitos outros tomadores de crédito e em equilíbrio teremos dois cenários possíveis, o cenário homogêneo e o cenário segregado.

As grandezas apresentadas nas tabelas 8 e 9 são $\rho_{q}$, a densidade de clientes nos bancos ocupados, $r_{q}$, a taxa de juros cobrada em cada banco (considerando $r_{0}=0$ ) e $Q_{v a z i o}$, a quantidade de bancos fechados.

\section{a. Cenário homogêneo}

Suponha que o governo imponha uma taxa (variável) a ser cobrada a cada movimentação do cliente. À medida que este imposto aumentasse, menor seria a quantidade de clientes dispostos a mudar sua dívida de banco caso esse movimento aumente a taxa média global de juros. Se, além disso, houvesse muitos clientes tomadores no mercado, iria acontecer uma disputa pelos clientes do mercado, e estes clientes migrariam por entre os bancos em busca de melhorar suas taxas, porém, no equilíbrio, os bancos teriam a mesma quantidade de clientes que tinham antes das 
movimentações. A importância do parâmetro de altruísmo é notada na tabela 8, quando nota-se que reduz cada vez a renda bruta dos bancos a medida que $\alpha$ aumenta.

\begin{tabular}{|c|c|c|c|c|c|c|c|}
\hline \multirow[b]{2}{*}{ Simulação } & \multirow[b]{2}{*}{$\rho_{0}$} & \multirow[b]{2}{*}{$U_{0}^{*}$} & \multirow[b]{2}{*}{$\alpha$} & \multicolumn{4}{|c|}{ Resultados Experimentais } \\
\hline & & & & $\overline{U^{*}}$ & $\overline{\rho_{q}}$ & $\overline{u_{q}}$ & $\overline{A_{B}}$ \\
\hline 1 & \multirow{6}{*}{0,60} & \multirow{6}{*}{0,100} & 0,00 & $0,358(19)$ & $0,858(19)$ & $0,358(19)$ & $315(2)$ \\
\hline 2 & & & 0,20 & $0,211(14)$ & $0,711(14)$ & $0,211(14)$ & $154(1)$ \\
\hline 3 & & & 0,40 & $0,100(02)$ & $0,600(02)$ & $0,100(02)$ & $62(2)$ \\
\hline 4 & & & 0,60 & $0,100(00)$ & $0,600(00)$ & $0,100(00)$ & $61(0)$ \\
\hline 5 & & & 0,80 & $0,100(00)$ & $0,600(00)$ & $0,100(00)$ & $61(0)$ \\
\hline 6 & & & 1,00 & $0,100(00)$ & $0,600(00)$ & $0,100(00)$ & $61(0)$ \\
\hline
\end{tabular}

Tabela 8: Tabela com os resultados médios de 50 simulações para modelo uniforme de Grauwin para $\boldsymbol{\rho}_{0}=\mathbf{0}, \mathbf{6 0}$. A medida que o governo impõe uma taxa que iniba a transferência entre bancos a renda total dos bancos reduz o que indica que a população estará pagando menos juros bancários.

\section{b. Cenário segregado}

Como o governo não impõe nenhum tributo durante a portabilidade e a quantidade de tomadores no mercado é pequeno, este cenário é mais interessante. Depois de um determinado tempo disputando os clientes, alguns bancos acabariam por perder todos os clientes, e consequentemente iriam à falência. Restariam apenas alguns grandes bancos, com a carteira de clientes maior que a inicial, criando um oligopólio. O movimento dos tomadores em busca de menores taxas levaria à concentração do sistema, e ao aumento das taxas. A simulação 1 da tabela 9 apresenta o renda com juros do sistema financeiro, se comparado com a simulação 6 (quando $\alpha=0,5$ ) podemos verificar a importância de existir uma taxa que iniba os agentes de trocaram de banco quando esta ação aumenta o custo total. Sem ela, os únicos beneficiados pela dinâmica de portabilidade seriam os bancos que conseguiram sobreviver (coluna $A_{B}$ ).

\begin{tabular}{|c|c|c|c|c|c|c|c|c|}
\hline \multirow[b]{2}{*}{ Simulação } & \multirow[b]{2}{*}{$\rho_{0}$} & \multirow[b]{2}{*}{$U_{0}^{*}$} & \multirow[b]{2}{*}{$\alpha$} & \multicolumn{5}{|c|}{ Resultados Experimentais } \\
\hline & & & & $\overline{U^{*}}$ & $\overline{\rho_{q}}$ & $\overline{u_{q}}$ & $\overline{A_{B}}$ & $\overline{Q_{\text {vazio }}}$ \\
\hline 1 & \multirow{6}{*}{0,30} & \multirow{6}{*}{0,400} & 0,00 & $0,396(19)$ & $0,896(19)$ & $0,396(19)$ & $364(2)$ & $19,9(3)$ \\
\hline 2 & & & 0,10 & $0,223(27)$ & $0,723(27)$ & $0,223(27)$ & $166(2)$ & $16,1(7)$ \\
\hline 3 & & & 0,20 & $0,078(16)$ & $0,578(16)$ & $0,078(16)$ & $47(1)$ & $11,1(7)$ \\
\hline 4 & & & 0,30 & $0,007(04)$ & $0,500(07)$ & $0,008(03)$ & $4(2)$ & $7,2(4)$ \\
\hline 5 & & & 0,40 & $0,006(00)$ & $0,497(00)$ & $0,007(00)$ & $4(0)$ & $7,0(0)$ \\
\hline 6 & & & 0,50 & $0,006(00)$ & $0,497(00)$ & $0,007(00)$ & $4(0)$ & $7,0(0)$ \\
\hline
\end{tabular}

Tabela 9: Tabela com os resultados médios de 50 simulações para modelo uniforme de Grauwin para $\boldsymbol{\rho}_{\mathbf{0}}=\mathbf{0 , 6 0}$. A medida que o governo impõe uma taxa que iniba a transferência entre bancos a renda total dos bancos reduz, o que indica que a população estará pagando menos juros bancários. 


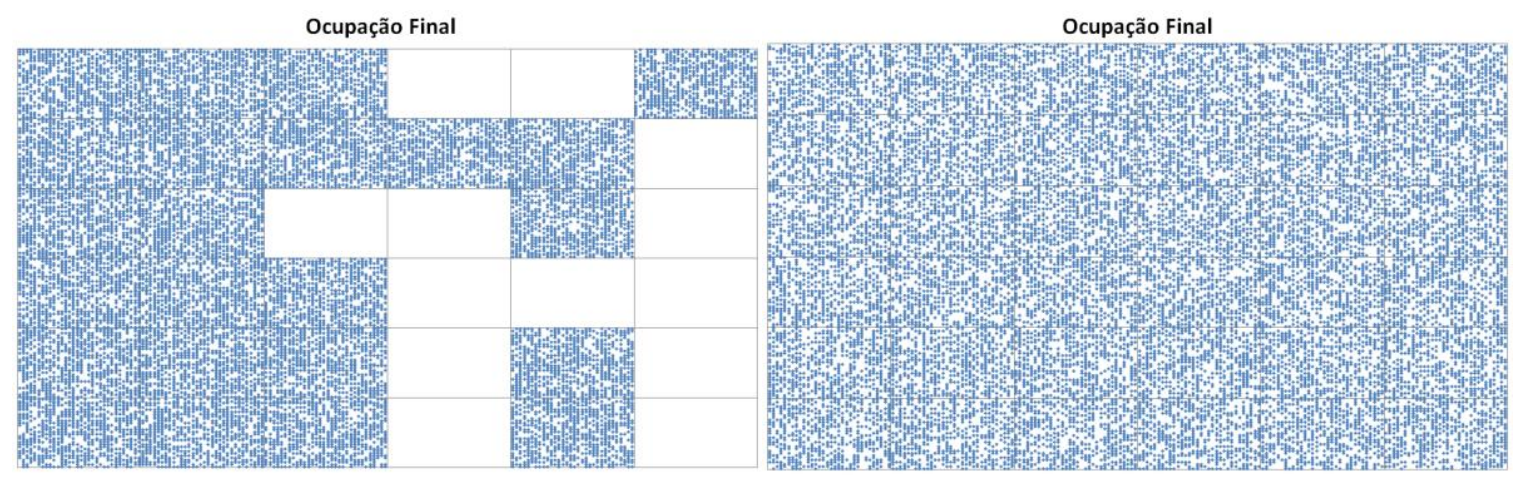

Figura 14: Resultado das simulações do modelo uniforme de portabilidade bancária

14A: Caso onde há segregação. $Q=36, H=1024, \rho_{0}=0.4, m=0.5 e \alpha=0.3$. Nesta configuração obtiveram-se 13 blocos completamente vazios e 23 blocos ocupados com densidade $\boldsymbol{\rho}_{2}=\mathbf{0 , 6 4 0}(\mathbf{1 6})$. O valor analítico de $\boldsymbol{\rho}_{2}$ é $\boldsymbol{\rho}_{2}=\mathbf{0 , 6 3 5}$. A utilidade dos tomadores que migraram de banco é de $\boldsymbol{u}_{2}=$ $\mathbf{0 , 8 6 0}(16)$.

14B: Caso homogêneo. $Q=36, H=1024, \rho 0=0.5, m=0.5 e \boldsymbol{\alpha}=0.6$. Nesta configuração todos os blocos foram ocupados com a densidade inicial. A utilidade deste grupo de tomadores é em $\boldsymbol{u}_{\mathbf{0}}=\mathbf{1}$.

\section{ii. Aplicação do caso desordenado do modelo de portabilidade:}

Num modelo mais realista os bancos oferecem taxas de saturação distintas e existe uma disputa acirrada entre os tomadores de crédito do mercado. Essa disputa ocorre mesmo que o banco tenha que reduzir seu lucro por cliente para atrair mais tomadores. Assumindo que a arrecadação de um banco é dada pela Equação 65, podemos observar pelos resultados das tabelas 10 e 11 que, exceto para o limite egoísta $\alpha=0$, o banco terá vantagem em abaixar suas taxas para "roubar" clientes da concorrência. No modelo de portabilidade o custo do incentivo dado a cada cliente no ato da mudança pode estar associado aos custos operacionais, que aumentam à medida que a carteira de clientes cresce, mas por conta da longevidade destes empréstimos (consignado, por exemplo, tem o tempo médio de pagamento de 36 meses) este custo é coberto pelo aumento de receita em longo prazo.

As grandezas apresentadas nas tabelas 10 e 11 são $\rho_{1}^{*}$ e $r_{1}^{*}$, a densidade e os juros de clientes nos bancos ocupados que não mudaram sua taxa de saturação na situação uniforme, $\rho_{Q}$ e $r_{Q}$, a densidade e os juros dos clientes do $Q_{\text {-ésimo banco }}$ (considerando $r_{0}=0$ ) e $Q_{\text {vazio }}$ a quantidade de bancos fechados. Para o modelo com segregação $\rho_{2}$ e $r_{2}$ representam a densidade e os juros dos bancos com taxas iguais. 


\section{a. Cenário homogêneo}

A alteração da taxa de juros de saturação em um dos bancos atrairá mais tomadores e com isso os demais bancos cederão parte de seus clientes. Interessante desta situação é que, como o governo inibe as movimentações e existe uma grande quantidade de tomadores no mercado, no equilíbrio todos os bancos continuarão coexistindo, então o banco que propôs reduzir sua taxa de juros terá mais clientes do que demais, exceto no limite $\alpha=0$. O que a princípio parecia ser uma manobra arriscada para o banco se torna um excelente negócio, mesmo que o governo crie mecanismos para inibir as transições, (comparação entre as colunas $A_{B 1}^{*}$ e $A_{B Q}$ ). Os juros também chamam a atenção, por conta do grande numero de tomadores (alta carga de risco) os clientes que optaram por mudar de banco terão uma taxa de juros maior do que aqueles que permaneceram no banco em que estavam (colunas $r_{Q}$ e $r_{1}^{*}$ ). $O$ que se pode observar nesta situação é que, assim como no modelo uniforme, a renda total dos bancos com juros reduz consideravelmente à medida que $\alpha$ aumenta.

O rendimento total do sistema financeiro é menor quando se tem um banco com taxa diferenciada do que quando todos os bancos praticam a mesma taxa (comparação das simulações 7 a 12 da tabela $10 \mathrm{com}$ as simulações 1 a 6 da tabela 8), isto indica que a adesão da guerra de taxa prejudica os próprios bancos.

Considerando apenas as variáveis do modelo, pode-se concluir que a criação, por parte do governo, de um imposto que iniba a migração de clientes entre os bancos é fundamental, pois mesmo para a situação onde a quantidade de tomadores no mercado é suficientemente grande $\rho>1 / 2$, existe $o$ risco de bancos irem a falência quando a "taxa de portabilidade" é pequena $(\alpha<0,2)$. Com $\alpha>0,2$, além do governo garantir a sobrevivência de todos os bancos, a arrecadação total do sistema diminui e isto pode desestimular a guerra de taxa. 


\begin{tabular}{|c|c|c|c|c|c|c|c|c|c|c|}
\hline \multirow[b]{2}{*}{ Simulação } & \multirow[b]{2}{*}{$\rho_{0}$} & \multirow[b]{2}{*}{$U_{0}^{*}$} & \multirow[b]{2}{*}{$\alpha$} & \multicolumn{7}{|c|}{ Resultados das simulações } \\
\hline & & & & $\overline{U^{*}}$ & $\overline{\rho_{1}^{*}}$ & $\overline{\rho_{Q}}$ & $\overline{r_{1}^{*}}$ & $\overline{r_{Q}}$ & $\overline{A_{B 1}^{*}}$ & $\overline{A_{B Q}}$ \\
\hline 1 & \multirow{6}{*}{0,55} & \multirow{6}{*}{0,050} & 0,00 & $0,353(24)$ & $0,833(26)$ & $1,000(00)$ & $0,333(26)$ & $0,250(00)$ & $284(3)$ & $256(0)$ \\
\hline 2 & & & 0,20 & $0,206(22)$ & $0,696(23)$ & $0,974(32)$ & $0,196(23)$ & $0,237(16)$ & $141(2)$ & $237(2)$ \\
\hline 3 & & & 0,40 & $0,058(11)$ & $0,555(11)$ & $0,752(21)$ & $0,055(11)$ & $0,126(11)$ & $31(7)$ & $97(1)$ \\
\hline 4 & & & 0,60 & $0,047(00)$ & $0,544(00)$ & $0,774(01)$ & $0,044(00)$ & $0,137(01)$ & $24(0)$ & $108(1)$ \\
\hline 5 & & & 0,80 & $0,047(00)$ & $0,543(00)$ & $0,806(01)$ & $0,043(00)$ & $0,153(00)$ & $24(0)$ & $126(1)$ \\
\hline 6 & & & 1,00 & $0,047(00)$ & $0,542(00)$ & $0,833(01)$ & $0,042(00)$ & $0,166(00)$ & $23(0)$ & $142(1)$ \\
\hline 7 & \multirow{6}{*}{0,60} & \multirow{6}{*}{0,100} & 0,00 & $0,348(20)$ & $0,853(21)$ & $1,000(00)$ & $0,353(21)$ & $0,250(00)$ & $309(2)$ & $256(0)$ \\
\hline 8 & & & 0,20 & $0,207(19)$ & $0,706(20)$ & $0,979(25)$ & $0,206(20)$ & $0,240(13)$ & $149(1)$ & $241(1)$ \\
\hline 9 & & & 0,40 & $0,096(00)$ & $0,593(00)$ & $0,828(01)$ & $0,093(00)$ & $0,164(01)$ & $57(0)$ & $139(1)$ \\
\hline 10 & & & 0,60 & $0,096(00)$ & $0,592(00)$ & $0,870(01)$ & $0,092(00)$ & $0,185(01)$ & $56(0)$ & $165(1)$ \\
\hline 11 & & & 0,80 & $0,096(00)$ & $0,591(00)$ & $0,903(01)$ & $0,091(00)$ & $0,201(01)$ & $55(0)$ & $186(1)$ \\
\hline 12 & & & 1,00 & $0,096(00)$ & $0,591(00)$ & $0,929(01)$ & $0,091(00)$ & $0,215(00)$ & $55(0)$ & $204(1)$ \\
\hline 13 & \multirow{6}{*}{0,65} & \multirow{6}{*}{0,150} & 0,00 & $0,351(15)$ & $0,856(16)$ & $1,000(00)$ & $0,356(16)$ & $0,250(00)$ & $312(1)$ & $256(0)$ \\
\hline 14 & & & 0,20 & $0,213(18)$ & $0,712(18)$ & $0,985(20)$ & $0,212(18)$ & $0,243(10)$ & $155(1)$ & $245(1)$ \\
\hline 15 & & & 0,40 & $0,145(00)$ & $0,642(00)$ & $0,925(01)$ & $0,142(00)$ & $0,212(01)$ & $93(0)$ & 201(1) \\
\hline 16 & & & 0,60 & $0,145(00)$ & $0,641(00)$ & $0,966(01)$ & $0,141(00)$ & $0,233(00)$ & $93(0)$ & 231(1) \\
\hline 17 & & & 0,80 & $0,145(00)$ & $0,640(00)$ & $0,997(01)$ & $0,140(00)$ & $0,248(00)$ & $92(0)$ & $254(1)$ \\
\hline 18 & & & 1,00 & $0,145(00)$ & $0,640(00)$ & $1,000(00)$ & $0,140(00)$ & $0,250(00)$ & $92(0)$ & $256(0)$ \\
\hline 19 & \multirow{6}{*}{0,70} & \multirow{6}{*}{0,200} & 0,00 & $0,354(16)$ & $0,858(17)$ & $1,000(00)$ & $0,358(17)$ & $0,250(00)$ & $315(2)$ & $256(0)$ \\
\hline 20 & & & 0,20 & $0,222(13)$ & $0,720(13)$ & $0,998(05)$ & $0,220(13)$ & $0,249(02)$ & $163(1)$ & $255(4)$ \\
\hline 21 & & & 0,40 & $0,194(00)$ & $0,691(00)$ & $1,000(00)$ & $0,191(00)$ & $0,250(00)$ & $136(0)$ & $256(0)$ \\
\hline 22 & & & 0,60 & $0,194(00)$ & $0,691(00)$ & $1,000(00)$ & $0,191(00)$ & $0,250(00)$ & $136(0)$ & $256(0)$ \\
\hline 23 & & & 0,80 & $0,194(00)$ & $0,691(00)$ & $1,000(00)$ & $0,191(00)$ & $0,250(00)$ & $136(0)$ & $256(0)$ \\
\hline 24 & & & 1,00 & $0,194(00)$ & $0,691(00)$ & $1,000(00)$ & $0,191(00)$ & $0,250(00)$ & $136(0)$ & $256(0)$ \\
\hline 25 & \multirow{6}{*}{0,75} & \multirow{6}{*}{0,250} & 0,00 & $0,351(16)$ & $0,854(16)$ & $1,000(00)$ & $0,354(16)$ & $0,250(00)$ & $310(2)$ & $256(0)$ \\
\hline 26 & & & 0,20 & $0,244(04)$ & $0,744(04)$ & $1,000(00)$ & $0,244(04)$ & $0,250(00)$ & $186(4)$ & $256(0)$ \\
\hline 27 & & & 0,40 & $0,243(00)$ & $0,743(00)$ & $1,000(00)$ & $0,243(00)$ & $0,250(00)$ & $185(0)$ & $256(0)$ \\
\hline 28 & & & 0,60 & $0,243(00)$ & $0,743(00)$ & $1,000(00)$ & $0,243(00)$ & $0,250(00)$ & $185(0)$ & $256(0)$ \\
\hline 29 & & & 0,80 & $0,243(00)$ & $0,743(00)$ & $1,000(00)$ & $0,243(00)$ & $0,250(00)$ & $185(0)$ & $256(0)$ \\
\hline 30 & & & 1,00 & $0,243(00)$ & $0,743(00)$ & $1,000(00)$ & $0,243(00)$ & $0,250(00)$ & $185(0)$ & $256(0)$ \\
\hline 31 & \multirow{6}{*}{0,80} & \multirow{6}{*}{0,300} & 0,00 & $0,355(12)$ & $0,859(13)$ & $1,000(00)$ & $0,359(13)$ & $0,250(00)$ & $316(1)$ & $256(0)$ \\
\hline 32 & & & 0,20 & $0,293(00)$ & $0,794(00)$ & $1,000(00)$ & $0,294(00)$ & $0,250(00)$ & $239(0)$ & $256(0)$ \\
\hline 33 & & & 0,40 & $0,293(00)$ & $0,794(00)$ & $1,000(00)$ & $0,294(00)$ & $0,250(00)$ & $239(0)$ & $256(0)$ \\
\hline 34 & & & 0,60 & $0,293(00)$ & $0,794(00)$ & $1,000(00)$ & $0,294(00)$ & $0,250(00)$ & $239(0)$ & $256(0)$ \\
\hline 35 & & & 0,80 & $0,293(00)$ & $0,794(00)$ & $1,000(00)$ & $0,294(00)$ & $0,250(00)$ & $239(0)$ & $256(0)$ \\
\hline 36 & & & 1,00 & $0,293(00)$ & $0,794(00)$ & $1,000(00)$ & $0,294(00)$ & $0,250(00)$ & $239(0)$ & $256(0)$ \\
\hline
\end{tabular}

Tabela 10: Reinterpretação dos resultados da tabela 1 do modelo desordenado. A importância do parâmetro $\boldsymbol{\alpha}$ é notada pelos resultados das arrecadações totais e dos bancos.
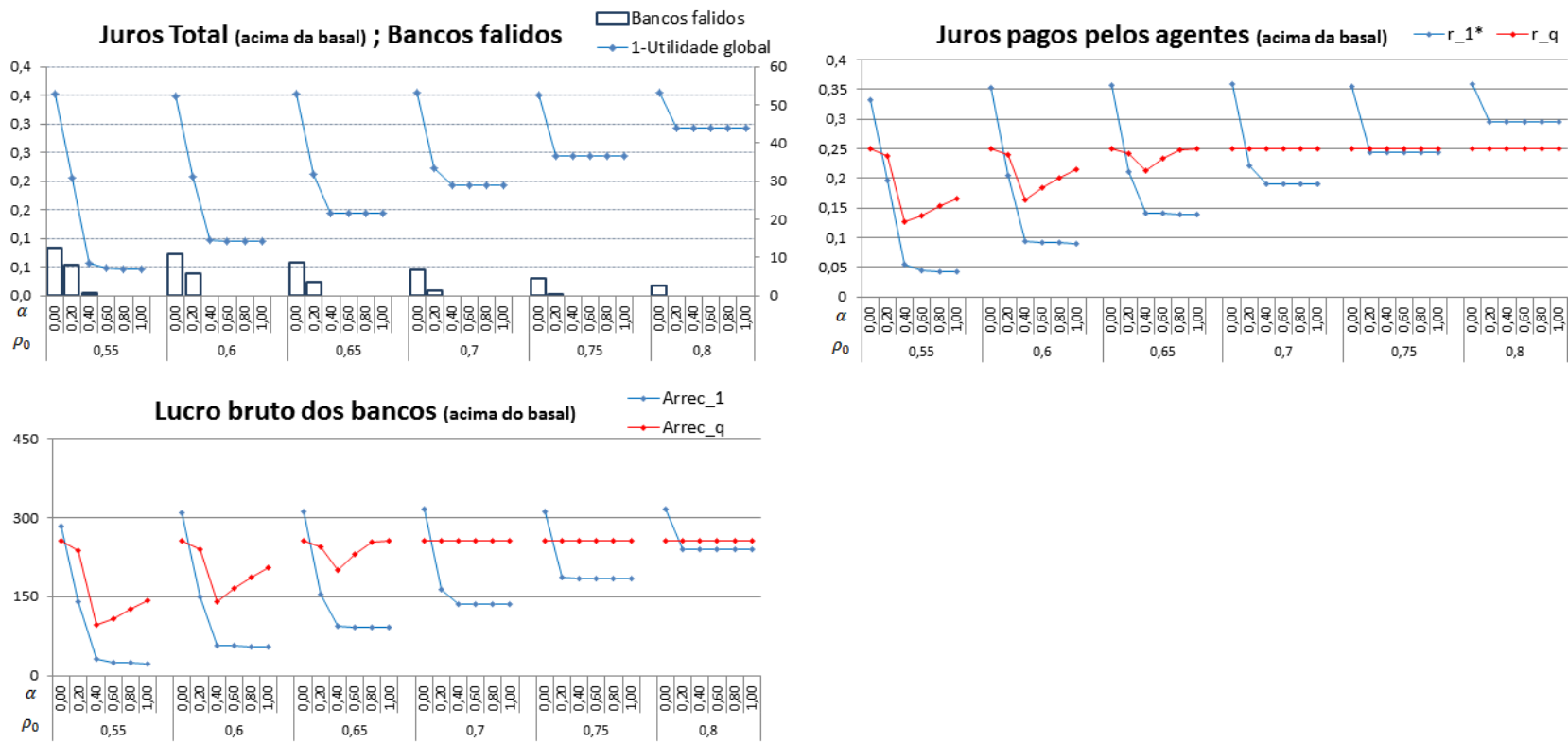

Figura 15: Gráficos com os resultados das simulações do modelo homogêneo para a portabilidade bancária 
15A: A importância do governo criar mecanismo que obriga o agente a pensar na sociedade é notada pela influencia do parâmetro $\alpha$ nos resultados da taxa total dos bancos. Mesmo quando a quantidade de tomadores de crédito é grande há risco de ter bancos fechando.

15B: Supondo dinâmica de refinanciamento, os clientes que optaram por migrar suas dívidas para o banco de taxa menor acaba pagando mais na hora de refinanciar seu empréstimo.

15C: Para o banco, fazer este tipo de manobra é vantajoso pois aumenta o número de clientes em sua carteira e passa a arrecadar mais que os demais bancos.

\section{b. Cenário segregado}

Essa é a situação que mais se aproxima da realidade por conta da densidade de tomadores de crédito no mercado ser baixa (o relatório de 2013 de economia bancária e crédito do Banco de Central do Brasil mostra que as operações com recursos livres correspondem a $55,6 \%$ da carteira total do sistema financeiro e a $31,1 \%$ do PIB) e não existir taxa da portabilidade. À medida que $\alpha$ cresce, menos agentes migram para o banco que aderiu a guerra da taxa, deixando seus bancos originais mais próximos do valor ótimo de ocupação (do ponto de vista dos clientes). Isto faz com que a arrecadação com juros destes bancos diminua cada vez mais, ou seja, na situação de equilíbrio vemos que os clientes que permaneceram nos bancos que não aderiram à disputa terão taxas de juros menores do que a inicial e os que mudaram para $Q_{- \text {esimo }}$ banco pagarão mais por isso.

Novamente, para este banco apesar do aumento do custo operacional, será vantagem, a longo prazo, fazer esta ação pois o ganho aumenta consideravelmente se comparado com os aqueles que mantiveram suas taxas. Notamos que este ambiente é mais suscetível à criação de oligopólio, pois quantidade de bancos esvaziados (falidos) nesta configuração é maior do que no caso uniforme (coluna $Q_{v a z i o}$ das tabelas 9 e 11) 


\begin{tabular}{|c|c|c|c|c|c|c|c|c|c|c|c|c|}
\hline \multirow[b]{2}{*}{ Simulação } & \multirow[b]{2}{*}{$\rho_{0}$} & \multirow[b]{2}{*}{$U_{0}^{*}$} & \multirow[b]{2}{*}{$\alpha$} & \multicolumn{8}{|c|}{ Resultados das simulações } & \\
\hline & & & & $\overline{U^{*}}$ & $\overline{\rho_{2}}$ & $\overline{\rho_{Q}}$ & $\overline{r_{2}}$ & $\overline{r_{Q}}$ & $\overline{A_{B 2}}$ & $\overline{A_{B Q}}$ & $\overline{Q_{\text {vazio }}}$ & రె \\
\hline 1 & & & 0,013 & $0,367(00)$ & $0,886(00)$ & $1,000(00)$ & $0,386(00)$ & $0,250(00)$ & $350(0)$ & $256(0)$ & $28,0(0)$ & 웅 \\
\hline 2 & & & 0,124 & $0,367(00)$ & $0,886(00)$ & $1,000(00)$ & $0,386(00)$ & $0,250(00)$ & $350(0)$ & $256(0)$ & $28,0(0)$ & E \\
\hline 3 & & & 0,221 & $0,311(48)$ & $0,821(55)$ & $1,000(00)$ & $0,321(55)$ & $0,250(00)$ & $273(6)$ & $256(0)$ & $27,4(5)$ & 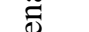 \\
\hline 4 & 0,20 & 0,60 & 0,305 & $0,220(39)$ & $0,716(44)$ & $0,989(23)$ & $0,216(44)$ & $0,245(12)$ & $161(4)$ & $248(1)$ & $26,3(5)$ & ¿ \\
\hline 5 & & & 0,378 & $0,165(29)$ & $0,656(29)$ & $0,941(52)$ & $0,156(29)$ & $0,221(26)$ & $106(2)$ & $214(3)$ & $25,4(5)$ & 0 \\
\hline 6 & & & 0,441 & $0,127(31)$ & $0,618(31)$ & $0,885(56)$ & $0,118(31)$ & $0,193(28)$ & $76(2)$ & $176(3)$ & $24,8(6)$ & $=$ \\
\hline 7 & & & 0,497 & $0,094(32)$ & $0,585(31)$ & $0,834(62)$ & $0,085(31)$ & $0,167(31)$ & $52(2)$ & $145(3)$ & $24,1(7)$ & $\frac{\pi}{\partial}$ \\
\hline 8 & & & 0,079 & $0,345(38)$ & $0,857(43)$ & $1,000(00)$ & $0,357(43)$ & $0,250(00)$ & $315(5)$ & $256(0)$ & $25,6(5)$ & $\Xi$ \\
\hline 9 & & & 0,173 & $0,251(33)$ & $0,751(36)$ & $0,998(12)$ & $0,251(36)$ & $0,249(06)$ & 194(3) & $255(8)$ & $24,3(5)$ & $\ddot{0}$ \\
\hline 10 & & & 0,249 & $0,206(29)$ & $0,702(31)$ & $0,971(30)$ & $0,202(31)$ & $0,236(15)$ & $146(2)$ & $235(2)$ & $23,5(5)$ & \\
\hline 11 & 0,25 & 0,50 & 0,315 & $0,160(26)$ & $0,655(26)$ & $0,924(46)$ & $0,155(26)$ & $0,212(23)$ & $104(2)$ & $201(3)$ & $22,6(6)$ & \\
\hline 12 & & & 0,373 & $0,124(25)$ & $0,618(24)$ & $0,870(48)$ & $0,118(24)$ & $0,185(24)$ & $75(1)$ & $166(3)$ & $21,8(6)$ & \\
\hline 13 & & & 0,425 & $0,100(22)$ & $0,593(22)$ & $0,835(44)$ & $0,093(22)$ & $0,167(22)$ & $57(1)$ & $144(2)$ & $21,2(6)$ & \\
\hline 14 & & & 0,472 & $0,070(19)$ & $0,563(19)$ & $0,785(38)$ & $0,063(19)$ & $0,142(19)$ & $36(1)$ & $115(2)$ & $20,4(6)$ & $\Xi$ \\
\hline 15 & & & 0,073 & $0,332(36)$ & $0,841(40)$ & $1,000(00)$ & $0,341(40)$ & $0,250(00)$ & $295(4)$ & $256(0)$ & $23,3(6)$ & $\Xi$ \\
\hline 16 & & & 0,144 & $0,275(28)$ & $0,778(31)$ & $1,000(00)$ & $0,278(31)$ & $0,250(00)$ & $222(3)$ & $256(0)$ & $22,4(5)$ & $\nabla$ \\
\hline 17 & & & 0,209 & $0,219(27)$ & $0,717(29)$ & $0,985(22)$ & $0,217(29)$ & $0,242(11)$ & $160(2)$ & $245(1)$ & $21,3(6)$ & 0 \\
\hline 18 & & & 0,267 & $0,185(22)$ & $0,680(22)$ & $0,961(42)$ & $0,180(22)$ & $0,230(21)$ & $126(1)$ & $228(3)$ & $20,5(5)$ & 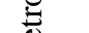 \\
\hline 19 & 0,30 & 0,40 & 0,321 & $0,154(21)$ & $0,649(21)$ & $0,916(39)$ & $0,149(21)$ & $0,208(20)$ & $100(1)$ & $196(2)$ & $19,8(6)$ & $\stackrel{0}{0}$ \\
\hline 20 & & & 0,369 & $0,127(22)$ & $0,621(22)$ & $0,875(44)$ & $0,121(22)$ & $0,188(22)$ & $78(1)$ & $169(2)$ & $19,0(6)$ & <हี \\
\hline 21 & & & 0,414 & $0,097(21)$ & $0,591(21)$ & $0,826(42)$ & $0,091(21)$ & $0,163(21)$ & $56(1)$ & $139(2)$ & $18,1(7)$ & E \\
\hline 22 & & & 0,454 & $0,068(16)$ & $0,563(16)$ & $0,780(32)$ & $0,063(16)$ & $0,140(16)$ & $36(1)$ & $113(1)$ & $17,2(6)$ & \\
\hline 23 & & & 0,491 & $0,055(21)$ & $0,549(21)$ & $0,762(42)$ & $0,049(21)$ & $0,131(21)$ & $28(1)$ & $103(2)$ & $16,7(8)$ & 음 \\
\hline 24 & & & 0,044 & $0,348(31)$ & $0,857(34)$ & $1,000(00)$ & $0,357(34)$ & $0,250(00)$ & $314(4)$ & $256(0)$ & $21,4(5)$ & 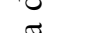 \\
\hline 25 & & & 0,113 & $0,293(27)$ & $0,797(29)$ & $1,000(01)$ & $0,297(29)$ & $0,250(00)$ & $243(3)$ & $256(1)$ & $20,4(5)$ & $\cdot \frac{\pi}{0}$ \\
\hline 26 & & & 0,176 & $0,241(24)$ & $0,741(26)$ & $0,998(12)$ & $0,241(26)$ & $0,249(06)$ & $183(2)$ & $254(9)$ & $19,3(6)$ & $\Xi$ \\
\hline 27 & & & 0,231 & $0,205(22)$ & $0,703(23)$ & $0,976(26)$ & $0,203(23)$ & $0,238(13)$ & $146(2)$ & $239(1)$ & $18,4(6)$ & 丞 \\
\hline 28 & & & 0,280 & $0,179(20)$ & $0,675(20)$ & $0,953(33)$ & $0,175(20)$ & $0,227(17)$ & $122(1)$ & $222(2)$ & $17,7(6)$ & రె \\
\hline 29 & 0,35 & 0,30 & 0,325 & $0,146(22)$ & $0,641(21)$ & $0,903(42)$ & $0,141(21)$ & $0,202(21)$ & $93(1)$ & $187(2)$ & $16,7(7)$ & 气 \\
\hline 30 & & & 0,367 & $0,113(21)$ & $0,608(20)$ & $0,849(41)$ & $0,108(20)$ & $0,175(20)$ & $68(1)$ & $153(2)$ & $15,7(7)$ &.$\Xi$ \\
\hline 31 & & & 0,405 & $0,092(23)$ & $0,588(23)$ & $0,818(46)$ & $0,088(23)$ & $0,159(23)$ & $53(1)$ & $134(2)$ & $14,9(9)$ & $\varangle$ \\
\hline 32 & & & 0,441 & $0,063(23)$ & $0,559(22)$ & $0,767(48)$ & $0,059(22)$ & $0,134(24)$ & $34(1)$ & $106(2)$ & $13,8(0)$ & \\
\hline 33 & & & 0,474 & $0,049(19)$ & $0,544(19)$ & $0,747(37)$ & $0,044(19)$ & $0,124(19)$ & $25(1)$ & $95(1)$ & $13,2(8)$ & $\dot{0}$ \\
\hline 34 & & & 0,047 & $0,651(28)$ & $0,857(30)$ & $1,000(00)$ & $0,357(30)$ & $0,250(00)$ & $314(3)$ & $256(0)$ & $19,3(6)$ & 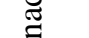 \\
\hline 35 & & & 0,102 & $0,699(25)$ & $0,805(27)$ & $1,000(00)$ & $0,305(27)$ & $0,250(00)$ & $252(3)$ & $256(0)$ & $18,3(6)$ & $\frac{1}{0}$ \\
\hline 36 & & & 0,154 & $0,740(21)$ & $0,760(23)$ & $0,999(04)$ & $0,260(23)$ & $0,250(02)$ & $203(2)$ & $256(3)$ & $17,4(5)$ & \\
\hline 37 & & & 0,202 & $0,773(24)$ & $0,726(25)$ & $0,993(14)$ & $0,226(25)$ & $0,246(07)$ & $168(2)$ & 250(1) & $16,5(6)$ & 5 \\
\hline 38 & & & 0,247 & $0,809(24)$ & $0,688(24)$ & $0,966(39)$ & $0,188(24)$ & $0,233(19)$ & $133(2)$ & $231(2)$ & $15,5(7)$ & 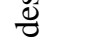 \\
\hline 39 & & & 0,289 & $0,833(19)$ & $0,663(19)$ & $0,934(34)$ & $0,163(19)$ & $0,217(17)$ & $111(1)$ & $208(2)$ & $14,7(6)$ & \\
\hline 40 & 0,40 & 0,20 & 0,329 & $0,864(19)$ & $0,633(19)$ & $0,887(37)$ & $0,133(19)$ & $0,194(19)$ & $86(1)$ & $176(2)$ & $13,6(7)$ & \\
\hline 41 & & & 0,365 & $0,891(20)$ & $0,605(20)$ & $0,843(39)$ & $0,105(20)$ & $0,171(19)$ & $66(1)$ & $149(2)$ & $12,6(8)$ & \\
\hline 42 & & & 0,399 & $0,912(15)$ & $0,584(15)$ & $0,809(29)$ & $0,084(15)$ & $0,154(15)$ & $50(1)$ & $128(1)$ & $11,7(6)$ & 5 \\
\hline 43 & & & 0,431 & $0,929(17)$ & $0,566(17)$ & $0,782(33)$ & $0,066(17)$ & $0,141(17)$ & $39(1)$ & $114(1)$ & $10,9(8)$ & \\
\hline 44 & & & 0,460 & $0,958(18)$ & $0,538(18)$ & $0,732(36)$ & $0,038(18)$ & $0,116(18)$ & $21(1)$ & $88(1)$ & $9,6(9)$ & 웅 \\
\hline 45 & & & 0,488 & $0,978(15)$ & $0,517(15)$ & $0,679(72)$ & $0,019(14)$ & $0,090(36)$ & $10(8)$ & $65(2)$ & $8,5(9)$ & + \\
\hline 46 & & & 0,025 & $0,633(23)$ & $0,875(24)$ & $1,000(00)$ & $0,375(24)$ & $0,250(00)$ & $337(3)$ & $256(0)$ & $17,6(5)$ & $\frac{\pi}{\pi}$ \\
\hline 47 & & & 0,079 & $0,687(28)$ & $0,817(30)$ & $1,000(00)$ & $0,317(30)$ & $0,250(00)$ & $267(3)$ & $256(0)$ & $16,4(7)$ & $\frac{\pi}{0}$ \\
\hline 48 & & & 0,130 & $0,723(21)$ & $0,779(23)$ & $1,000(01)$ & $0,279(23)$ & $0,250(00)$ & $223(2)$ & $256(0)$ & $15,5(6)$ & है \\
\hline 49 & & & 0,177 & $0,762(19)$ & $0,737(20)$ & $0,998(08)$ & $0,237(20)$ & $0,249(04)$ & $179(2)$ & $255(6)$ & $14,4(6)$ & $\stackrel{\Xi}{\Xi}$ \\
\hline 50 & & & 0,221 & $0,792(18)$ & $0,706(19)$ & $0,982(22)$ & $0,206(19)$ & $0,241(11)$ & $150(1)$ & $243(1)$ & $13,4(6)$ & $\pi$ \\
\hline 51 & & & 0,260 & $0,812(19)$ & $0,685(20)$ & $0,965(32)$ & $0,185(20)$ & $0,232(16)$ & $130(1)$ & $230(2)$ & $12,7(7)$ & 0 \\
\hline 52 & 0,45 & 0,90 & 0,331 & $0,868(22)$ & $0,629(22)$ & $0,880(44)$ & $0,129(22)$ & $0,190(22)$ & $83(1)$ & $172(2)$ & $10,6(9)$ & 0 \\
\hline 53 & & & 0,364 & $0,893(18)$ & $0,604(18)$ & $0,839(36)$ & $0,104(18)$ & $0,170(18)$ & $65(1)$ & $147(2)$ & $9,5(8)$ & శ్ర \\
\hline 54 & & & 0,394 & $0,914(16)$ & $0,583(16)$ & $0,805(32)$ & $0,083(16)$ & $0,153(16)$ & $50(1)$ & $126(1)$ & $8,6(8)$ & 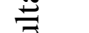 \\
\hline 55 & & & 0,423 & $0,941(16)$ & $0,555(16)$ & $0,758(31)$ & $0,055(16)$ & $0,129(16)$ & $32(1)$ & $101(1)$ & $7,2(8)$ & $\overrightarrow{7}$ \\
\hline 56 & & & 0,449 & $0,962(17)$ & $0,535(16)$ & $0,723(33)$ & $0,035(16)$ & $0,112(17)$ & $19(1)$ & $83(1)$ & $6,0(0)$ & 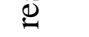 \\
\hline 57 & & & 0,475 & $0,980(15)$ & $0,516(15)$ & $0,693(29)$ & $0,016(15)$ & $0,096(15)$ & $9(8)$ & $69(1)$ & $4,9(9)$ & $\sqrt{n}$ \\
\hline 58 & & & 0,498 & $0,991(08)$ & $0,506(08)$ & $0,677(16)$ & $0,006(08)$ & $0,088(08)$ & $3(4)$ & $61(7)$ & $4,3(5)$ & 음 \\
\hline 59 & & & 0,030 & $0,669(22)$ & $0,836(23)$ & $1,000(00)$ & $0,336(23)$ & $0,250(00)$ & $288(2)$ & $256(0)$ & $14,6(6)$ & \\
\hline 60 & & & 0,076 & $0,710(20)$ & $0,793(21)$ & $1,000(00)$ & $0,293(21)$ & $0,250(00)$ & $238(2)$ & $256(0)$ & $13,5(6)$ & \\
\hline 61 & & & 0,119 & $0,736(21)$ & $0,765(22)$ & $0,999(04)$ & $0,265(22)$ & $0,250(02)$ & $208(2)$ & $256(3)$ & $12,8(7)$ & \\
\hline 62 & & & 0,160 & $0,772(20)$ & $0,728(21)$ & $0,990(17)$ & $0,228(21)$ & $0,245(09)$ & $170(2)$ & $248(1)$ & $11,6(7)$ & \\
\hline 63 & & & 0,198 & $0,790(21)$ & $0,708(22)$ & $0,980(26)$ & $0,208(22)$ & $0,240(13)$ & $151(2)$ & $241(1)$ & $10,9(8)$ & \\
\hline 64 & & & 0,235 & $0,823(18)$ & $0,674(18)$ & $0,940(33)$ & $0,174(18)$ & $0,220(17)$ & $121(1)$ & $212(2)$ & $9,7(7)$ & \pm \\
\hline 65 & & & 0,270 & $0,851(16)$ & $0,646(15)$ & $0,897(31)$ & $0,146(15)$ & $0,198(15)$ & $97(1)$ & $183(2)$ & $8,5(7)$ & $=$ \\
\hline 66 & 0,50 & 0,00 & 0,302 & $0,883(19)$ & $0,615(19)$ & $0,844(38)$ & $0,115(19)$ & $0,172(19)$ & $73(1)$ & $149(2)$ & $7,1(9)$ & $\bar{\alpha}$ \\
\hline 67 & & & 0,333 & $0,902(20)$ & $0,595(20)$ & $0,814(39)$ & $0,095(20)$ & $0,157(20)$ & $58(1)$ & $131(2)$ & $6,1(0)$ & \\
\hline 68 & & & 0,362 & $0,928(17)$ & $0,569(17)$ & $0,770(33)$ & $0,069(17)$ & $0,135(17)$ & $41(1)$ & $107(1)$ & $4,7(0)$ & \\
\hline 69 & & & 0,390 & $0,952(15)$ & $0,546(15)$ & $0,730(31)$ & $0,046(15)$ & $0,115(15)$ & $26(9)$ & $87(1)$ & $3,3(9)$ & \\
\hline 70 & & & 0,416 & $0,972(10)$ & $0,525(10)$ & $0,697(20)$ & $0,025(10)$ & $0,098(10)$ & $14(6)$ & $71(9)$ & $2,1(7)$ & \\
\hline 71 & & & 0,441 & $0,985(10)$ & $0,512(10)$ & $0,649(72)$ & $0,012(10)$ & $0,075(36)$ & $7(5)$ & $52(2)$ & $1,1(7)$ & $\overline{8}$ \\
\hline 72 & & & 0,464 & $0,994(09)$ & $0,505(07)$ & $0,569(89)$ & $0,005(07)$ & $0,034(45)$ & $2(4)$ & $24(3)$ & $0,4(6)$ & है \\
\hline 73 & & & 0,486 & $0,996(06)$ & $0,503(05)$ & $0,551(83)$ & $0,003(05)$ & $0,026(42)$ & $2(3)$ & $18(2)$ & $0,3(5)$ & $E$ \\
\hline
\end{tabular}



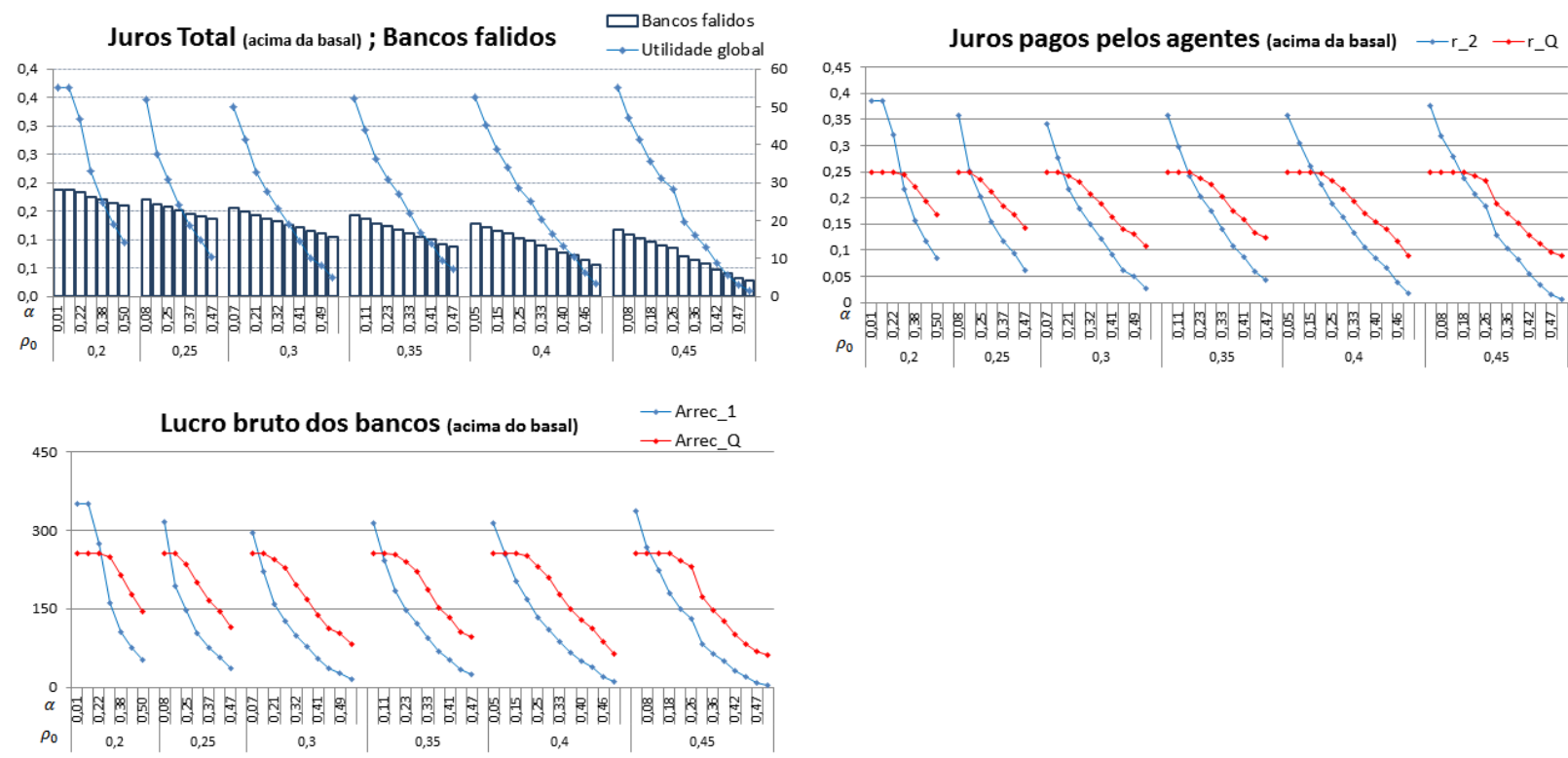

Figura 16: Gráficos com os resultados das simulações do modelo segregado para a portabilidade bancária

16A: No modelo segregado o é ainda maior a necessidade de criar mecanismo que obriga o agente a pensar na sociedade. À medida que $\alpha$ cresce a taxa de juros cobrada pelos bancos tendem ao valor $r_{0}$ próximo do basal. 16B: Novamente, supondo dinâmica de refinanciamento, os clientes que optaram por migrar suas dívidas para o banco de taxa menor acaba pagando mais na hora de refinanciar seu empréstimo, exceto no limite egoísta.

16C: Somente no limite altruísta o banco com incentivo arrecada menos que os outros

Uma manobra para evitar a falência de um banco que fora esvaziado é reduzir sua taxa de juros, mesmo não tendo carteira, para atrair os primeiros clientes mesmo correndo o risco de ter seu spread zerado. Lembrando dos resultados da tabela 6 da guerra fiscal, para que o banco atraia clientes dos bancos que "sobreviveram" a guerra ele deverá reduzir sua taxa para o valor menor ou igual a taxa de equilíbrio dos demais bancos e isso nem sempre é uma manobra sustentável.

Conclui-se, com as idealizações e simplificações do modelo, que o cenário de portabilidade bancária pode se tornar perigoso se não houver outra regulamentação que impeça trocas sucessivas de empréstimos por parte dos clientes. Umas das opções seria - Banco Central limitar a quantidade de vezes que um cliente poderia portar sua dívida; outra seria a criação de uma taxa de portabilidade que o tomador pagaria a cada troca. Estas manobras garantiriam a sustentabilidade de todos os bancos no mercado financeiro. 
Este é apenas um exemplo qualitativo de como podemos aplicar os modelos apresentados nos capítulos 2 e 3 a um sistema de micro economia. Estes modelos, mesmo que incompletos, ajudam a nortear quais situações possíveis a que determinados comportamentos podem conduzir. 


\section{Outros tipos de funções utilidade}

A função utilidade apropriada para um modelo pode ser determinada com base em algum estudo fenomenológico. De um ponto de vista sociológico, a origem das funções utilidade dos agentes é essencial e elas podem depender de aspectos sociais, culturais ou econômicos.

Neste trabalho usamos a mesma função utilidade pico-assimétrica escolhida por Grauwin et al. É plausível usarmos esta função no modelo de guerra fiscal, pois um Estado vazio carece de fornecedores próximos, mão de obra qualificada e infraestrutura. À medida que a densidade de indústrias em uma determinada região aumenta, esse Estado atrairá fornecedores e mão de obra, aumentando a utilidade das empresas que ali fixaram base. No entanto, quando a quantidade de indústrias for suficientemente grande há uma redução da utilidade por conta do aumento da concorrência e redução da margem de lucro das empresas.

Para o estudo da portabilidade bancária, a função utilidade adotada foi uma oposta à função pico-assimétrica do modelo de Grauwin. A interpretação é a seguinte: um banco com densidade nula possui uma taxa de juros alta por carecer de clientes superavitários na sua carteira. À medida que a carteira aumenta, o "custo" do dinheiro fica menor para esta instituição, pois existe um balanceamento saudável entre clientes deficitários e superavitários, o que possibilita ao banco reduzir suas taxas de juros. Após uma determinada densidade limite a carga de risco cresce, atribuída ao crescimento da carteira de clientes deficitários, obrigando o banco a aumentar suas taxas de juros.

Este trabalho pode ser generalizado para outros tipos de funções utilidade, ampliando sua aplicação a outros fenômenos econômicos (ou até mesmo permitindo outra abordagem dos fenômenos discutidos aqui). Listaremos a seguir algumas das funções conhecidas na literatura. 
A

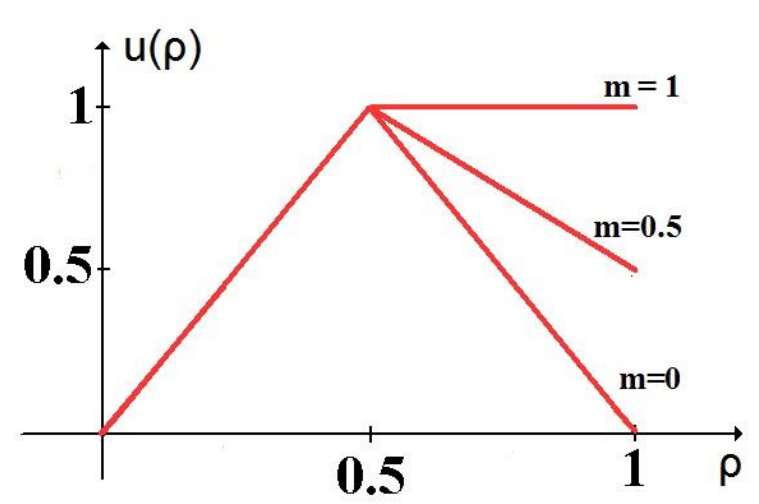

C

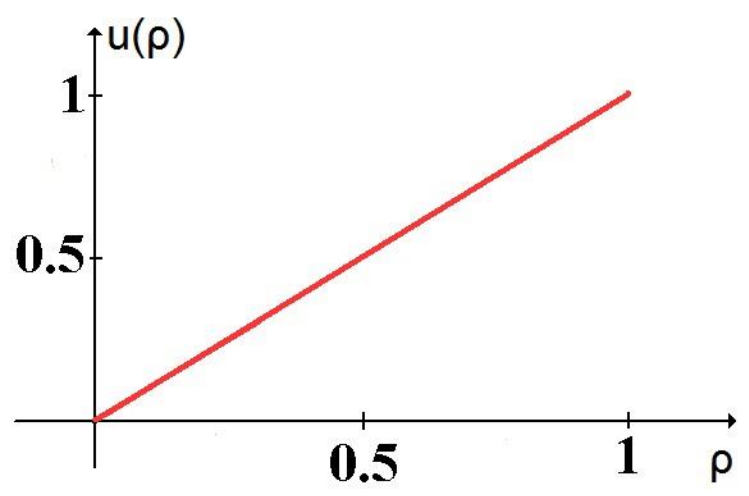

B

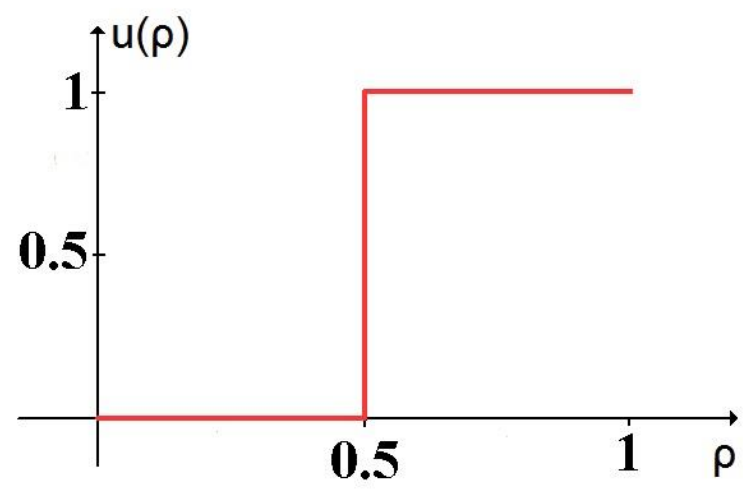

D

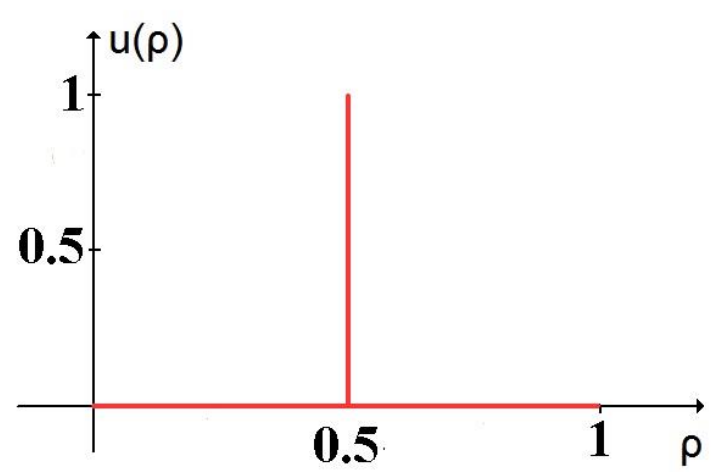

Figura 17: Ref [12] - Algumas funções utilidade conhecidas na literatura

\section{A. Função pico-assimétrica}

Função utilidade usada por Grauwin [3] que indica que os agentes preferem viver em blocos com densidade 0,5 e possui um parâmetro de assimetria $m$, que mede a satisfação do agente quando o bloco estiver totalmente ocupado.

\section{B. Função utilidade degrau}

Função utilidade semelhante à função binária usada no modelo de Schelling que indica que os agentes atinge a satisfação máxima ao ultrapassar uma densidade limite, chamada de threshold rule.

\section{Função utilidade linear}

Função estudada por Grauwin et al [12] que indica que a utilidade dos agentes aumenta linearmente com a densidade de agentes. 


\section{Função pico-simples}

Função estudada por Grauwin et al [12] que indica que os agentes só ficarão satisfeito somente quando o bloco tiver com uma densidade específica, no caso $\rho=0,5$.

\begin{tabular}{|c|c|c|c|c|c|}
\hline \multirow[b]{2}{*}{ Simulação } & \multirow[b]{2}{*}{ Função Utilidade } & \multirow[b]{2}{*}{$\alpha$} & \multicolumn{3}{|c|}{ Resultados das simulações } \\
\hline & & & $\overline{\rho_{1}}$ & $\overline{u_{1}}$ & $\overline{Q_{\text {vazio }}}$ \\
\hline 1 & \multirow{6}{*}{ A } & 0,154 & $0,761(25)$ & $0,739(25)$ & $17,1(6)$ \\
\hline 2 & & 0,202 & $0,723(25)$ & $0,777(25)$ & $16,1(7)$ \\
\hline 3 & & 0,247 & $0,690(21)$ & $0,810(21)$ & $15,1(6)$ \\
\hline 4 & & 0,289 & $0,670(21)$ & $0,830(21)$ & $14,5(7)$ \\
\hline 5 & & 0,329 & $0,631(23)$ & $0,869(23)$ & $13,2(8)$ \\
\hline 6 & & 0,365 & $0,607(23)$ & $0,893(23)$ & $12,3(9)$ \\
\hline 7 & \multirow{6}{*}{ B } & 0,154 & $0,960(00)$ & $1,000(00)$ & $21,0(0)$ \\
\hline 8 & & 0,202 & $0,960(00)$ & $1,000(00)$ & $21,0(0)$ \\
\hline 9 & & 0,247 & $0,960(00)$ & $1,000(00)$ & $21,0(0)$ \\
\hline 10 & & 0,289 & $0,960(00)$ & $1,000(00)$ & $21,0(0)$ \\
\hline 11 & & 0,329 & $0,960(00)$ & $1,000(00)$ & $21,0(0)$ \\
\hline 12 & & 0,365 & $0,960(00)$ & $1,000(00)$ & $21,0(0)$ \\
\hline 13 & \multirow{6}{*}{ C } & 0,154 & $0,960(00)$ & $0,960(00)$ & $21,0(0)$ \\
\hline 14 & & 0,202 & $0,960(00)$ & $0,960(00)$ & $21,0(0)$ \\
\hline 15 & & 0,247 & $0,960(00)$ & $0,960(00)$ & $21,0(0)$ \\
\hline 16 & & 0,289 & $0,960(00)$ & $0,960(00)$ & $21,0(0)$ \\
\hline 17 & & 0,329 & $0,960(00)$ & $0,960(00)$ & $21,0(0)$ \\
\hline 18 & & 0,365 & $0,960(00)$ & $0,960(00)$ & $21,0(0)$ \\
\hline 19 & \multirow{6}{*}{ D } & 0,154 & $0,400(00)$ & $0,000(00)$ & $0,0(0)$ \\
\hline 20 & & 0,202 & $0,400(00)$ & $0,000(00)$ & $0,0(0)$ \\
\hline 21 & & 0,247 & $0,400(00)$ & $0,000(00)$ & $0,0(0)$ \\
\hline 22 & & 0,289 & $0,400(00)$ & $0,000(00)$ & $0,0(0)$ \\
\hline 23 & & 0,329 & $0,400(00)$ & $0,000(00)$ & $0,0(0)$ \\
\hline 24 & & 0,365 & $0,400(00)$ & $0,000(00)$ & $0,0(0)$ \\
\hline
\end{tabular}

Tabela 12: Tabela com uma os resultados das simulações para diferentes funções utilidade. Parâmetros $\boldsymbol{m}_{\boldsymbol{a}}=\mathbf{0}, 5, \boldsymbol{H}=\mathbf{1 0 2 4}, \boldsymbol{\rho}_{\mathbf{0}}=\mathbf{0}, \mathbf{4} \boldsymbol{e} \boldsymbol{Q}=\mathbf{3 6}$. A: Função pico-assimétrica $-\mathrm{B}$ : Função degrau - C:Função linear - D: Pico-simples. Para as funções B e C o nível de segregação é maior já que o agente sempre aumenta a utilidade com o crescimento da densidade. Para a função D os agentes não mudam de bloco pois não há aumento de utilidade neste movimento.

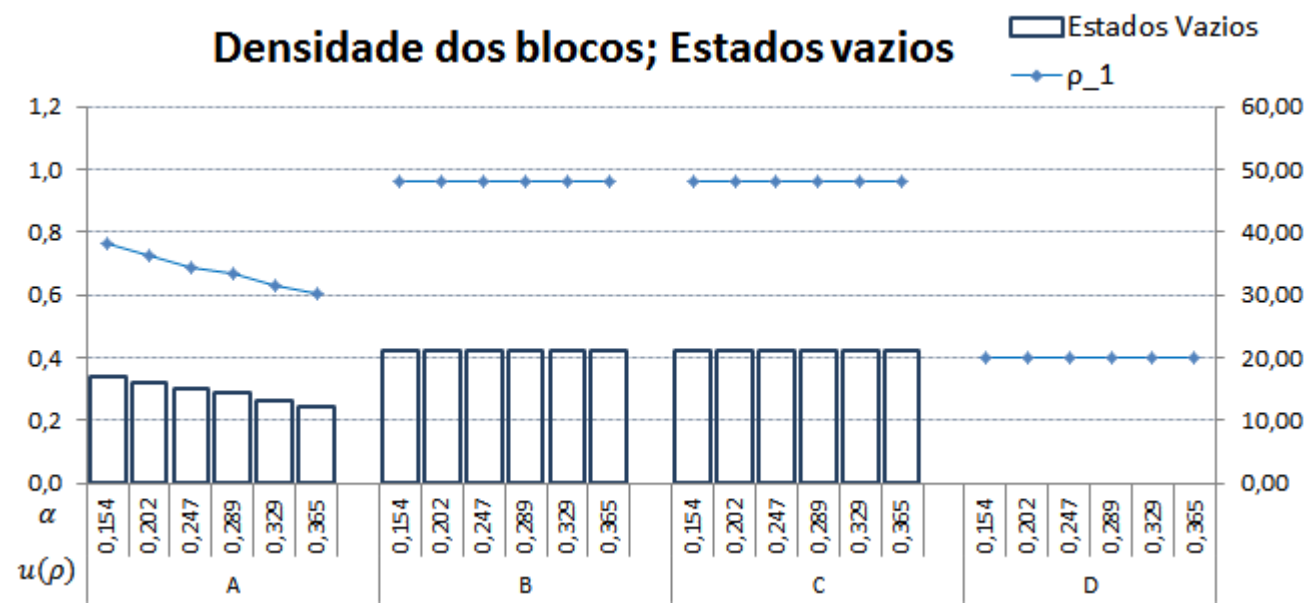

Figura 18: Gráfico com os resultados das simulações para outras funções utilidade 
A

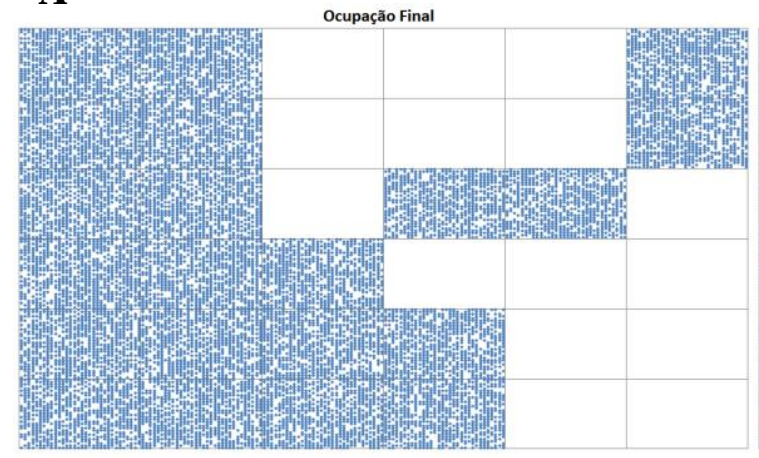

C

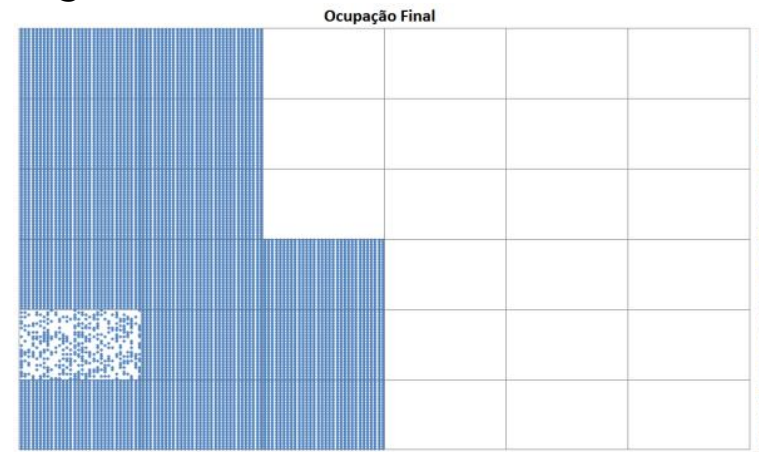

B

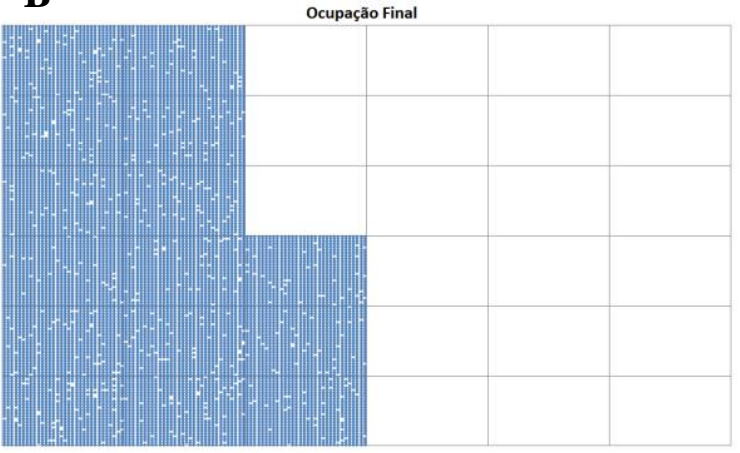

D

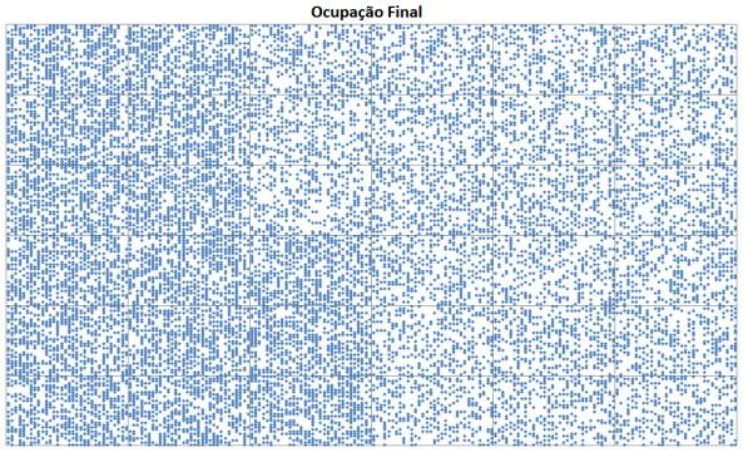

Figura 19: Simulações para diferentes tipos de funções utilidade

Os resultados para as funções $B$ e $C$ são muito parecidos, o que era esperado, já que o agente sempre vai aumenta a utilidade com o crescimento da densidade. Para a função $D$ dificilmente haverá segregação, pois os agentes não mudam de quarteirão, ou seja, $\rho_{1}=\rho_{0}$.

Estas são apenas algumas simulações, não muito exploradas, para diferentes tipos de funções utilidade. No futuro pode ser incorporado ao modelo a possibilidade usarmos outras funções. 


\section{Conclusões}

Grauwin e seus colaboradores fizeram uma generalização do modelo de segregação de Schelling incluindo uma função link, que une o comportamento individual e coletivo, existindo para qualquer $\alpha$ e permitindo tratar o problema do ponto de vista de um equilíbrio térmico. Neste trabalho inserimos uma desordem no modelo de Grauwin, considerando que um de seus blocos teria o parâmetro de ordem $m_{q}$ diferente dos demais. Sem perda de generalidade todas as deduções analíticas foram feitas e foi possível determinar, para os caso homogêneo e segregado, o valor das três densidades do sistema em equilíbrio. Todas as deduções foram conferidas com as simulações feitas em computador $(\mathrm{C}++)$.

Por conta das semelhanças destes resultados com alguns modelos econômicos, foi possível usar as deduções para estudar a dinâmica de uma guerra fiscal travada entre os estados de uma federação, onde cada bloco de Grauwin será considerando como uma unidade de uma federação.

Com os resultados das simulações vimos que onde não há segregação os agentes começam a ocupar o Estado diferente para aumentar sua utilidade, mas como há outros agentes com este mesmo comportamento, a utilidade deste Estado acaba por ficar menor do que nos demais. O lucro total no Estado com incentivo é maior que nos demais, mas existe também um alto custo de incentivo para atrair indústrias. Este custo obriga que o Estado cobre uma taxa de imposto pesada da sociedade. Ainda no caso sem segregação vimos que ter mais Estados concedendo incentivos numa generalização da guerra fiscal não é prejudicial ao país.

No caso segregado o que vimos foi que o Estado com incentivo precisa cobrar uma alíquota de imposto menor da sociedade para não ter prejuízo com a renuncia de impostos. Uma interpretação possível foi que à medida que o governo incentive um comportamento mais altruísta das indústrias elas migrarão mais facilmente para os Estados pois esta ação aumenta a arrecadação da nação (e consequentemente a satisfação da sociedade). No caso segregado vimos que perto do limite egoísta não faz diferença ter mais de um Estado dando incentivo fiscal, no entanto, à medida que o governo impõe mais altruísmo às indústrias a arrecadação do país diminui à medida que a guerra vai se generalizando. 
Outro cenário que analisamos foi como se comportarão os agentes se um Estado, após o equilíbrio, der incentivos fiscais para atrair as primeiras empresas. Para o Estado que fora esvaziado abrir mão dos impostos só é vantagem porque isto tira sua arrecadação do zero, pois seu custo de incentivo é extremamente alto fazendo com que a carga de imposto sobre a sociedade que optou por viver ali seja altíssima. Mas para o país essa ação reduz o numero de Estados vazios, o que é vantajoso, por isso podemos observar um aumento na utilidade global com esta ação.

Uma análise geral de todos os resultados nos leva a acreditar que o cenário de centralização industrial obriga os Estados a utilizarem a guerra fiscal na tentativa de mudar este quadro. Se a centralização industrial se mantiver, a guerra fiscal tende a se tornar um elemento ainda mais importante para um Estado vazio, surgindo como única alternativa de auto defesa na tentativa de buscar reverter o cenário de segregação, reduzindo o número de Estados desocupados. No entanto, os custos de incentivos dos Estados que aderem a guerra é tão alto que estes Estados deverão ter uma alíquota de imposto pesada para que a ação seja vantajosa.

Uma reinterpretação destes resultados pôde ser aplicada ao modelo de portabilidade de crédito bancário, onde a dinâmica que rege os clientes tomadores de empréstimos em busca de reduzir suas taxas é a mesma dinâmica das indústrias que visam aumentar seus lucros.

No caso homogêneo, como o governo criou meio de inibir as movimentações $(\alpha>0)$ e existe uma quantidade suficiente de tomadores no mercado, todos os bancos sobreviveram, mas pudemos observar que o rendimento total dos bancos reduziu quando comparado com o modelo uniforme.

No caso segregado, no limite em que $\alpha \sim 0$, a dinâmica leva a um cenário onde apenas alguns bancos sobreviverão e no âmbito geral a taxa de juros cobrada dos clientes reduz, fazendo com que a guerra da taxa beneficie os tomadores de crédito e prejudique a saúde do sistema financeiro. Os aqueles clientes que optaram por trocar de banco terão uma taxa de juros maior do que os que decidiram ficar no banco em que estava.

A importância do parâmetro $\alpha$ é notada nas simulações, já que, à medida que $\alpha$ cresce menos o mercado financeiro arrecada com a guerra da taxa e isto desestimula tal pratica. Aqui mostramos a importância do governo em criar um mecanismo que obrigue 
os tomadores de crédito a pensarem no cenário global antes de optarem por migrar suas dívidas.

Como uma análise geral, mesmo com todas as simplificações deste modelo, é possível entender a que direções as práticas de uma disputa (seja ela fiscal ou de taxa de juros) podem levar. 


\section{Referencias}

[1] T. C. Shelling, “Dynamic models of segregation”, J. Math. Sociol. 1, 143 (1971).

[2] L. Dall' Asta, C. Castellano e M. Marsili, "Statistical physics of the Schelling model of segregation", J. Stat. Mech. L07002 (2008)

[3] S. Grauwin, E. Bertin, R. Lemoy e P. Jensen, "Competition between collective and individual dynamics", PNAS 106, 20622 (2009)

[4] Banco Central do Brasil - Resolução № 4.292, de 20 de dezembro de 2013

[5] VALOR ECONÔMICO. Vários números;

[6] S.P, Nacimento, "Guerra Fiscal: uma avaliação comparativa entre alguns Estados participantes*" - Artigo derivado de tese de doutorado: "Guerra Fiscal: uma avaliação com base no PI B, nas receitas de IC MS e na geração de empregos, comparando Estados participantes e não participantes, Premio CNI de Economia (2008)

[7] ALVES, M. A. da S. "Guerra fiscal e finanças federativas no Brasil: o caso do setor automotivo". 2001. 111 - .Dissertação (Mestrado em Economia) - Universidade Estadual de Campinas, Campinas, (2001)

[8] INSTITUTO BRASILEIRO DE GEOGRAFIA E ESTATÍSTICA - IBGE. Contas regionais. Disponível em: <http://www.ibge.gov.br>. Acesso em: 30 abr. 2015.

[9] https://www.bcb.gov.br/?ECOIMPOM

[10] Varsano, R. "A guerra fiscal do ICMS: quem ganha e quem perde". - Texto para discussão Seminário Internacional Políticas Industriais, (1997)

[11] W.A.V Clark e M. Fosset. "Understanding the social contexto of the Schelling segregatio model", PNAS 105, (2008)

[12] S. Grauwin, F. Goffette-Nagot e P. Jensen, "Dynamics models of residential: Brief review, analytical resolution and study of the introduction of coordination", GATE, W.P 09-14, 1436978 (2009)

[13] T. Rogers e A. J McKane, "A unified framework for Schelling's model of segregation", Journal of Statistical Mechanics, P07006, (2011)

[14] G. Lambert, G. Chevereau e E. Bertin, "A symmetry-breaking phase transition in a dynamical decision model", Journal of Statistical Mechanics, P06005, (2011)

[15] L. Gauvin, J.P. Nadal e Jean Vannimenus, "Schelling segregation in a open city: A kinetically constrained Blume-Emery-Griffiths spin-1 system”, Physical Review, E 81, 066120, (2010)

[16] R. Lemoy, E. Bertin e P. Jensen, "Socio-economic utility chemical potential", EPL 93, 38002, (2011)

[17] S. Grauwin, D. Hunt, E. Bertin e P. Jensen, "Effective free energy for individual dynamics", Advanced in Complex Systems, Vol. 14, No 4, 529-536, (2011) 